\title{
Catalytic Chain Transfer Polymerization to Functional Reactive End Groups for Controlled Free Radical Growth
}

Sonja M. Stadler, Inigo Göttker-Schnetmann, Amelie S. Fuchs, Stephan R. R. Fischer, Stefan Mecking*,

Universität Konstanz, Fachbereich Chemie, Universitätsstrasse 10, D-78457 Konstanz, Germany

*Corresponding Author

E-mail: stefan.mecking@uni-konstanz.de

\section{Contents}

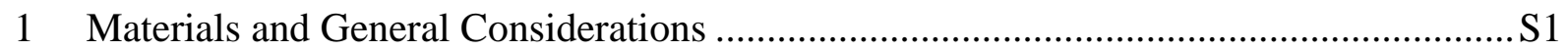

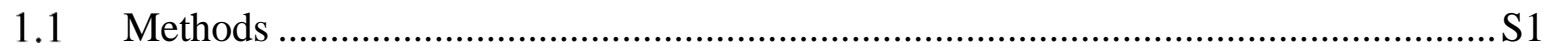

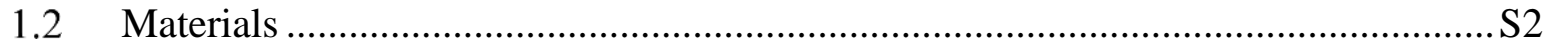

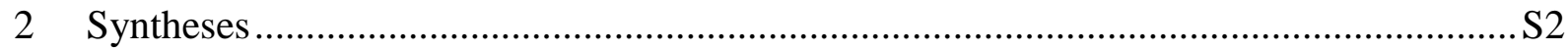

$2.1 \quad$ Synthesis of Palladium Complexes ....................................................................... 2

2.1.1 Synthesis of $N, N^{N}$-bis(2,6-diisopropylphenyl)-2,3-butanediimine ..................... S2

2.1.2 Synthesis of chloromethyl palladium precursor complex $\left[N, N^{\prime}\right.$-bis(2,6diisopropyl-phenyl)-2,3-butanediimine] chloromethyl palladium(II) .................S3

2.1.3 Synthesis of palladium complexes $\left[\left(2,6-i \mathrm{Pr}_{2} \mathrm{C}_{6} \mathrm{H}_{3}-\mathrm{N}=\mathrm{C}(\mathrm{Me})-\mathrm{C}(\mathrm{Me})=\mathrm{N}-2,6-\right.\right.$ $\left.\left.i \mathrm{Pr}_{2} \mathrm{C}_{6} \mathrm{H}_{3}\right) \mathrm{Pd}\left(\mathrm{CH}_{2}\right)_{3} \mathrm{C}(\mathrm{O}) \mathrm{OMe}\right] \mathrm{BArF} \quad(2) \quad$ and $\quad\left[\left(2,6-i \mathrm{Pr}_{2} \mathrm{C}_{6} \mathrm{H}_{3}-\mathrm{N}=\mathrm{C}(\mathrm{Me})-\right.\right.$

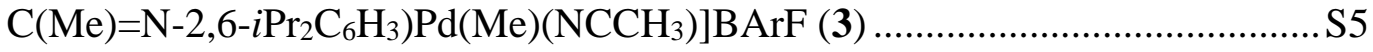

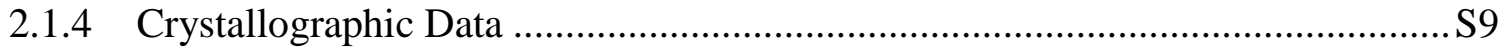

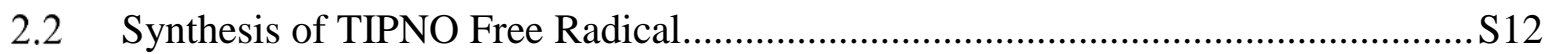

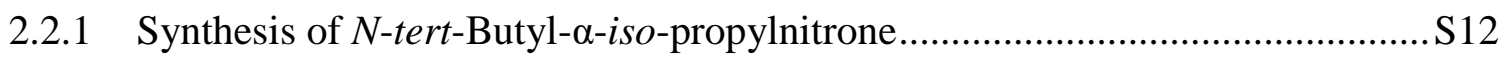

2.2.2 Synthesis of $N$-(tert-Butyl)- $N$-(2-methyl-1-phenylpropyl)hydroxyl amine .......S13

2.2.3 Synthesis of 2,2,5-Trimethyl-4-phenyl-3-azahexan-3-nitroxide (TIPNO Free Radical)

2.3 Synthesis of Alkoxyamine Modified Chain Transfer Agent .................................S18

2.3.1 $\mathrm{N}$-(tert-Butyl)- $\mathrm{N}$-(2-methyl-1-phenylpropyl)-O-(1-(4-((pent-4-en-1yloxy)methyl)-phenyl)ethyl)hydroxylamine. 
2.3.2 N-(tert-Butyl)-O-(1-(4-(((5-(diethylsilyl)pentyl)oxy)methyl)phenyl)ethyl)- $N$ (2-methyl-1-phenylpropyl)hydroxylamine (alkoxyamine modified CTA, 1).... S21

3 Investigation of the Chain Transfer Mechanism ........................................................ 26

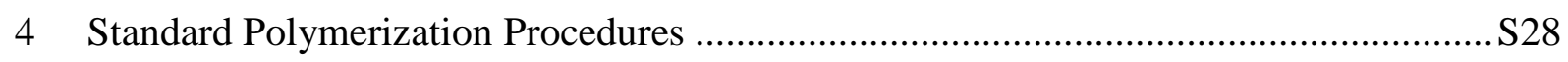

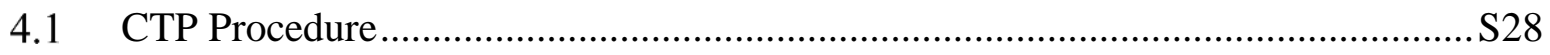

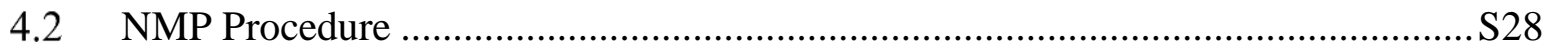

5 Additional Chain Transfer Polymerization Experiments ............................................ S29

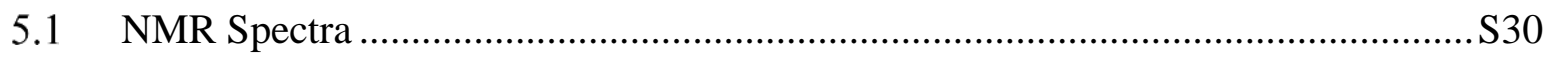

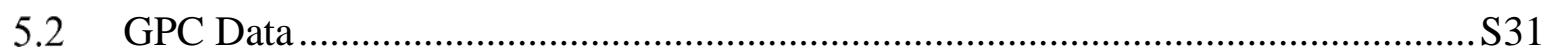

6 Correlation between Inverse Degree of Molecular Weight and CTA concentration...... S32

7 Exemplary NMR Spectra of Homopolymers Obtained in CTP .....................................S35

8 Controlled Free Radical Polymerization of Styrene, $n$-and tert-Butyl Acrylate.............S41

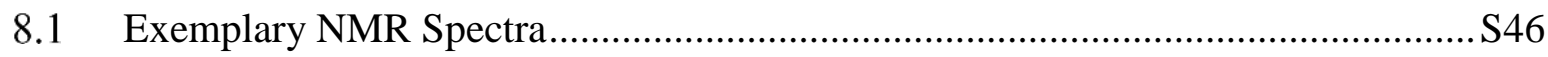

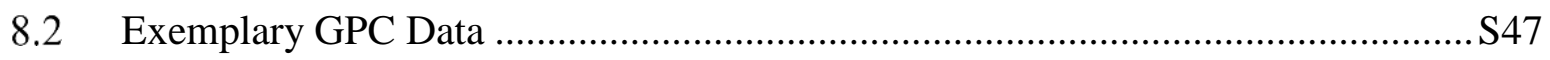

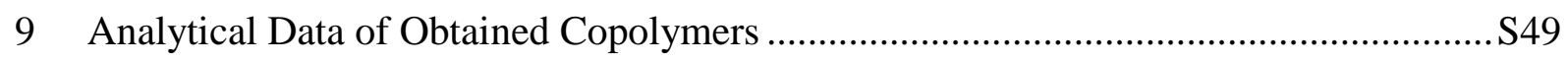

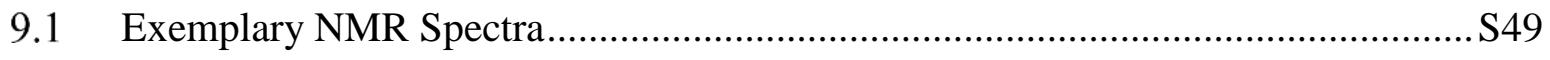

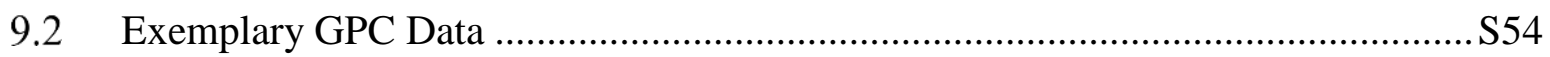

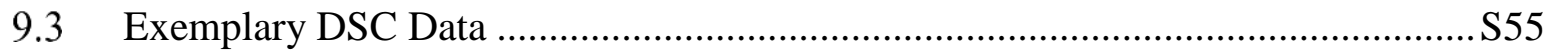

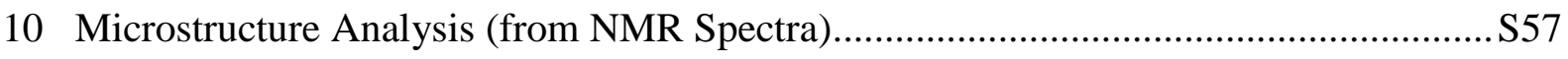

10.1 Calculation of Number Average Molecular Weight $M_{n}$ of the Polyethylene

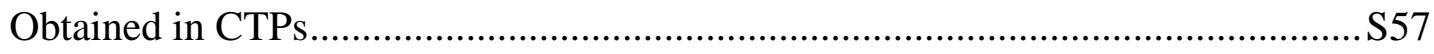

10.2 Calculation of the Amount of Chains Formed per Pd Center................................. S58

10.3 Calculation of the Conversion of Monomer in NMPs.............................................S58

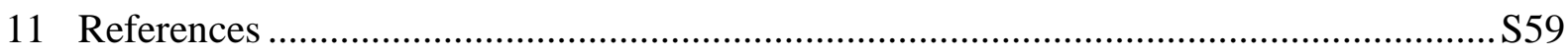




\section{Materials and General Considerations}

\subsection{Methods}

NMR spectra were measured either on a Bruker Avance III HD 400 equipped with a TBO N to $\mathrm{P} / \mathrm{H} / \mathrm{F}$ triple resonance probe, a Bruker Avance III 400 equipped with a BBFO plus probe for $\mathrm{N}$ to $\mathrm{F} / \mathrm{H}$ or a Bruker Avance III 600 equipped with a TCI-H/C/N triple resonance cryoprobe. ${ }^{1} \mathrm{H}$ chemical shifts were referenced to the residual proton signal of the solvent. ${ }^{13} \mathrm{C}$ chemical shifts were referenced to the carbon signal of the solvent. NMR spectra are reported as follows: chemical shift $(\delta \mathrm{ppm})$, multiplicity, coupling constant $(\mathrm{Hz})$, integration and assignment. Multiplicities are given as follows (or combinations thereof): s: singlet, d: doublet, t: triplet, q: quartet, quint: quintet, sept: septet, oct: octet, m: multiplet, v: virtual, br.: broad. The identity of compounds and detailed NMR assignments were established by ${ }^{1} \mathrm{H}$ TOCSY and 2D NMR experiments $\left({ }^{1} \mathrm{H}-{ }^{1} \mathrm{H}\right.$ gCOSY,${ }^{1} \mathrm{H}^{-13} \mathrm{C}$ gHSQC and ${ }^{1} \mathrm{H}_{-}{ }^{13} \mathrm{C}$ gHMBC) experiments in addition to 1D NMR experiments. Acquired data were processed and analyzed using MestReNova software. DOSY data were processed using the TopSpin (Bruker) software package.

Single crystal X-ray diffraction analysis was performed at $100 \mathrm{~K}$ on a STOE IPDS-2T diffractometer equipped with a graphite-monochromated radiation source (Mo-K,$\lambda=$ $0.71073 \AA$ ) and an image plate detection system. Crystals were mounted on a fine glass fiber with silicon grease. The selection, integration and averaging procedure of the measured reflex intensities, the determination of the unit cell dimensions and a least-squares fit of the $2 \theta$ values as well as data reduction, LP-correction and space group determination were performed using the X-Area software package delivered with the diffractometer. ${ }^{1}$ A semi empirical absorption correction was performed. The structures were solved by Patterson or Direct methods, completed with difference Fourier synthesis, and refined with full-matrix least-square using SHELXL $2016 / 6^{2}$ minimizing $\omega\left(\mathrm{F}_{0}^{2}-\mathrm{F}_{\mathrm{c}}{ }^{2}\right)^{2}$. Weighted $\mathrm{R}$ factor $\left(\omega \mathrm{R}^{2}\right)$ and the goodness of fit (GooF) are based on $\mathrm{F}^{2}$. All non-hydrogen atoms were refined with anisotropic displacement parameters. All hydrogen atoms were treated in a riding model unless otherwise noted. Graphical output (ORTEP plots) were created using ORTEP-3 V2.02 for Windows. ${ }^{3}$

Gel permeation chromatography (GPC) for molecular weight determination was carried out on a PSS Agilent 1260 infinity II instrument equipped with two PSS SDV LinearM analytical columns at $308 \mathrm{~K}$ in THF using refractive index and UV-detection (254 nm) and linear calibration against polystyrene standards.

Differential scanning calorimetry (DSC) measurements of polymers were carried out on a Netzsch DSC 204 F1 instrument (software: Netzsch Proteus Thermal Analysis, version 6.1.0) with a heating/cooling rate of $30 \mathrm{~K} \mathrm{~min}^{-1}$.

All manipulations of air- and/or moisture-sensitive compounds were carried out under an inert atmosphere using standard Schlenk or glovebox techniques. 


\subsection{Materials}

Solvents were dried and degassed prior to use: Benzene, diethyl ether and tetrahydrofuran were distilled from blue sodium/benzophenone, acetonitrile from calcium hydride under a nitrogen atmosphere. Toluene and methylene chloride were dried and degassed by passage through columns containing oxygen scavenger copper(0) and $4 \AA$ molecular sieves under a nitrogen atmosphere. Ethanol was dried using molecular sieves $(3 \AA)$. Methanol was used without further purification. Chloroform- $d_{1}$, methylene chloride- $d_{2}$ and benzene- $d_{6}$ were dried over $4 \AA$ molecular sieves.

Chloromethyl(1,5-cyclooctadiene)palladium(II) (abcr), diethylsilane (abcr), isobutyraldehyde (abcr), 2-methyl-2-nitropropane (abcr), ethylene 3.5 grade (Air Liquide), manganese(III) acetate dihydrate (chemPUR), pentafluorophenylhydrazine (fluorochem), 2,3-butanedione (Merck), formic acid (Merck), $\mathrm{N}$-tert-butyl-O-[1-[4-(chloromethyl)phenyl]ethyl]- $N$-(2-methyl1-phenylpropyl)hydroxylamine (Merck), $\quad N$-tert-Butyl- $N$-(2-methyl-1-phenylpropyl)-O-(1phenylethyl)hydroxylamine (Merck), 4-penten-1-ol (Merck), phenylmagnesium bromide 3M solution in diethyl ether (Merck), triethylsilane (Merck), 4-vinylbenzyl chloride (Merck), and 2,6-diisopropylaniline (TCI) were commercially available and used without further purification. Sodium tetrakis[3,5-bis(trifluoromethyl)phenyl]borate ${ }^{4}$ was available in the group.

Commercially available methyl acrylate (Merck), tert-butyl acrylate (Meck) and $n$-butyl acrylate (Merck) were filtered over basic aluminum oxide, degassed by repeated freeze-pumpthaw cycles and stored at $-25{ }^{\circ} \mathrm{C}$ prior to use.

\section{Syntheses}

\subsection{Synthesis of Palladium Complexes}

\subsubsection{Synthesis of $N, N$ '-bis(2,6-diisopropylphenyl)-2,3-butanediimine}

The $\alpha$-diimine ligand was synthesized from 2,6-diisopropylaniline and dimethyl glyoxal according to a reported procedure (Scheme S1). ${ }^{5}$ NMR data agrees with reported data. ${ }^{6}$
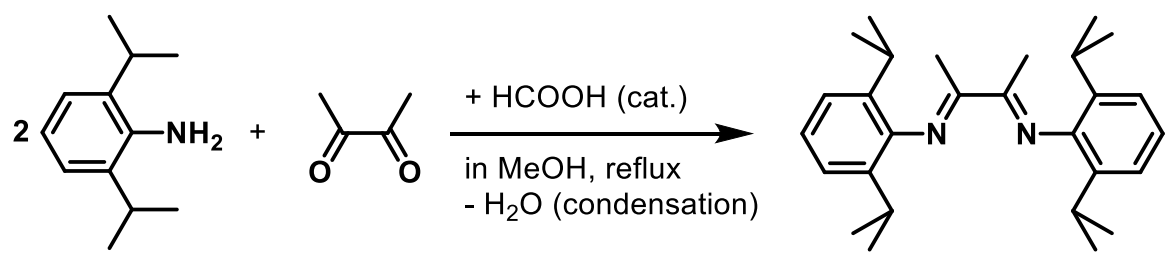

Scheme S1: Synthesis of the the $\alpha$-diimine ligand by condensation of 2,6-diisopropylaniline and dimethyl glyoxal.

$N, N^{\prime}$-bis(2,6-diisopropylphenyl)-2,3-butanediimine:

To a solution of aniline $(2.13 \mathrm{~g}, 12.0 \mathrm{mmol}, 2.0$ equiv. $)$ in methanol $(10 \mathrm{~mL})$ a catalytic amount of formic acid was added. Dimethyl glyoxal $(0.52 \mathrm{~g}, 6.0 \mathrm{mmol}, 1.0$ equiv.) was added dropwise and the reaction mixture was stirred at room temperature over night. A yellow solid precipitated 
and was isolated by filtration of the reaction mixture. The solid residue was washed with cold methanol $(10 \mathrm{~mL})$ and dried under reduced pressure to yield $1.28 \mathrm{~g}(3.15 \mathrm{mmol}, 53 \%)$ of the desired ligand. Concentration of the mother liquor yielded another $0.27 \mathrm{~g}(0.67 \mathrm{mmol}, 11 \%)$ of $N, N^{\prime}$-bis(2,6-diisopropylphenyl)-2,3-butanediimine.

The ${ }^{1} \mathrm{H}$ NMR spectrum (Figure $\mathrm{S} 1$ ) agrees with reported data. ${ }^{7}$

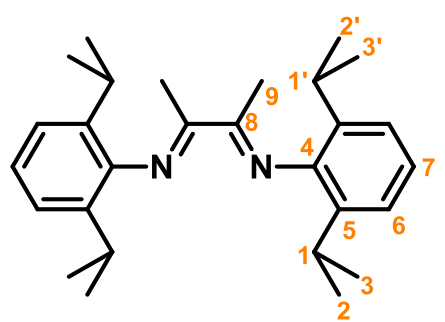

${ }^{1} \mathbf{H}$ NMR (400 MHz, $\left.\mathrm{CDCl}_{3}, 300 \mathrm{~K}\right): \delta=1.18,1.20\left(\mathrm{~d},{ }^{3} \mathrm{~J}_{\mathrm{H}, \mathrm{H}}=6.9 \mathrm{~Hz}, 12 \mathrm{H}\right.$ each, $\mathrm{H}-2 / 2$ ', H-3/3'), 2.07 (s, 6H, H-9), 2.71 (sept, ${ }^{3} J_{\mathrm{H}, \mathrm{H}}=6.9 \mathrm{~Hz}, 4 \mathrm{H}, \mathrm{H}-1 / 1^{\prime}$ ), $7.07-7.19$ (m, 6H, H-6, H-7) ppm.

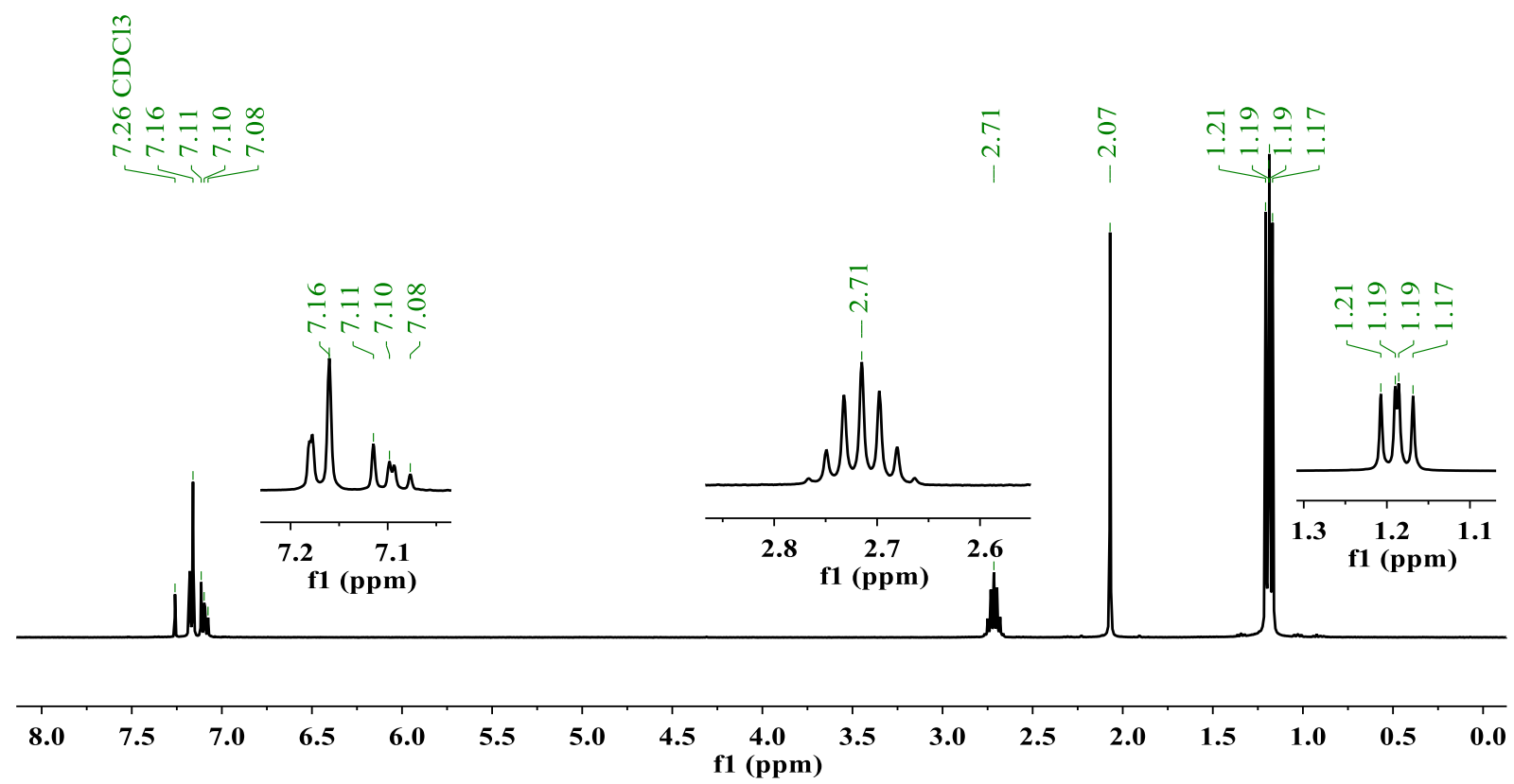

Figure S1: $\quad{ }^{1} \mathrm{H} \mathrm{NMR}$ spectrum $\left(400 \mathrm{MHz}, \mathrm{CDCl}_{3}, 300 \mathrm{~K}\right)$ of $N, N$ '-bis(2,6-diisopropylphenyl)-2,3-butanediimine.

2.1.2 Synthesis of chloromethyl palladium precursor complex [ $N, N$ '-bis(2,6-diisopropylphenyl)-2,3-butanediimine] chloromethyl palladium(II)

The chloromethyl palladium(II) complex was synthesized from the $\alpha$-diimine ligand according to a reported procedure (Scheme S2). ${ }^{8}$ 

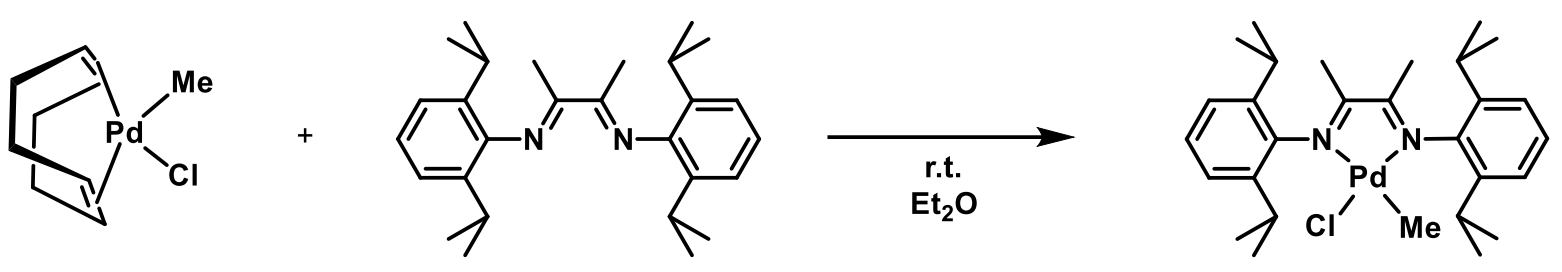

Scheme S2: Reaction of chloromethyl(1,5-cyclooctadiene)palladium(II) with $N, N$ '-bis(2,6diisopropylphenyl)-2,3-butanediimine yielding the chloromethyl palladium precursor complex.

[ $N, N^{\prime}$-bis(2,6-diisopropylphenyl)-2,3-butanediimine] chloromethyl palladium(II):

The $\alpha$-diimine $(0.57 \mathrm{~g}, 1.41 \mathrm{mmol}, 1.01$ equiv.) and chloro(1,5-cyclooctadiene)methylpalladium $(0.37 \mathrm{~g}, 1.40 \mathrm{mmol}, 1.00$ equiv.) were dissolved in diethyl ether $(8 \mathrm{~mL})$ under nitrogen atmosphere. The reaction mixture was stirred at room temperature over night. An orange solid precipitated and was isolated by filtration of the reaction mixture. The solid residue was washed with diethyl ether and dried under reduced pressure. [N,N'-bis(2,6diisopropylphenyl)-2,3-butanediimine] chloromethyl palladium(II) was isolated in $86 \%$ yield (0.68 g, $1.21 \mathrm{mmol})$.

The formation of the desired compound was confirmed by a ${ }^{1} \mathrm{H}$ NMR spectrum which agrees with reported data (Figure S2). ${ }^{8}$

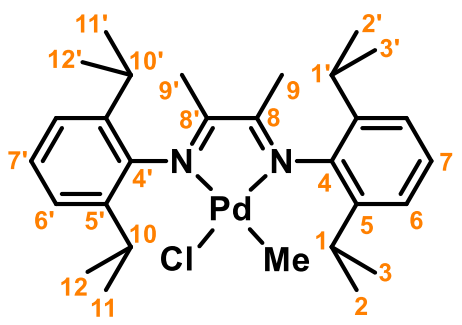

${ }^{1} \mathbf{H}$ NMR (400 MHz, $\mathrm{CD}_{2} \mathrm{Cl}_{2}, 300 \mathrm{~K}$ ): $\delta=0.37$ (s, 3H, Pd-CH3 $, 1.18,1.19,1.36,1.40$ (d, ${ }^{3} J_{\mathrm{H}, \mathrm{H}}=6.9 \mathrm{~Hz},{ }^{3} J_{\mathrm{H}, \mathrm{H}}=6.7 \mathrm{~Hz}, 6 \mathrm{H}$ each, H-2/2', H-3/3', H-11/11', H-12/12'), 2.02, 2.04 (s, 3H each, H-9/9'), 3.01, 3.07 (vsept, ${ }^{3} J_{\mathrm{H}, \mathrm{H}}=6.9 \mathrm{~Hz},{ }^{3} J_{\mathrm{H}, \mathrm{H}}=6.7 \mathrm{~Hz}, 2 \mathrm{H}$ each, H-1/1', H-10/10'), 7.20 - 7.40 (m, 6H, H-6/6', H-7/7') ppm. 


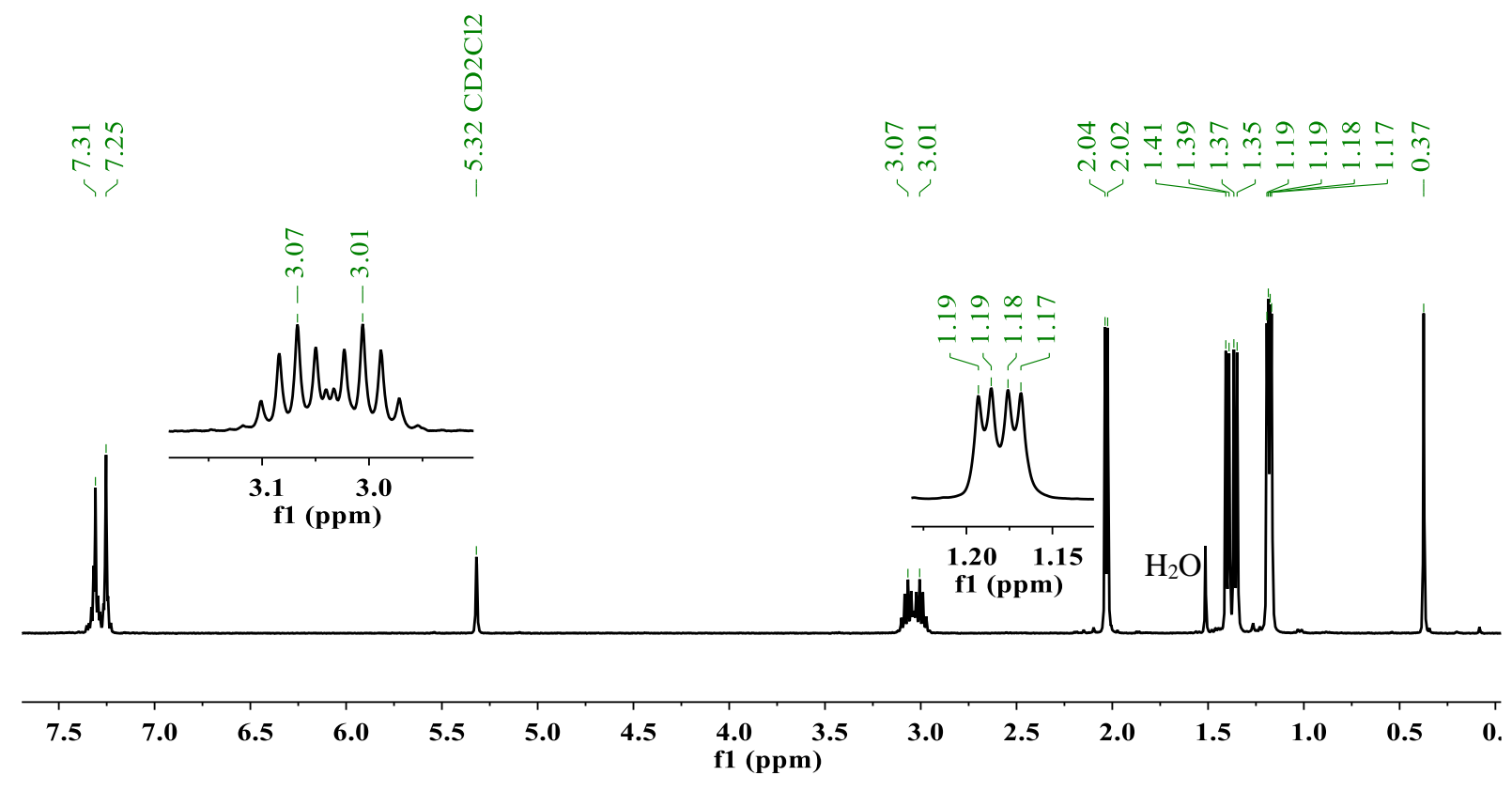

Figure S2: $\quad{ }^{1} \mathrm{H} \mathrm{NMR} \quad$ spectrum $\quad\left(400 \mathrm{MHz}, \quad \mathrm{CDCl}_{3}, \quad 300 \mathrm{~K}\right) \quad$ of $\quad[N, N$ '-bis(2,6diisopropylphenyl)-2,3-butanediimine] chloromethyl palladium(II).

2.1.3 Synthesis of palladium complexes $\left[\left(2,6-i \mathrm{Pr}_{2} \mathrm{C}_{6} \mathrm{H}_{3}-\mathrm{N}=\mathrm{C}(\mathrm{Me})-\mathrm{C}(\mathrm{Me})=\mathrm{N}-2,6-\right.\right.$ $\left.\left.i \mathrm{Pr}_{2} \mathrm{C}_{6} \mathrm{H}_{3}\right) \mathrm{Pd}\left(\mathrm{CH}_{2}\right)_{3} \mathrm{C}(\mathrm{O}) \mathrm{OMe}\right] \mathrm{BArF}(2)$ and $\left[\left(2,6-i \mathrm{Pr}_{2} \mathrm{C}_{6} \mathrm{H}_{3}-\mathrm{N}=\mathrm{C}(\mathrm{Me})-\mathrm{C}(\mathrm{Me})=\mathrm{N}-2,6-\right.\right.$ $\left.\left.i \mathrm{Pr}_{2} \mathrm{C}_{6} \mathrm{H}_{3}\right) \mathrm{Pd}(\mathrm{Me})\left(\mathrm{NCCH}_{3}\right)\right] \mathrm{BArF}(\mathbf{3})$

The Pd complexes $\mathbf{2}$ and $\mathbf{3}$ were synthesized from the chloromethyl palladium(II) complex according to reported procedures (Scheme S3 and Scheme S4). ${ }^{8,9}$
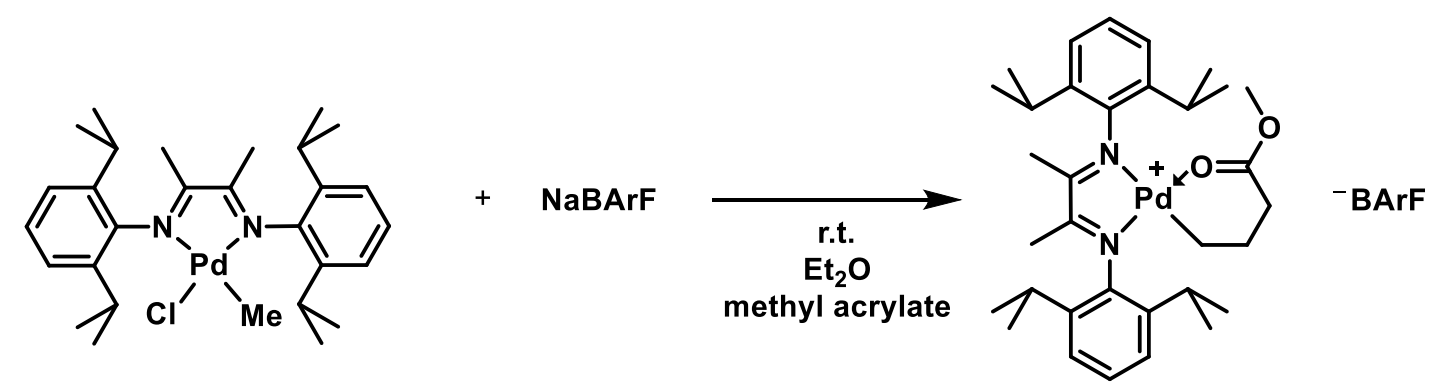

Scheme S3: Reaction of [N,N'-bis(2,6-diisopropylphenyl)-2,3-butanediimine] chloromethyl palladium(II) with methyl acrylate and sodium tetrakis[3,5bis(trifluoromethyl)phenyl]borate yielding $\alpha$-diimine Pd complex 2. 

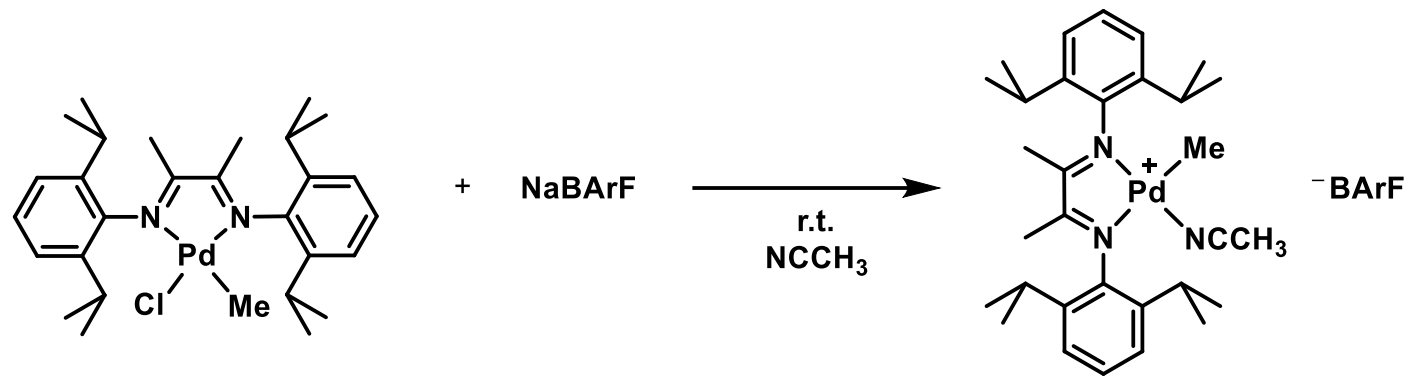

Scheme S4: Reaction of [N,N'-bis(2,6-diisopropylphenyl)-2,3-butanediimine] chloromethyl palladium(II) with sodium tetrakis[3,5-bis(trifluoromethyl)phenyl]borate in acetonitrile yielding $\alpha$-diimine Pd complex 3 .

$\left[\left(2,6-i \mathrm{Pr}_{2} \mathrm{C}_{6} \mathrm{H}_{3}-\mathrm{N}=\mathrm{C}(\mathrm{Me})-\mathrm{C}(\mathrm{Me})=\mathrm{N}-2,6-i \mathrm{Pr}_{2} \mathrm{C}_{6} \mathrm{H}_{3}\right) \mathrm{Pd}\left(\mathrm{CH}_{2}\right)_{3} \mathrm{C}(\mathrm{O}) \mathrm{OMe}\right] \mathrm{B} \operatorname{ArF}(\mathbf{2})$ :

[ $N, N$ '-bis(2,6-diisopropylphenyl)-2,3-butanediimine] chloromethyl palladium(II) (0.63 g, $1.13 \mathrm{mmol}, 1.0$ equiv.) and sodium tetrakis[3,5-bis(trifluoromethyl)phenyl]borate (NaBArF, $1.00 \mathrm{~g}, 1.13 \mathrm{mmol}, 1.0$ equiv.) were dissolved in diethylether $(12 \mathrm{~mL})$ under a nitrogen atmosphere. Methyl acrylate $(0.11 \mathrm{~g}, 1.30 \mathrm{mmol}, 1.15$ equiv.) was diluted with diethyl ether $(4 \mathrm{~mL})$ and added to the reaction mixture. The reaction mixture was stirred over night and filtered through a syringe filter. Evaporation of the solvent under reduced pressure yielded $87 \%$ of complex 2 and its constitutional isomers (1.45 g, $0.98 \mathrm{mmol})$.

The formation of the isomer mixture was confirmed by a ${ }^{1} \mathrm{H}$ NMR spectrum which agrees with reported data (Figure S3 and Figure S4). ${ }^{8}$
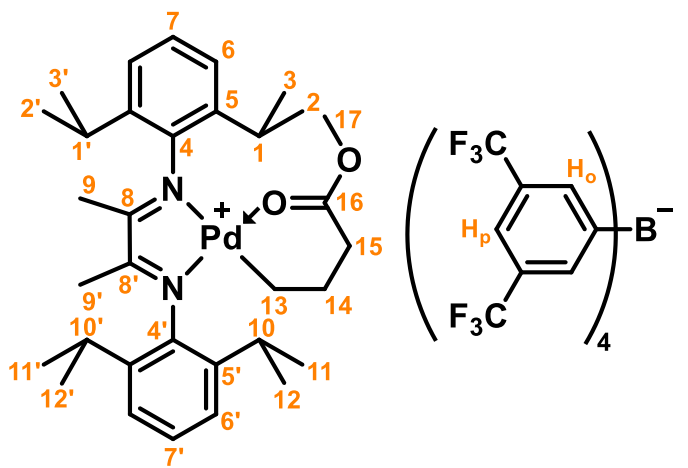

${ }^{1} \mathbf{H}$ NMR (400 MHz, $\mathrm{CD}_{2} \mathrm{Cl}_{2}, 300 \mathrm{~K}$ ): $\delta=0.66$ (vquint, ${ }^{3} J_{\mathrm{H}, \mathrm{H}}=5.8 \mathrm{~Hz}, 2 \mathrm{H}, \mathrm{H}-14$ ), 1.22, 1.26, $1.31,1.38,\left(\mathrm{~d},{ }^{3} J_{\mathrm{H}, \mathrm{H}}=6.9 \mathrm{~Hz}, 6 \mathrm{H}\right.$ each, H-2/2', H-3/3', H-11/11', H-12/12'), 1.41 (t, $\left.{ }^{3} J_{\mathrm{H}, \mathrm{H}}=6.4 \mathrm{~Hz}, 2 \mathrm{H}, \mathrm{H}-13\right), 2.21,2.22$ (s, 3H each, H-9, H-9'), $2.41\left(\mathrm{t},{ }^{3} J_{\mathrm{H}, \mathrm{H}}=5.9 \mathrm{~Hz}, 2 \mathrm{H}, \mathrm{H}-\right.$ 15), 2.93, 2.95 (sept, ${ }^{3} J_{\mathrm{H}, \mathrm{H}}=6.9 \mathrm{~Hz}, 2 \mathrm{H}$ each, H-1/1', H-4/4'), 3.04, (s, 3H, H-17), $7.26-7.43$ (m, 6H, H-6/6', H-7/7'), 7.56 (br, 4H, BArF- $H_{\mathrm{p}}$ ), 7.72 (br, 8H, BArF- $H_{\mathrm{o}}$ ) ppm.

Deviating resonances of isomer 2.2:

${ }^{1} \mathbf{H}$ NMR $\left(400 \mathrm{MHz}, \mathrm{CD}_{2} \mathrm{Cl}_{2}, 300 \mathrm{~K}\right): \delta=1.03\left(\mathrm{~d},{ }^{3} \mathrm{~J}_{\mathrm{H}, \mathrm{H}}=7.2 \mathrm{~Hz}, 3 \mathrm{H}, \mathrm{H}-15\right), 2.18,2.19(\mathrm{~s}, 3 \mathrm{H}$ each, H-9, H-9'), 2.54 (m, 2H, H-14/14'), 3.49 (s, 3H, H-17/17') ppm. 


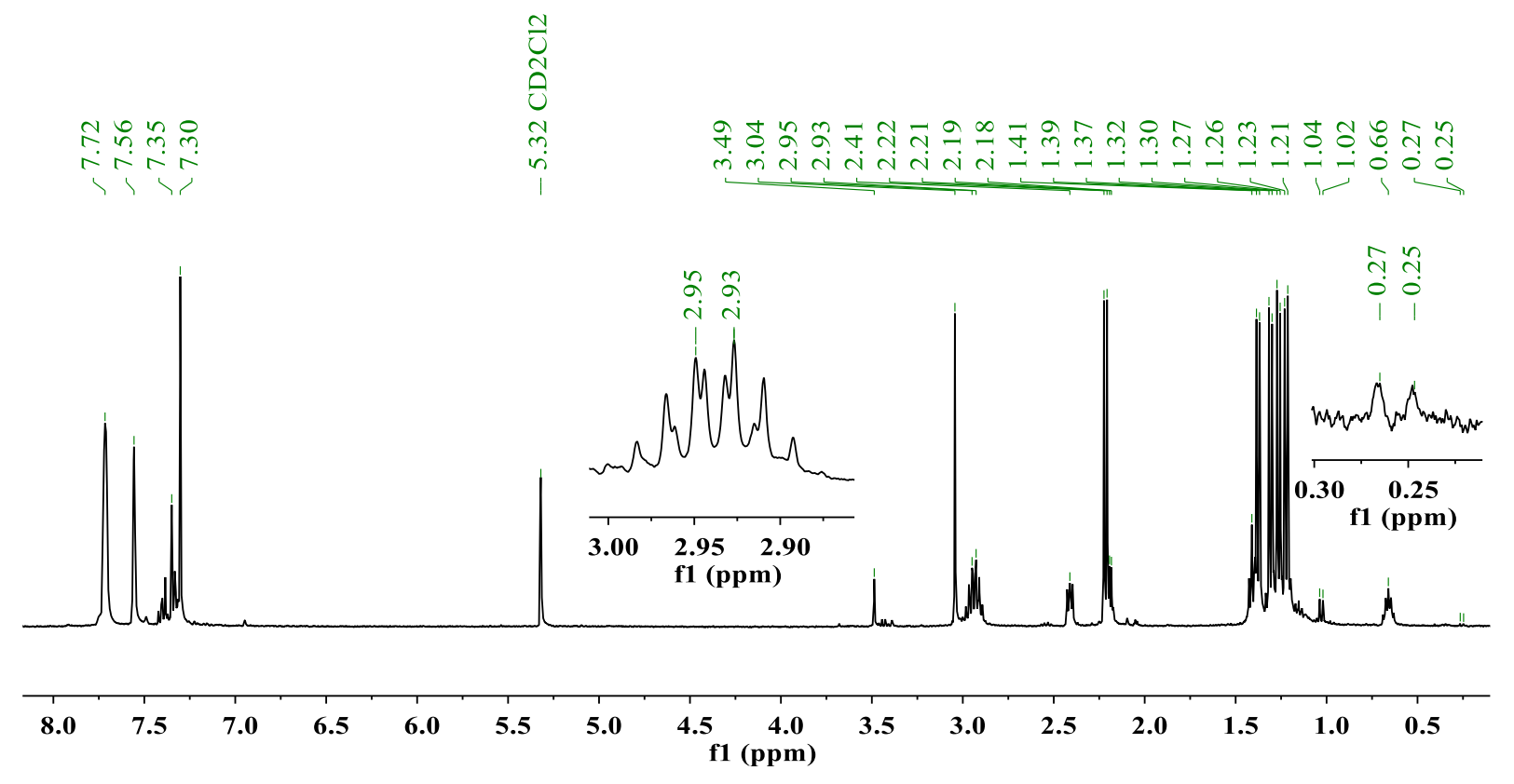

Figure S3: $\quad{ }^{1} \mathrm{H}$ NMR spectrum $\left(400 \mathrm{MHz}, \mathrm{CD}_{2} \mathrm{Cl}_{2}, 300 \mathrm{~K}\right)$ of the isomer mixture 2, 2.1 and 2.2.

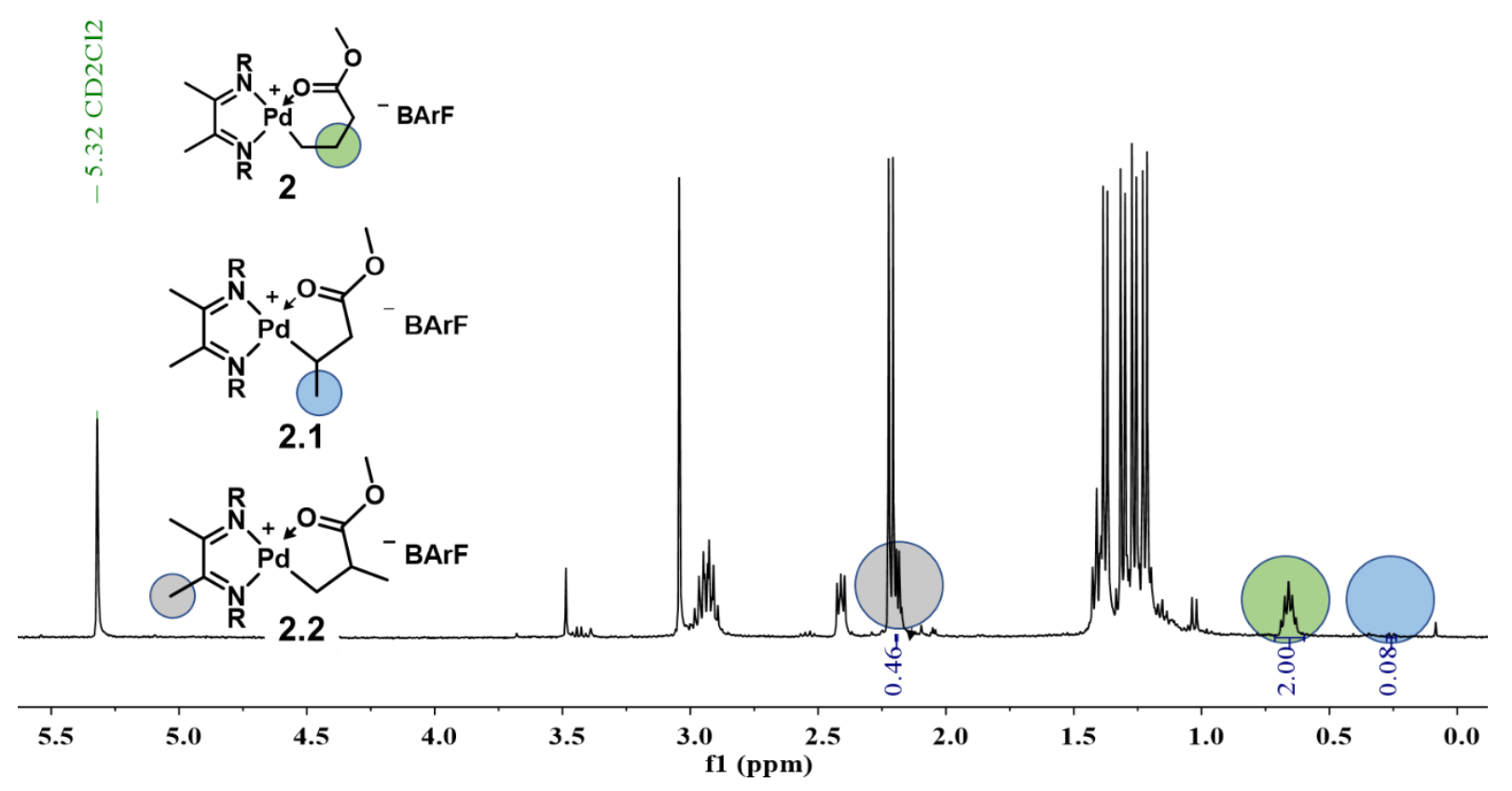

Figure S4: $\quad$ Enlarged ${ }^{1} \mathrm{H}$ NMR spectrum $\left(400 \mathrm{MHz}, \mathrm{CD}_{2} \mathrm{Cl}_{2}, 300 \mathrm{~K}\right)$ of the isomer mixture containing compound $2(85 \%), \mathbf{2 . 1}(2 \%)$ and $\mathbf{2 . 2}(13 \%)$ and the assignment of signals used for the calculation of the isomer composition.

$\left[\left(2,6-i \mathrm{Pr}_{2} \mathrm{C}_{6} \mathrm{H}_{3}-\mathrm{N}=\mathrm{C}(\mathrm{Me})-\mathrm{C}(\mathrm{Me})=\mathrm{N}-2,6-i \mathrm{Pr}_{2} \mathrm{C}_{6} \mathrm{H}_{3}\right) \mathrm{Pd}(\mathrm{Me})\left(\mathrm{NCCH}_{3}\right)\right] \mathrm{BArF}(\mathbf{3})$ :

The precursor complex [N,N'-bis(2,6-diisopropylphenyl)-2,3-butanediimine] chloromethyl palladium(II) $\quad(0.46 \mathrm{~g}, \quad 0.82 \mathrm{mmol}, \quad 1.0$ equiv. $)$ and sodium tetrakis[3,5-bis(trifluoromethyl)phenyl]borate (NaBArF, $0.73 \mathrm{~g}, 0.82 \mathrm{mmol}, 1.0$ equiv.) were dissolved in acetonitrile 
$(16 \mathrm{~mL})$. The reaction mixture was stirred at room temperature over night. After filtration to remove sodium chloride, the solvent was removed and the residue was redissolved in dichloromethane (circa $3 \mathrm{~mL}$ ). An orange solid precipitated upon slow addition of pentane $(18 \mathrm{~mL})$. The solid was isolated by filtration, washed with $2 \times 2 \mathrm{~mL}$ of pentane and dried under vacuum to yield $87 \%$ (1.02 $\mathrm{g}, 0.72 \mathrm{mmol})$ of complex 3 .

The ${ }^{1} \mathrm{H}$ NMR spectrum of complex 3 agrees with reported data (Figure S5). ${ }^{9}$

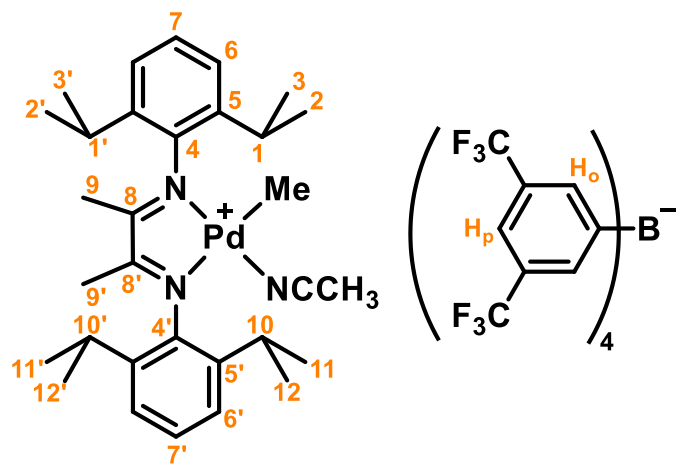

${ }^{1} \mathbf{H}$ NMR (400 MHz, $\mathrm{CD}_{2} \mathrm{Cl}_{2}, 300 \mathrm{~K}$ ): $\delta=0.51$ (s, 3H, Pd-CH3), 1.21, 1.25, 1.33, 1.38 (d, ${ }^{3} J_{\mathrm{H}, \mathrm{H}}=6.9 \mathrm{~Hz}, 6 \mathrm{H}$ each, H-2/2', H-3/3', H-11/11', H-12/12'), 1.80 (s, 3H, Pd-NCCH ( $_{3}, 2.23$ (vs, 6H, H-9/9'), 2.86, 2.90 (vsept, ${ }^{3} J_{\mathrm{H}, \mathrm{H}}=6.9 \mathrm{~Hz}, 2 \mathrm{H}$ each, H-1/1', H-10/10'), $7.30-7.44$ (m, 6H, H-6/6', H-7/7'), 7.56 (br, 4H, BArF- $H_{\mathrm{p}}$ ), 7.72 (br, 8H, BArF- $H_{\mathrm{o}}$ ) ppm.

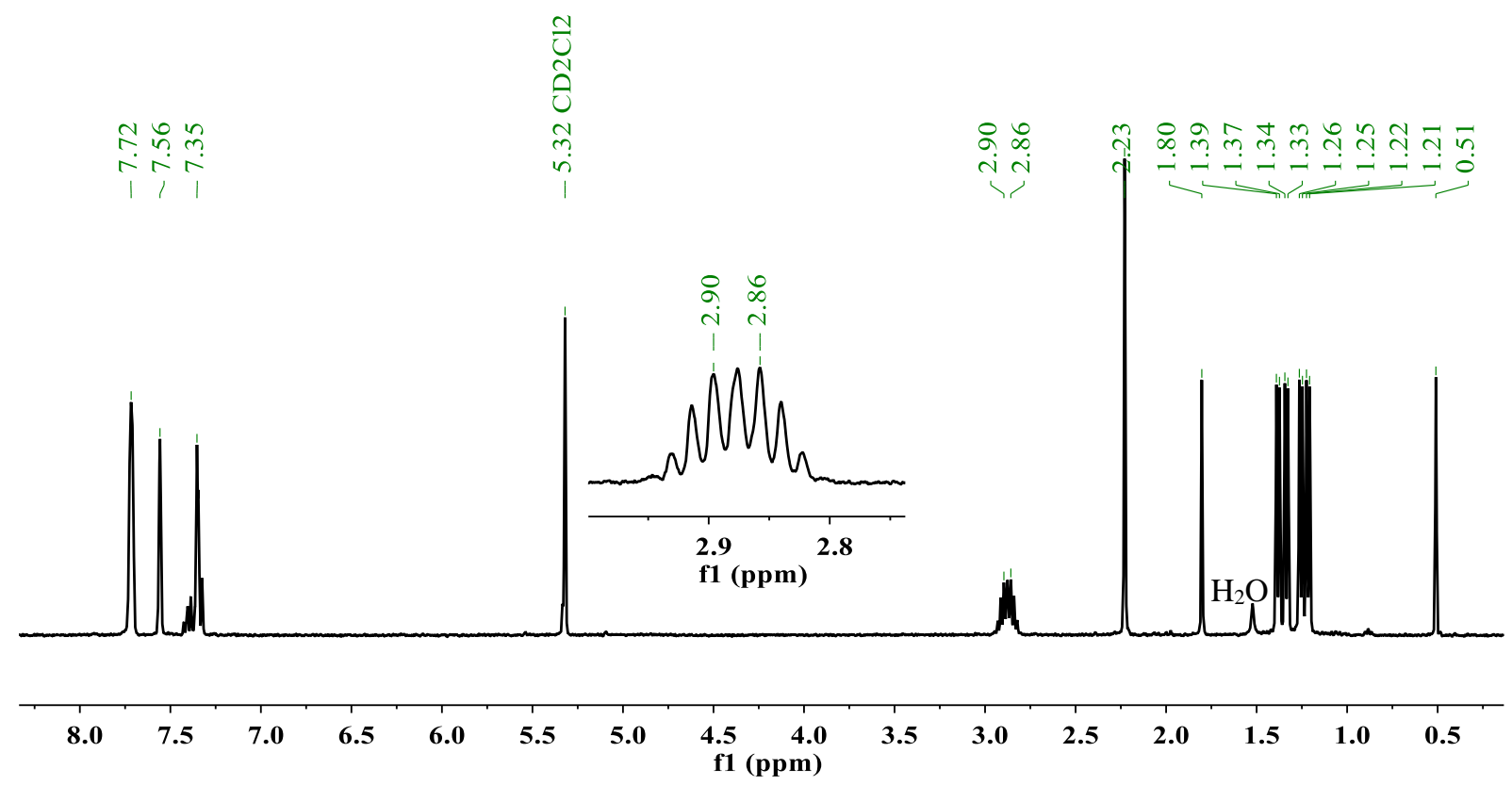

Figure S5: $\quad{ }^{1} \mathrm{H}$ NMR spectrum $\left(400 \mathrm{MHz}, \mathrm{CD}_{2} \mathrm{Cl}_{2}, 300 \mathrm{~K}\right)$ of complex 3. 


\subsubsection{Crystallographic Data}

Table S1: Crystal data and structure refinement for $\alpha$-diimine Pd complexes 2 and $\mathbf{3}$.

\begin{tabular}{|c|c|c|}
\hline & $\begin{array}{l}{\left[\left(2,6-i \mathrm{Pr}_{2} \mathrm{C}_{6} \mathrm{H}_{3}-\mathrm{N}=\mathrm{C}(\mathrm{Me})-\right.\right.} \\
\left.\mathrm{C}(\mathrm{Me})=\mathrm{N}-2,6-i \mathrm{Pr}_{2} \mathrm{C}_{6} \mathrm{H}_{3}\right) \\
\mathrm{Pd}\left(\mathrm{CH}_{2}\right)_{3} \mathrm{C}(\mathrm{O}) \mathrm{OMe}_{\mathrm{BArF}} \\
\text { complex } 2\end{array}$ & $\begin{array}{l}{\left[\left(2,6-i \mathrm{Pr}_{2} \mathrm{C}_{6} \mathrm{H}_{3}-\mathrm{N}=\mathrm{C}(\mathrm{Me})-\right.\right.} \\
\left.\mathrm{C}(\mathrm{Me})=\mathrm{N}-2,6-i \mathrm{Pr}_{2} \mathrm{C}_{6} \mathrm{H}_{3}\right) \\
\left.\left.\mathrm{Pd}(\mathrm{Me})(\mathrm{NCCH})_{3}\right)\right] \mathrm{BArF}, \\
\text { complex } 3\end{array}$ \\
\hline Identification code & CCDC 1968074 & CCDC 1968956 \\
\hline Empirical formula & $\mathrm{C}_{65} \mathrm{H}_{61} \mathrm{BN}_{2} \mathrm{O}_{2} \mathrm{~F}_{24} \mathrm{Pd}$ & $\mathrm{C}_{63} \mathrm{H}_{58} \mathrm{BF}_{24} \mathrm{~N}_{3} \mathrm{Pd}$ \\
\hline Formula weight & 1475.36 & 1430.33 \\
\hline Temperature/K & 100.15 & 100.15 \\
\hline Crystal system & triclinic & triclinic \\
\hline Space group & $\mathrm{P}-1$ & $\mathrm{P}-1$ \\
\hline $\mathrm{a} / \AA$ & $12.4860(5)$ & $12.7207(5)$ \\
\hline $\mathrm{b} / \AA ̊ \AA$ & $15.7992(7)$ & 15.1193(7) \\
\hline $\mathrm{c} / \AA$ & $18.2813(8)$ & $16.6268(6)$ \\
\hline$\alpha /^{\circ}$ & $74.958(3)$ & $93.278(3)$ \\
\hline$\beta /{ }^{\circ}$ & $70.373(3)$ & $98.104(3)$ \\
\hline$\gamma /{ }^{\circ}$ & $83.080(3)$ & $98.439(3)$ \\
\hline Volume $/ \AA^{3}$ & $3278.2(3)$ & $3121.7(2)$ \\
\hline $\mathrm{Z}$ & 2 & 2 \\
\hline$\rho_{\text {calc }} \mathrm{g} / \mathrm{cm}^{3}$ & 1.495 & 1.522 \\
\hline$\mu / \mathrm{mm}^{-1}$ & 0.396 & 0.411 \\
\hline $\mathrm{F}(000)$ & 1496.0 & 1448.0 \\
\hline Crystal size $/ \mathrm{mm}^{3}$ & $0.35 \times 0.233 \times 0.05$ & $0.5 \times 0.35 \times 0.05$ \\
\hline Radiation & $\operatorname{MoK} \alpha(\lambda=0.71073)$ & $\operatorname{MoK} \alpha(\lambda=0.71073)$ \\
\hline $2 \Theta$ range for data collection ${ }^{\circ}$ & 3.466 to 53.814 & 3.798 to 53.65 \\
\hline Index ranges & $-15 \leq \mathrm{h} \leq 15,-19 \leq \mathrm{k} \leq 19,-22 \leq 1 \leq 23$ & $-16 \leq \mathrm{h} \leq 14,-19 \leq \mathrm{k} \leq 19,-21 \leq 1 \leq 21$ \\
\hline Reflections collected & 32280 & 27373 \\
\hline Independent reflections & $13902\left[\mathrm{R}_{\mathrm{int}}=0.0343, \mathrm{R}_{\text {sigma }}=0.0433\right]$ & $13210\left[\mathrm{R}_{\mathrm{int}}=0.0216, \mathrm{R}_{\mathrm{sigma}}=0.0286\right]$ \\
\hline Data/restraints/parameters & $13902 / 0 / 935$ & $13210 / 0 / 862$ \\
\hline Goodness-of-fit on $\mathrm{F}^{2}$ & 1.038 & 1.021 \\
\hline Final $R$ indexes $[I>=2 \sigma(I)]$ & $\mathrm{R}_{1}=0.0711, \mathrm{wR}_{2}=0.1520$ & $\mathrm{R}_{1}=0.0393, \mathrm{wR}_{2}=0.0891$ \\
\hline Final $\mathrm{R}$ indexes [all data] & $\mathrm{R}_{1}=0.1098, \mathrm{wR}_{2}=0.1769$ & $\mathrm{R}_{1}=0.0508, \mathrm{w} \mathrm{R}_{2}=0.0946$ \\
\hline Largest diff. peak/hole / e $\AA^{-3}$ & $1.23 /-1.00$ & $0.84 /-0.70$ \\
\hline
\end{tabular}




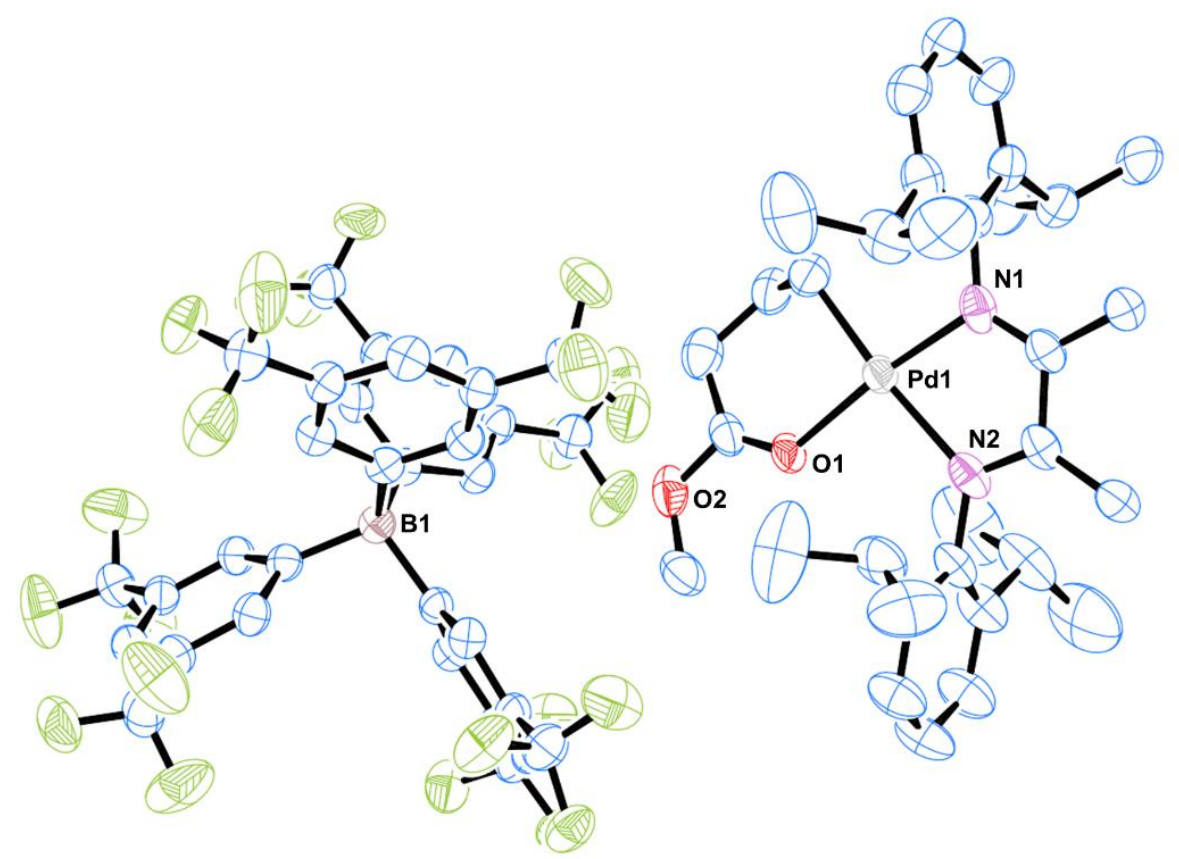

Figure S6: Ortep plot of complex 2, hydrogen atoms and second disordered positions of the $\mathrm{CF}_{3}$-group and chelate omitted for clarity. The ellipsoids shown represent $50 \%$ probability.

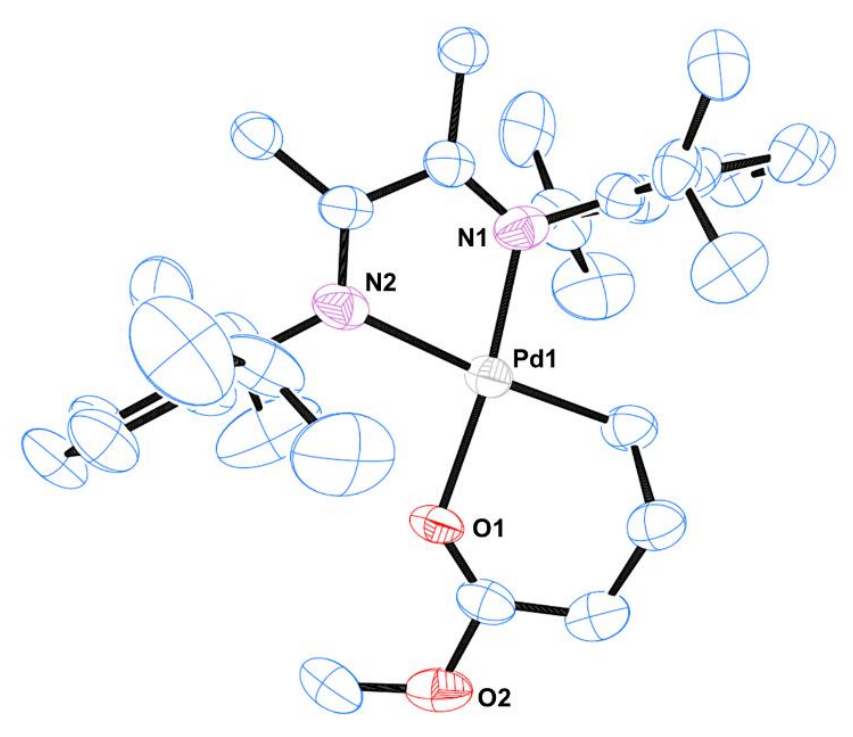

Figure S7: Ortep plot of the $\alpha$-diimine Pd cation of complex 2, hydrogen atoms and second disordered position of the chelate omitted for clarity. The ellipsoids shown represent $50 \%$ probability.

Single crystals of $\left[\left(2,6-i \mathrm{Pr}_{2} \mathrm{C}_{6} \mathrm{H}_{3}-\mathrm{N}=\mathrm{C}(\mathrm{Me})-\mathrm{C}(\mathrm{Me})=\mathrm{N}-2,6-i \mathrm{Pr}_{2} \mathrm{C}_{6} \mathrm{H}_{3}\right) \mathrm{Pd}\left(\mathrm{CH}_{2}\right)_{3} \mathrm{C}(\mathrm{O}) \mathrm{OMe}\right]$ $\mathrm{BArF}(2)$ were grown from dichloromethane layered with pentane. A suitable crystal was selected and mounted on a STOE IPDS 2T diffractometer. The crystal was kept at $100.15 \mathrm{~K}$ during data collection. Using Olex $2^{10}$, the structure was solved with the ShelXT ${ }^{11}$ structure solution program using Intrinsic Phasing and refined with the ShelXL ${ }^{12}$ refinement package using Least Squares minimization. One $\mathrm{CF}_{3}$-group split into two positions and was refined to 60:40 occupancy, the palladium carbyl chelate split into two positions and was refined to 80:20 
occupancy. Graphical representation were created by the ORTEP-3 V2.02. for Windows XP software package. ${ }^{3}$

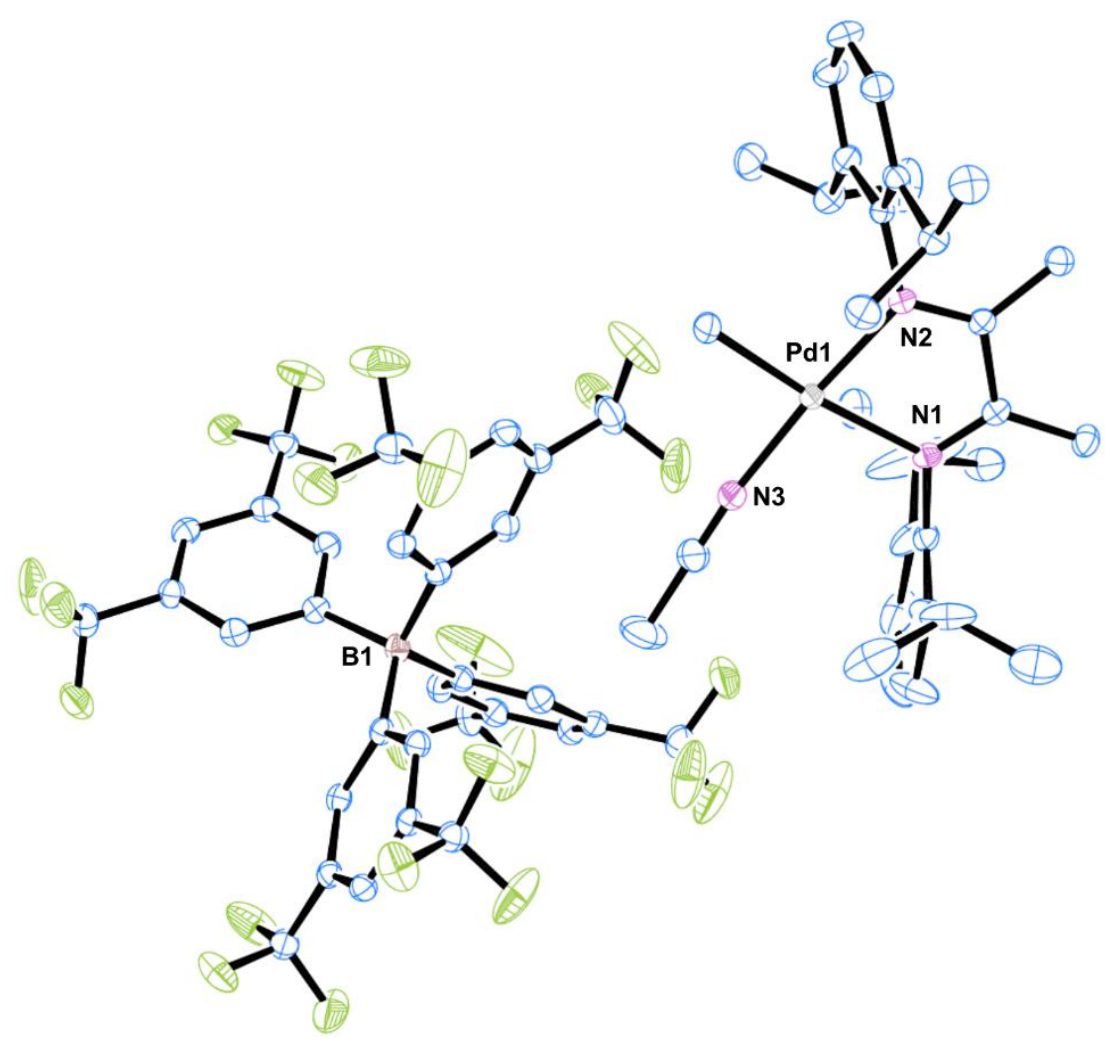

Figure S8: Ortep plot of complex 3, hydrogen atoms and second disordered position of the isopropyl group omitted for clarity. The ellipsoids shown represent $50 \%$ probability.

Single crystals of $\left[\left(2,6-i \mathrm{Pr}_{2} \mathrm{C}_{6} \mathrm{H}_{3}-\mathrm{N}=\mathrm{C}(\mathrm{Me})-\mathrm{C}(\mathrm{Me})=\mathrm{N}-2,6-i \mathrm{Pr}_{2} \mathrm{C}_{6} \mathrm{H}_{3}\right) \mathrm{Pd}(\mathrm{Me})\left(\mathrm{NCCH}_{3}\right)\right] \mathrm{B} A r F$ (3) were grown from dichloromethane layered with pentane. A suitable crystal was selected and mounted on a STOE IPDS 2T diffractometer. The crystal was kept at $100.15 \mathrm{~K}$ during data collection. Using Olex $2^{10}$, the structure was solved with the ShelXT ${ }^{11}$ structure solution program using Intrinsic Phasing and refined with the ShelXL ${ }^{12}$ refinement package using Least Squares minimization. One isopropyl group split into two positions and was refined to 50:50 occupancy. Graphical representation were created by the ORTEP-3 V2.02. for Windows XP software package. ${ }^{3}$ 


\subsection{Synthesis of TIPNO Free Radical}

2,2,5-Trimethyl-4-phenyl-3-azahexane-3-nitroxide (TIPNO free radical) was synthesized from 2-methyl-2-nitropropane and isobutyraldehyde according to a reported procedure (Scheme S5). ${ }^{13,14}$
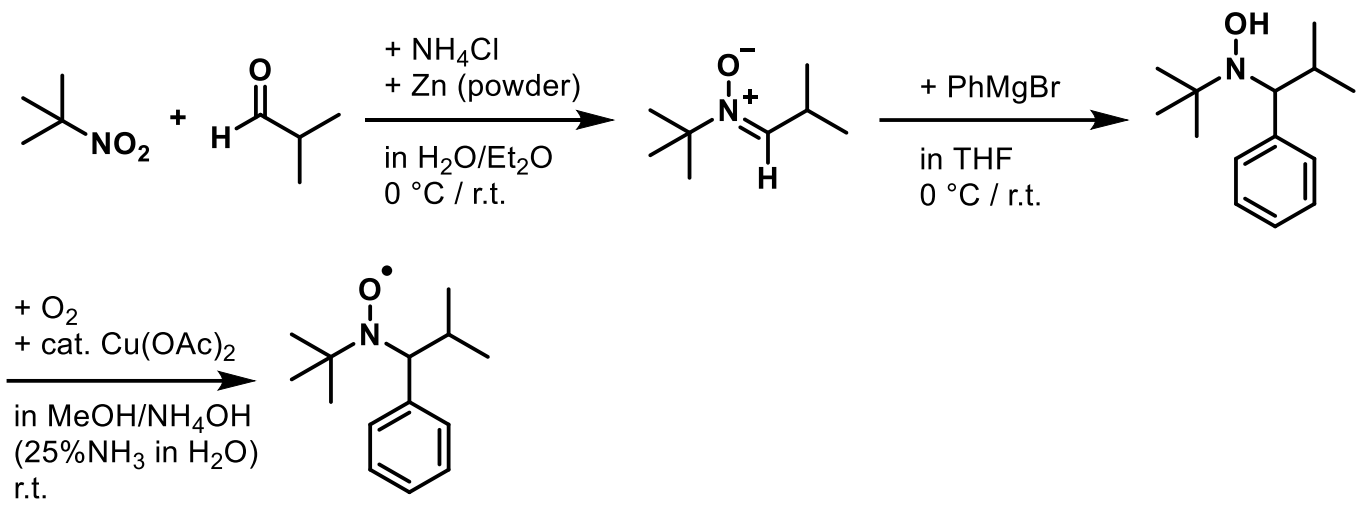

Scheme S5: Synthesis of TIPNO free radical via addition of phenylmagnesium bromide to $N$-tert-butyl- $\alpha$-iso-propylnitrone and subsequent oxidation of the formed $N$-(tertbutyl)- $N$-(2-methyl-1-phenylpropyl)hydroxylamine.

\subsubsection{Synthesis of $N$-tert-Butyl- $\alpha$-iso-propylnitrone}

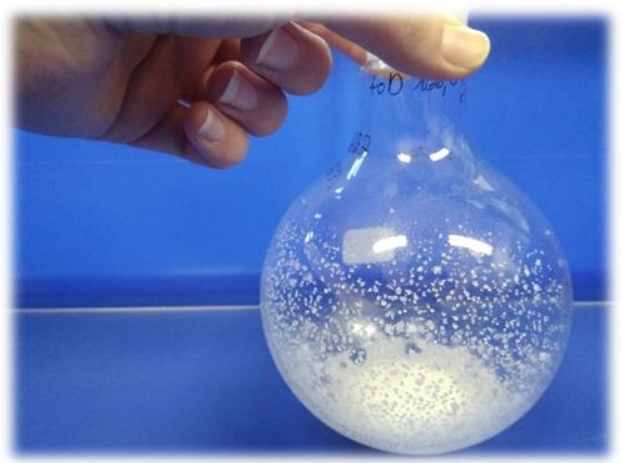

Figure 59: Photograph of the obtained $N$-tert-butyl$\alpha$-iso-propyl-nitrone.
Ammonium chloride $(5.9 \mathrm{~g}, 110 \mathrm{mmol}, 1.1$ equiv.), isobutyraldehyde (7.2 g, $100 \mathrm{mmol}, 1.0$ equiv.) and 2methyl-2-nitropropane (10.3 g, $100 \mathrm{mmol}, 1.0$ equiv.) were dissolved in $200 \mathrm{~mL}$ of deionized water. The clear solution was cooled to $0{ }^{\circ} \mathrm{C}$ under stirring and $100 \mathrm{~mL}$ of diethyl ether were added. Zinc powder $(26.0 \mathrm{~g}$, $400 \mathrm{mmol}, 4.0$ equiv.) were added stepwise over $1 \mathrm{~h}$. The solution turned turbid and slightly blue. The solution was warmed to room temperature overnight and a two-phasic mixture was obtained. The mixture was filtered over a glass frit. The white solid was washed with $2 \times 50 \mathrm{~mL}$ of methanol. The combined

filtrate was extracted with $4 \times 90 \mathrm{~mL}$ of dichloromethane. The combined organic phases were washed with circa $125 \mathrm{~mL}$ of brine, dried with magnesium sulfate and filtered. After removal of the solvent at $40^{\circ} \mathrm{C}$ and 50 mbar $N$-tert-butyl- $\alpha$-iso-propylnitrone was obtained as a colorless oil to sticky white solid (10.6 g, $74 \mathrm{mmol}, 74 \%)$. Please note that the compound is susceptible to sublimation at high vacuum.

The formation of the desired compound was confirmed by an ${ }^{1} \mathrm{H}$ NMR spectrum which agrees with reported data (Figure S10). ${ }^{14}$ 
<smiles>CC(C)C=[N+]([O-])C(C)(C)C</smiles>

${ }^{1} \mathbf{H}$ NMR (400 MHz, $\left.\mathrm{CDCl}_{3}, 300 \mathrm{~K}\right): \delta=1.09\left(\mathrm{~d},{ }^{3} J_{\mathrm{H}, \mathrm{H}}=6.8 \mathrm{~Hz}, 6 \mathrm{H}, \mathrm{H}-1\right), 1.48$ (s, 9H, H-6), 3.17 (voct, $\left.{ }^{3} J_{\mathrm{H}, \mathrm{H}}=6.8 \mathrm{~Hz}, 1 \mathrm{H}, \mathrm{H}-2\right), 6.61\left(\mathrm{~d},{ }^{3} J_{\mathrm{H}, \mathrm{H}}=6.9 \mathrm{~Hz}, 1 \mathrm{H}, \mathrm{H}-4\right) \mathrm{ppm}$.

ESI-HRMS: found 144.1384 $[\mathrm{M}+\mathrm{H}]^{+}, 287.2694\left[\mathrm{M}_{2}+\mathrm{H}\right]^{+},\left(\right.$calcd. $144.1383[\mathrm{M}+\mathrm{H}]^{+}, 287.2693$ $\left.\left[\mathrm{M}_{2}+\mathrm{H}\right]^{+}\right)$.

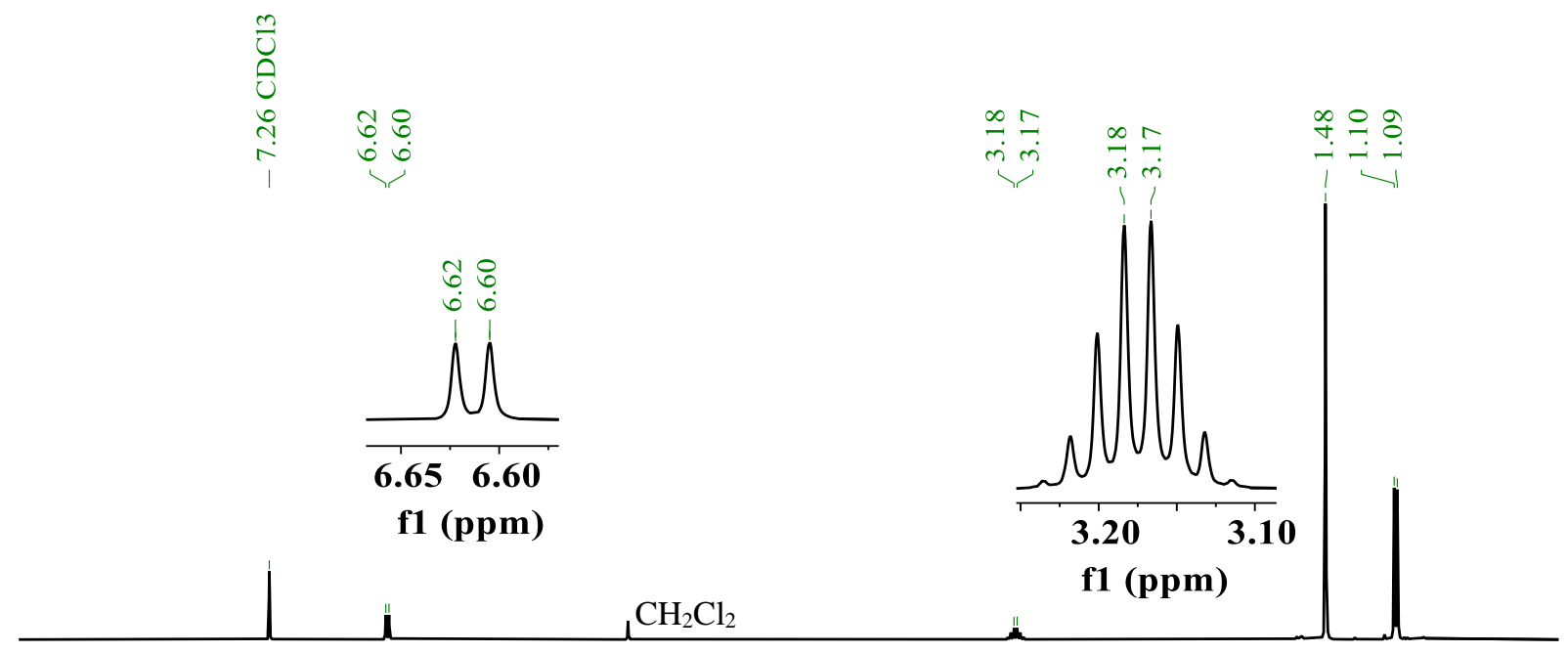

\section{\begin{tabular}{lllllllllllllllll}
\hline $\mathbf{8 . 5}$ & 8.0 & 7.5 & 7.0 & 6.5 & 6.0 & 5.5 & 5.0 & 4.5 & 4.0 & 3.5 & 3.0 & 2.5 & 2.0 & 1.5 & 1.0 & 0.5
\end{tabular} f1 (ppm)}

Figure S10: ${ }^{1} \mathrm{H}$ NMR spectrum $\left(400 \mathrm{MHz}, \mathrm{CDCl}_{3}, 300 \mathrm{~K}\right)$ of $N$-tert-butyl- $\alpha$-iso-propylnitrone.

\subsubsection{Synthesis of $N$-(tert-Butyl)- $N$-(2-methyl-1-phenylpropyl)hydroxyl amine}

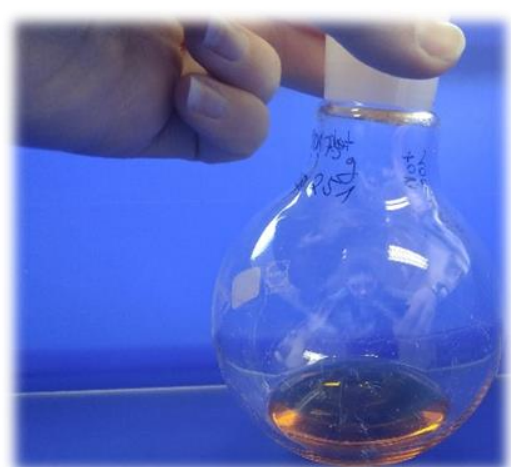

Figure S11: Photograph of $N$-(tert-Butyl)$N$-(2-methyl-1phenylpropyl)hydroxyl amine.
Under inert atmosphere $N$-tert-butyl- $\alpha$-iso-propylnitrone (7.16 g, $50 \mathrm{mmol}, 1.0$ equiv.) was dissolved in $51 \mathrm{~mL} \mathrm{THF}$ at $0^{\circ} \mathrm{C}$. At this temperature $33.3 \mathrm{~mL}$ of phenyl magnesium bromide solution (3M solution in diethyl ether, i.e. $100 \mathrm{mmol}$, 2.0 equiv.) were added slowly. The reaction mixture turned yellow and a white precipitate formed. Subsequently the reaction mixture was warmed to room temperature and vigorously stirred over night. $10 \mathrm{~mL}$ of ammonium chloride solution followed by $30 \mathrm{~mL}$ of deionized water were added carefully under slight cooling of the mixture to destroy residual Grignard reagent. A yellow to orange organic phase and a colorless water phase with white solid was obtained. The phases were separated and the aqueous phase was extracted 
with $2 \times 50 \mathrm{~mL}$ of diethyl ether. All organic phases were combined, dried with magnesium sulfate and filtered. The crude $N$-(tert-butyl)- $N$-(2-methyl-1-phenylpropyl)hydroxyl amine was obtained in $87 \%$ yield as orange oil after concentration at $23{ }^{\circ} \mathrm{C}$ and 7 mbar. Please note, that warming to $40^{\circ} \mathrm{C}$ decomposes the product.<smiles>CC(C)C(c1ccccc1)N(O)C(C)(C)C</smiles>

${ }^{1} \mathbf{H}$ NMR $\left(400 \mathrm{MHz}_{\mathrm{CDCl}}, 300 \mathrm{~K}\right): \delta=0.58,1.13,\left(\mathrm{~d},{ }^{3} \mathrm{~J}_{\mathrm{H}, \mathrm{H}}=6.7 \mathrm{~Hz},{ }^{3} J_{\mathrm{H}, \mathrm{H}}=6.4 \mathrm{~Hz}, 3 \mathrm{H}\right.$ each, H-7, H-8), 0.92 (s, 9H, H-10), 2.28 (m, 1H, H-6), 3.38 (d, $\left.{ }^{3} J_{\mathrm{H}, \mathrm{H}}=10.0 \mathrm{~Hz}, 1 \mathrm{H}, \mathrm{H}-5\right), 4.41$ (br, 1H, H-11), $7.20-7.63$ (m, 5H, H-1, H-2, H-3) ppm.

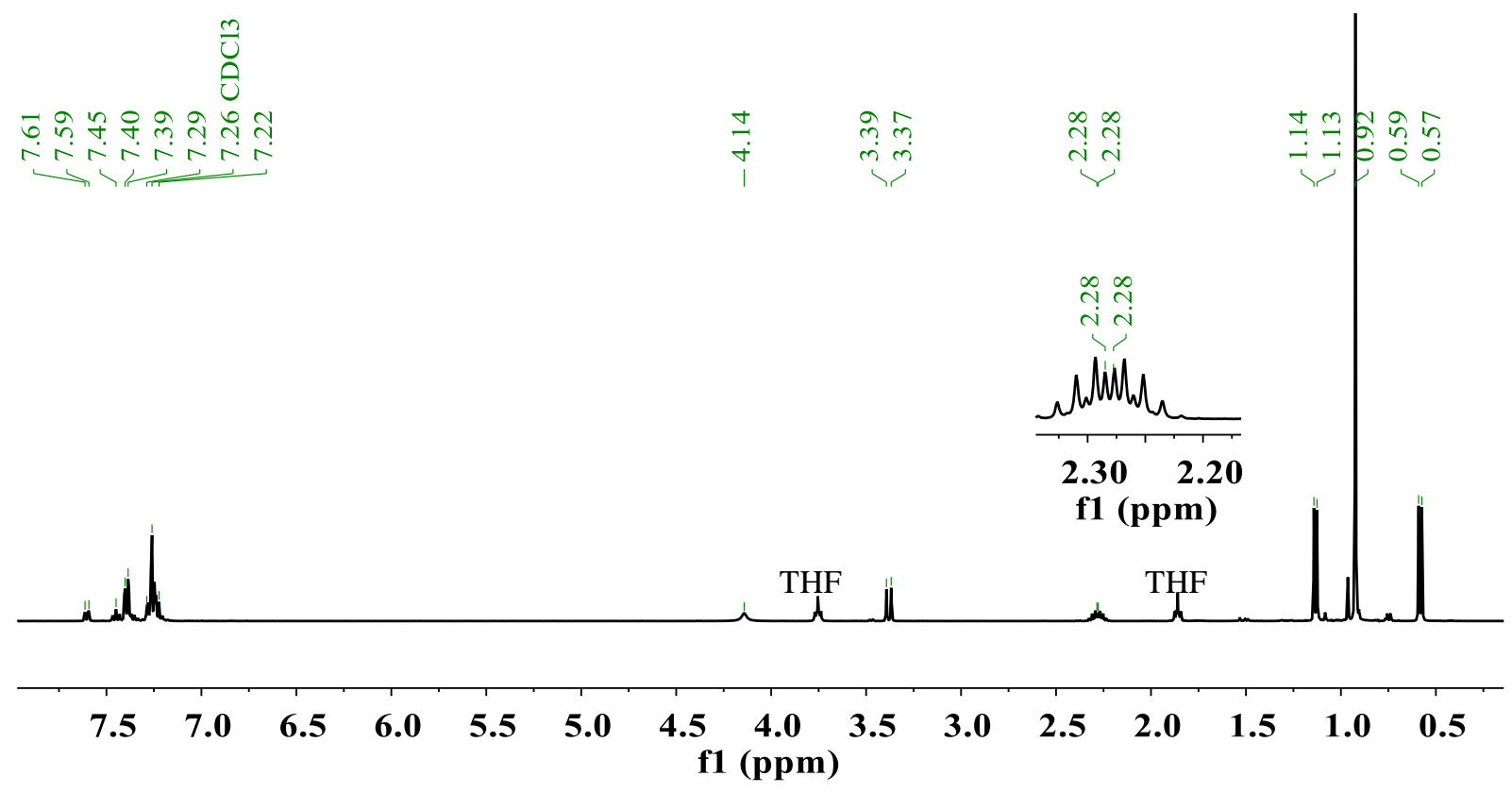

Figure S12: $\quad{ }^{1} \mathrm{H}$ NMR spectrum $\left(400 \mathrm{MHz}, \mathrm{CDCl}_{3}, 300 \mathrm{~K}\right)$ of crude $N$-(tert-butyl)- $N-(2-$ methyl-1-phenylpropyl)hydroxyl amine. 

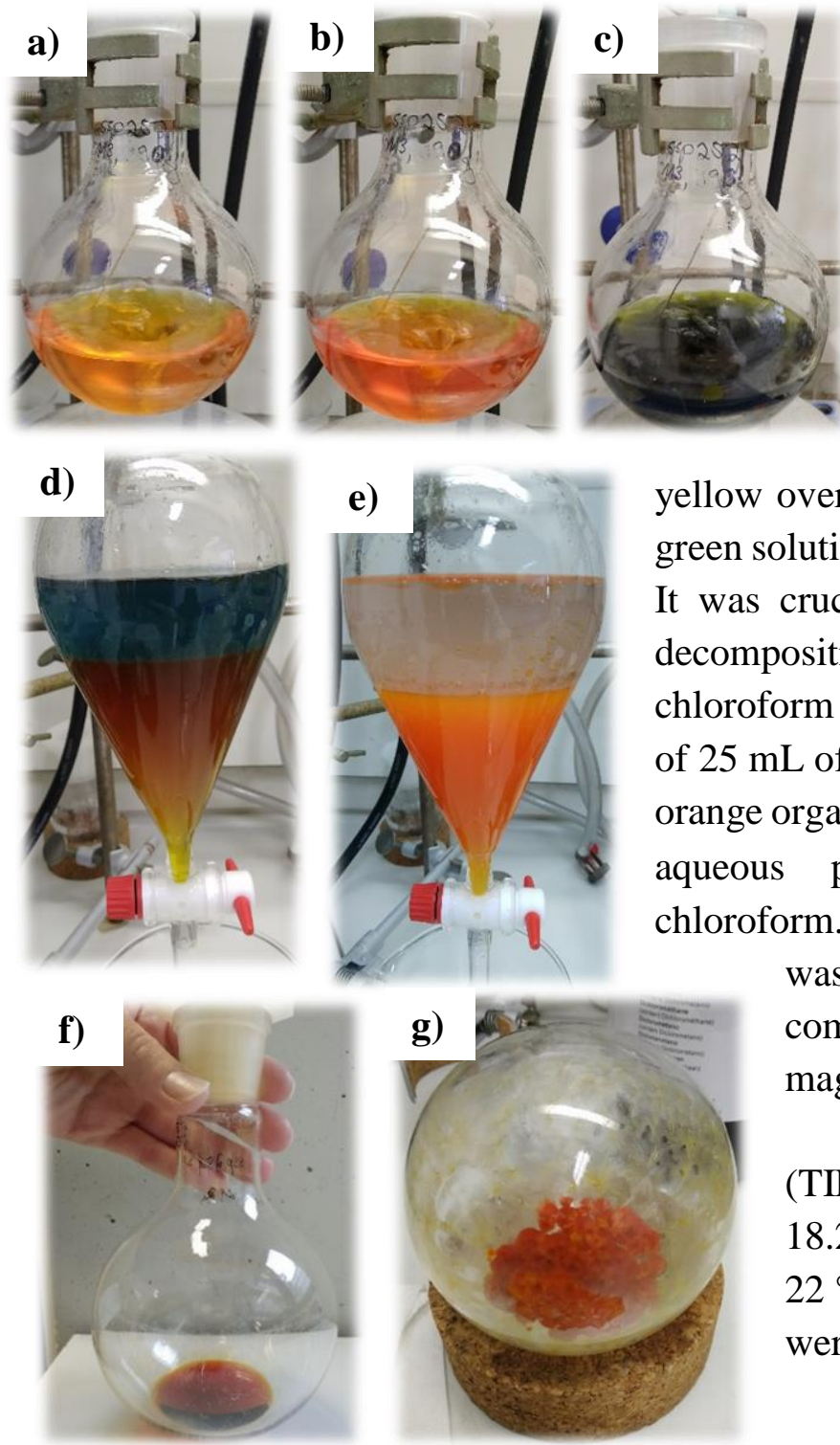
yellow over red to dark green was observed. The dark green solution was concentrated to circa $50 \mathrm{~mL}$ at $22{ }^{\circ} \mathrm{C}$. It was crucial to keep the temperature low to avoid decomposition. The residue was dissolved in $100 \mathrm{~mL}$ chloroform and $100 \mathrm{~mL}$ of water were added. Addition of $25 \mathrm{~mL}$ of saturated potassium bisulfate resulted in an orange organic phase and a colorless aqueous phase. The aqueous phase was extracted with $2 \times 25 \mathrm{~mL}$ chloroform. The organic phases were combined and washed with $30 \mathrm{~mL}$ sodium bicarbonate. The combined organic phases were dried with magnesium sulfate and filtered. The crude 2,2,5trimethyl-4-phenyl-3-azahexan-3-nitroxide (TIPNO) was obtained in $83 \%$ yield $(4.0 \mathrm{~g}$, $18.2 \mathrm{mmol}$ ) as orange oil after concentration at $22{ }^{\circ} \mathrm{C}$. Spherically arranged crystalline needles were observed after cooling to $-25^{\circ} \mathrm{C}$.

Figure S13: a-c) Color change after exposure of the reaction mixture to air. d),e) Work up with color change upon addition of potassium bisulfate solution. f),g) Crude product at r.t. and after cooling to $-25^{\circ} \mathrm{C}$.
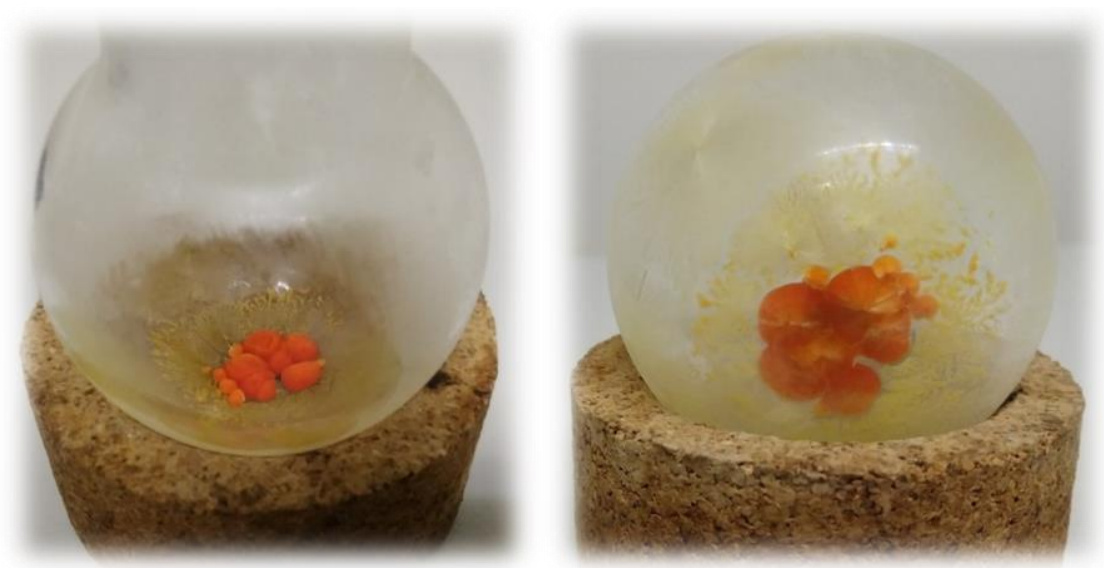

Figure S14: Photographs of TIPNO after purification by column chromatography.
NMR showed very broad signals at circa $1.2 \mathrm{ppm}$ and $4.4 \mathrm{ppm}$ and additional sharp signals in the aromatic region corresponding to biphenyl, which formed as a side product. The crude TIPNO was purified by column chromate-graphy (silica, gradient hexane:EE 16:1 to $1: 1$ ) yielding clean 
fractions as orange oil, which formed spherically arranged crystalline needles upon cooling to $-25{ }^{\circ} \mathrm{C}$. It was possible to obtain a ${ }^{1} \mathrm{H}$ NMR spectrum with addition of pentafluorophenyl hydrazine, which reduced the originally broad peaks to sharper signals. The quality was sufficient to observe the protons of the TIPNO-hydrazine adduct (Figure S15).<smiles>CC(C)C(c1ccccc1)N([O-])C(C)(C)C</smiles>

(NMR measurements as adduct with pentafluorphenyl hydrazine)

${ }^{1} \mathbf{H}$ NMR (400 MHz, $\left.\mathrm{CDCl}_{3}, 300 \mathrm{~K}\right): \delta=0.83,1.03\left(\mathrm{~d},{ }^{3} J_{\mathrm{H}, \mathrm{H}}=6.7 \mathrm{~Hz}, 3 \mathrm{H}\right.$ each, H-7, H-8), 1.43 (br, 9H, H-10), 2.00 (m, 1H, H-6), $4.41\left(\mathrm{~d},{ }^{3} J_{\mathrm{H}, \mathrm{H}}=6.7 \mathrm{~Hz}, 1 \mathrm{H}, \mathrm{H}-5\right), 7.26-7.44$ (m, 5H, H-1, $\mathrm{H}-2, \mathrm{H}-3) \mathrm{ppm}$.

ESI-HRMS: found $220.1692[\mathrm{M}]^{+},\left(\right.$calcd. $\left.220.1696[\mathrm{M}]^{+}\right)$.

Note that $[\mathrm{M}]^{+}$rather than $[\mathrm{M}+\mathrm{H}]^{+}$species are observed in ESI-HRMS measurements of TIPNO. At first this seems unusual, however a preferred oxidation over protonation has been observed for nitroxide radicals previously. Reid et al. rationalize this finding by avoidance of a potentially unstable odd-electron species. ${ }^{15}$
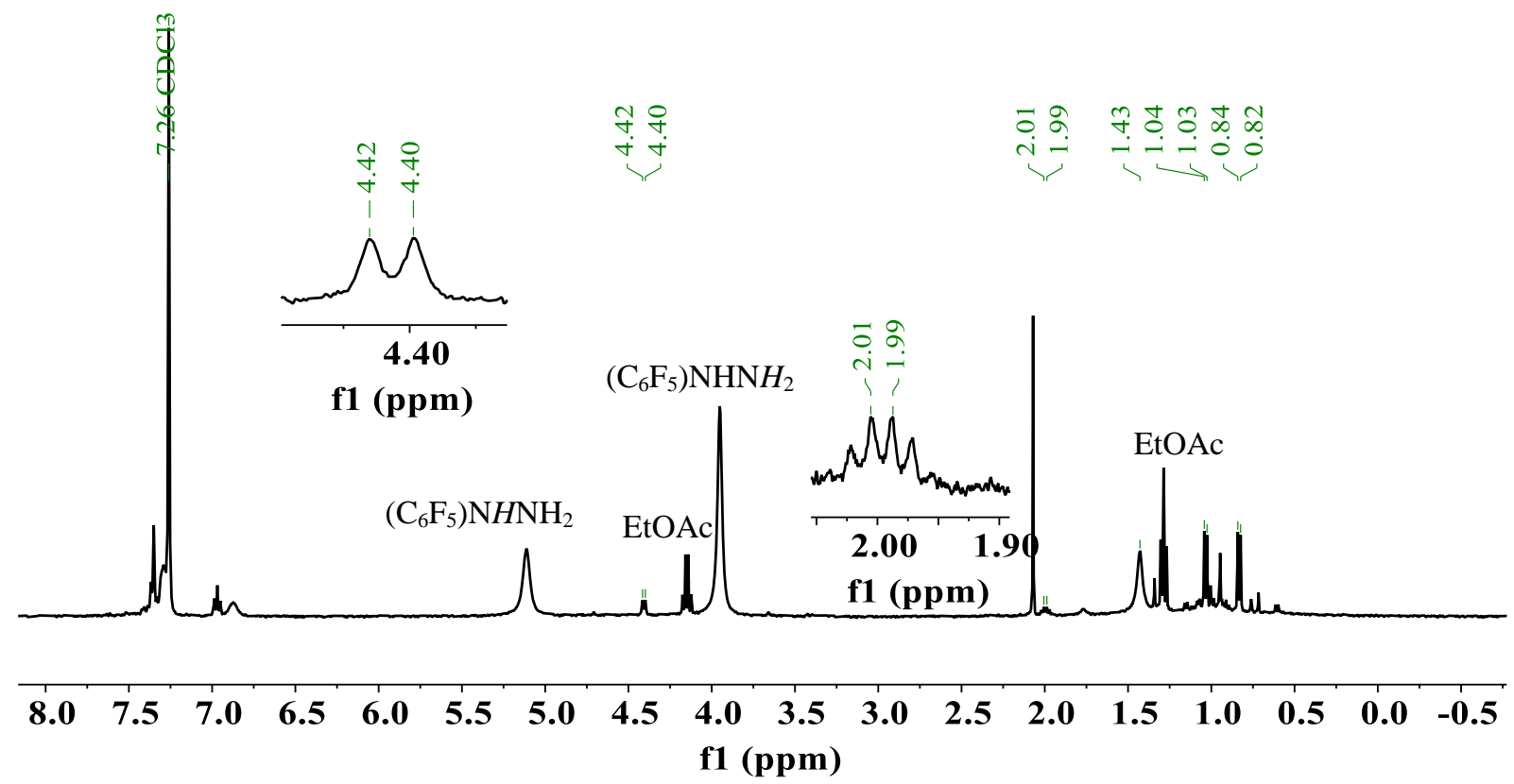

Figure S15: $\quad{ }^{1} \mathrm{H}$ NMR spectrum $\left(400 \mathrm{MHz}, \mathrm{CDCl}_{3}, 300 \mathrm{~K}\right.$ ) of 2,2,5-trimethyl-4-phenyl-3azahexan-3-nitroxide (TIPNO free radical) after addition of pentafluorophenyl hydrazine.

The obtained product was also characterized by electron paramagnetic resonance spectrometry (EPR). The EPR trace obtained at room temperature with a microwave attenuation of $10 \mathrm{~dB}$ 
(Figure S16, left trace) fits to a previously reported trace of 2,2,5-trimethyl-4-phenyl-3azahexan-3-nitroxide (TIPNO free radical). ${ }^{16}$ The obtained g value of 1,9967 fits for an organic radical. Measurements with variable temperature at a microwave attenuation of $5 \mathrm{~dB}$ show increasing signal intensity with decreasing temperature (Figure S16, traces on the right).
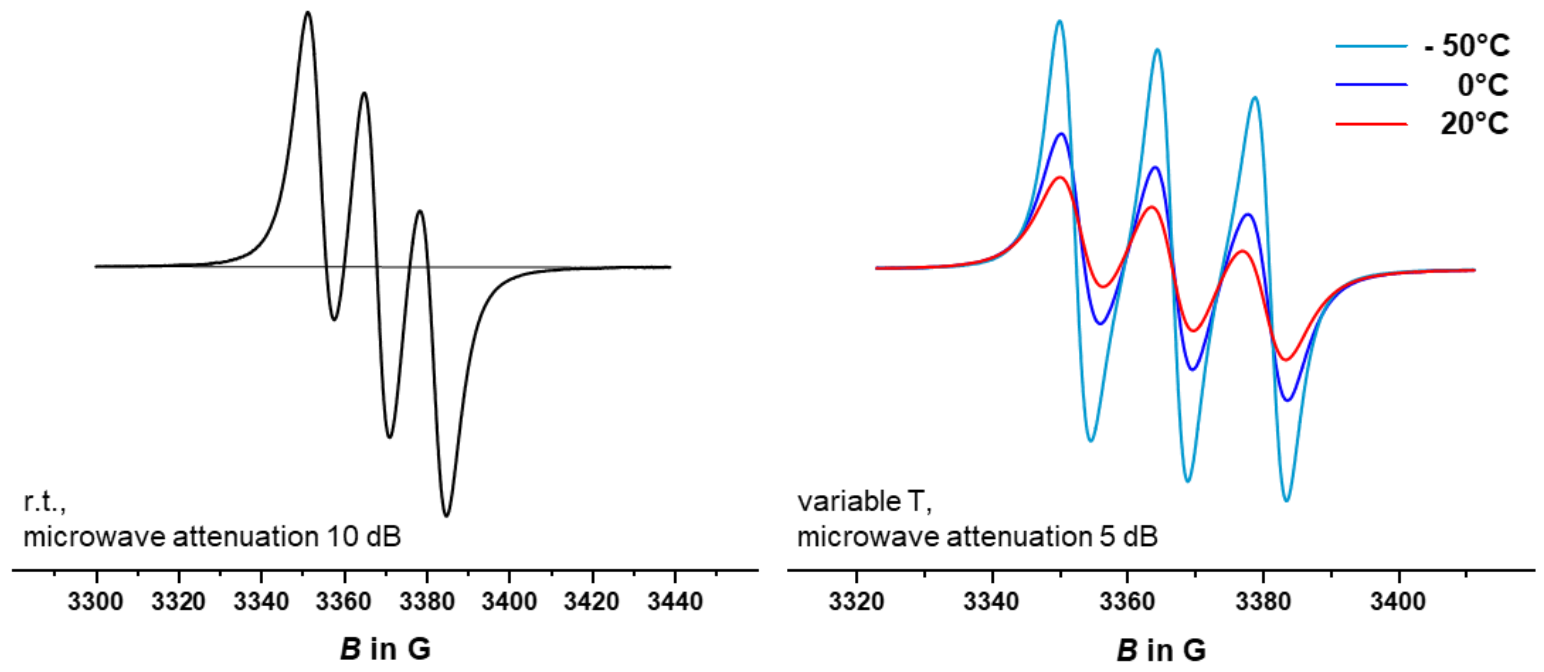

Figure S16: EPR traces of 2,2,5-trimethyl-4-phenyl-3-azahexan-3-nitroxide (TIPNO free radical). 


\subsection{Synthesis of Alkoxyamine Modified Chain Transfer Agent}

The alkoxyamine modified CTA (1) was synthesized from the commercially available $N$-tertbutyl-O-[1-[4-(chloromethyl)phenyl]ethyl]- $N$-(2-methyl-1-phenylpropyl)hydroxylamine similar to a reported procedure (Scheme S6). ${ }^{17,18}$

The synthesis route can also be performed starting from TIPNO free radical (Scheme S6, grey). Here addition of 4-vinylbenzyl chloride to the nitroxide radical can be achieved with different $\mathrm{Mn}$ (III) compounds as reported previously. ${ }^{19,20}$ We adapted a procedure with $\mathrm{Mn}(\mathrm{OAc})_{3}$ and did observe the desired addition product albeit with 4,4'-(butane-2,3-diyl)bis((chloromethyl)benzene) as side product.
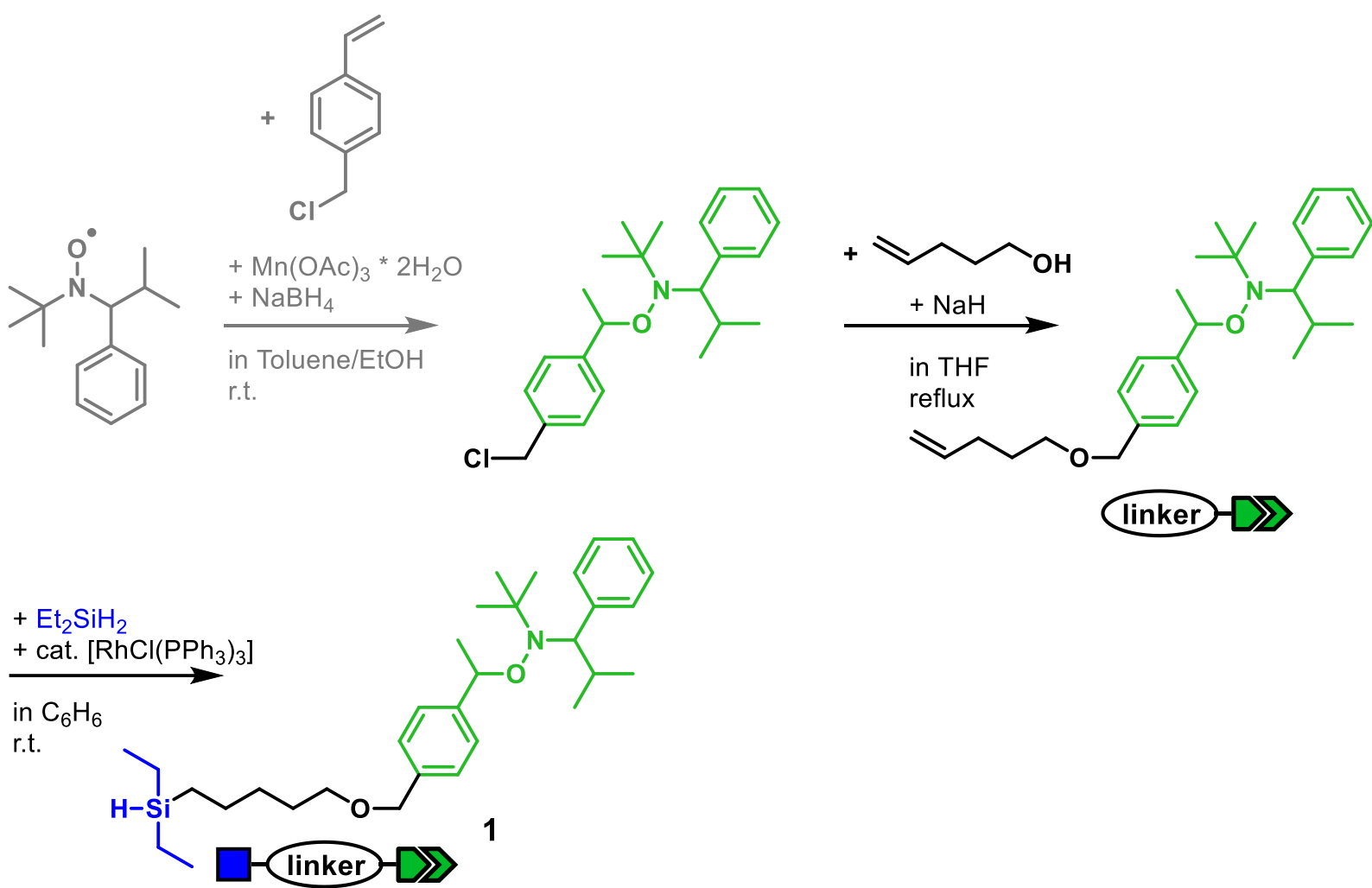

Scheme S6: Synthesis of the alkoxyamine modified CTA (1) by reaction of $\mathrm{N}$-tert-butyl-O [1-[4-(chloromethyl)phenyl]ethyl]- $N$-(2-methyl-1-phenylpropyl)hydroxylamine with 4-pentenol and subsequent hydrosilylation of the double bond.

\subsubsection{N-(tert-Butyl)- $N$-(2-methyl-1-phenylpropyl)-O-(1-(4-((pent-4-en-1-yloxy)methyl)- phenyl)ethyl)hydroxylamine}

Sodium hydride (384 mg, $16.0 \mathrm{mmol}, 4.0$ equiv.) was dispersed in dry THF (circa $16 \mathrm{~mL}$ ) and $800 \mathrm{mg}$ (9.3 mmol, 2.3 equiv.) of 4-penten-1-ol were added. Formation of hydrogen was observed. $1.50 \mathrm{~g}$ (4.0 mmol, 1.0 equiv.) of $N$-tert-butyl- $O$-[1-[4-(chloromethyl)phenyl]ethyl]$N$-(2-methyl-1-phenylpropyl)-hydroxylamine dissolved in THF were added slowly. The reaction mixture was refluxed and aliquots were drawn to monitor the conversion by ${ }^{1} \mathrm{H}$ NMR. Usually after $48 \mathrm{~h}$ the solvent was removed under vacuum and the residue was dissolved in dichloromethane $(20 \mathrm{~mL})$. Water $(20 \mathrm{~mL})$ was added carefully. Gas formation indicated reaction of residual sodium hydride. The phases were separated and the water phase extracted 
with $3 \times 15 \mathrm{~mL}$ dichloromethane. All organic phases were combined, dried over magnesium sulfate and filtered. Removal of the solvent under vacuum yielded the product as clear slightly yellow oil $(80 \%, 1.35 \mathrm{~g} 3.2 \mathrm{mmol})$.

In contrast to the procedure reported by Hawker and coworkers ${ }^{17}$ we did not use 18-crown-6 ether and could thus avoid the purification by column chromatography.

The ${ }^{1} \mathrm{H}$ NMR spectrum of the obtained compound (Figure S17) agrees with published data. ${ }^{17}$

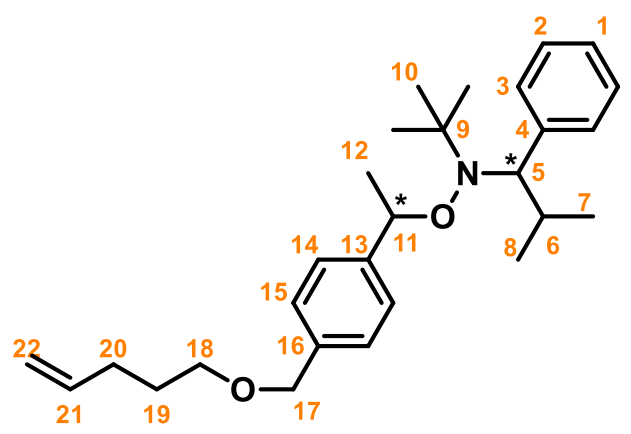

${ }^{1} \mathbf{H}$ NMR $\left(400 \mathrm{MHz}_{\mathrm{CDCl}}, 300 \mathrm{~K}\right): \delta=0.22,0.54,0.93,1.30\left(\mathrm{~d},{ }^{3} J_{\mathrm{H}, \mathrm{H}}=6.6 \mathrm{~Hz}, 3 \mathrm{H}\right.$ each, H-7, H-7‘, H-8, H-8'), 0.78 (s, 9H, H-10), 1.04 (s, 9H, H-10'), 1.40 (m, 1H, H-6’), 1.53 (d, ${ }^{3} J_{\mathrm{H}, \mathrm{H}}=6.7 \mathrm{~Hz}, 3 \mathrm{H}, \mathrm{H}-12$ '), $1.61\left(\mathrm{~d},{ }^{3} J_{\mathrm{H}, \mathrm{H}}=6.7 \mathrm{~Hz}, 3 \mathrm{H}, \mathrm{H}-12\right), 1.71$ (vqint, ${ }^{3} J_{\mathrm{H}, \mathrm{H}}=6.8 \mathrm{~Hz}, 4 \mathrm{H}$, $\left.\mathrm{H}-19 / 19^{\circ}\right), 2.14\left(\mathrm{vq},{ }^{3} J_{\mathrm{H}, \mathrm{H}}=7.2 \mathrm{~Hz}, 4 \mathrm{H}, \mathrm{H}-20 / 20^{\circ}\right), 2.33(\mathrm{~m}, 1 \mathrm{H}, \mathrm{H}-6), 3.30\left(\mathrm{~d},{ }^{3} J_{\mathrm{H}, \mathrm{H}}=10.8 \mathrm{~Hz}\right.$, $\left.1 \mathrm{H}, \mathrm{H}-5^{\circ}\right), 3.41\left(\mathrm{~d},{ }^{3} J_{\mathrm{H}, \mathrm{H}}=10.5 \mathrm{~Hz}, 1 \mathrm{H}, \mathrm{H}-5\right), 3.47,3.48\left(\mathrm{t},{ }^{3} J_{\mathrm{H}, \mathrm{H}}=6.3 \mathrm{~Hz},{ }^{3} J_{\mathrm{H}, \mathrm{H}}=6.8 \mathrm{~Hz}, 2 \mathrm{H}\right.$ each, H-18, H-18'), 4.47, 4.52 (s, 2H each, H-17/17'), 4.91, 4.91 (q, ${ }^{3} J_{\mathrm{H}, \mathrm{H}}=6.7 \mathrm{~Hz}, 1 \mathrm{H}$ each,

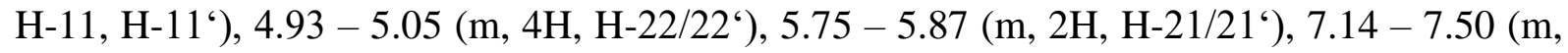
$18 \mathrm{H}, \mathrm{H}-1 / 1^{`}, \mathrm{H}-2 / 2^{`}, \mathrm{H}-3 / 3^{`}, \mathrm{H}-14 / 14^{`}, \mathrm{H}-15 / 15^{`}$ ) ppm.

${ }^{13} \mathbf{C}\left\{{ }^{1} \mathbf{H}\right\}$ NMR $\left(150 \mathrm{MHz}, \mathrm{C}_{6} \mathrm{D}_{6}, 300 \mathrm{~K}\right): \delta=21.2,21.3,22.1,22.3\left(\mathrm{C}-7, \mathrm{C}-7{ }^{`}, \mathrm{C}-8, \mathrm{C}-8^{\circ}\right), 23.3$ (C-12'), 24.9 (C-12), 28.4 (C-10), 28.5 (C-10`), 29.1, 29.1 (C-19, C-19`), 30.5, 30.5 (C-20, C-20'), 31.8 (C-6“), 32.2 (C-6), 60.6, 60.6 (C-9, C-9`), 69.6, 69.9 (C-18, C-18'), 72.3, 72.3 (C-5, C-5'), 72.9, 73.0 (C-17, C-17'), 82.7, 83.4 (C-11, C-11'), 114.9 (C-22/C-22'), 138.5 $\left(\mathrm{C}-21 / 21^{\circ}\right), 126.3,126.3,126.5,127.2,127.3,127.5,127.6,127.7,131.1,131.1\left(\mathrm{C}-1 / 1^{\circ}, \mathrm{C}-2 / 2^{\prime}\right.$, C-3/3‘, C-14/14', C-15/15'), 137.0, 142.4, 142.6, 144.5, 145.3 (C-4/4', C-13/13`, C-16/16`) ppm.

ESI-HRMS: found $424.3214[\mathrm{M}+\mathrm{H}]^{+},\left(\right.$calcd. $\left.424.3210[\mathrm{M}+\mathrm{H}]^{+}\right)$. 

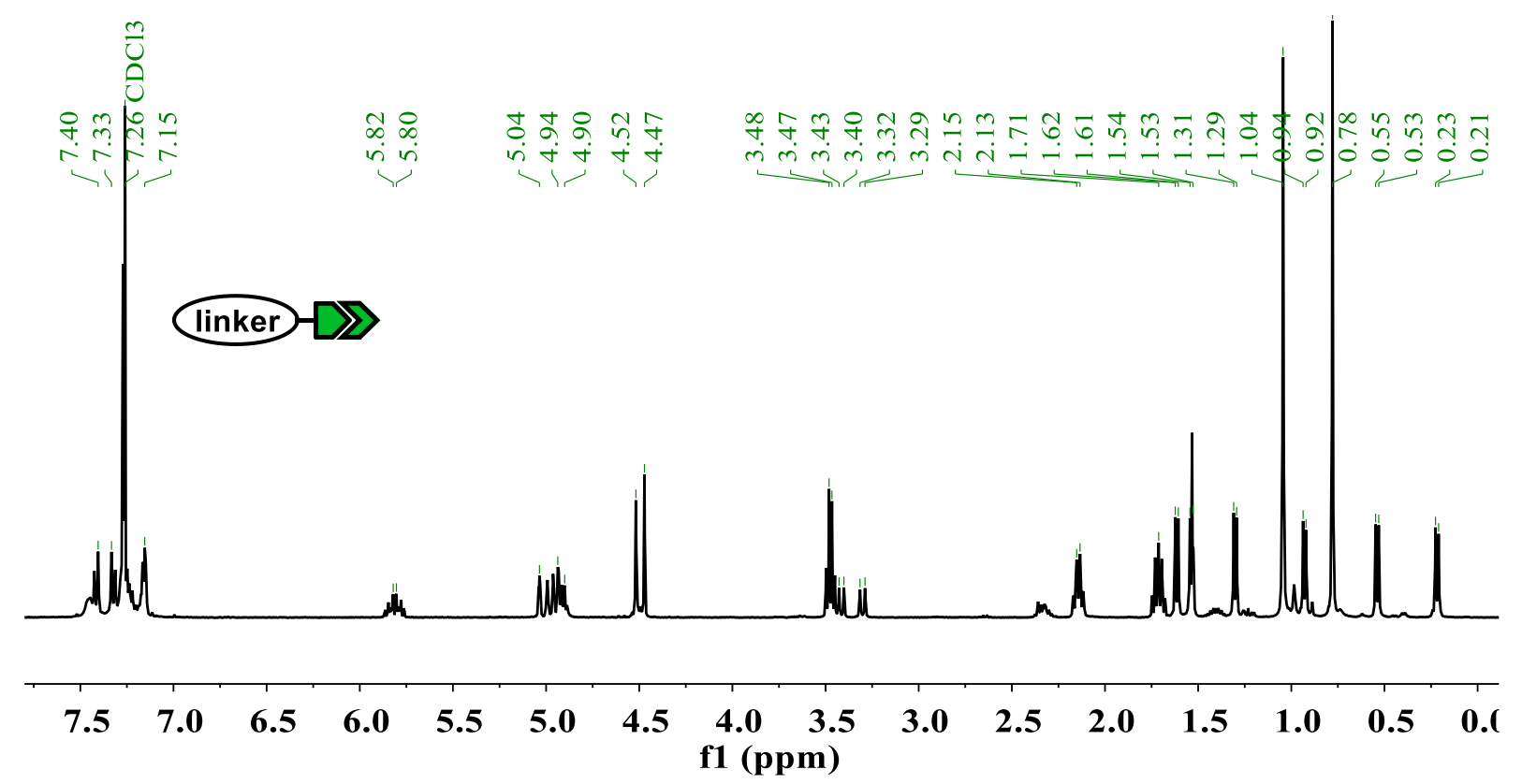

Figure S17: $\quad{ }^{1} \mathrm{H}$ NMR spectrum $\left(400 \mathrm{MHz}, \mathrm{CDCl}_{3}, 300 \mathrm{~K}\right)$ of $N$-(tert-butyl)- $N$-(2-methyl-1phenylpropyl)-O-(1-(4-((pent-4-en-1-yloxy)methyl)phenyl)ethyl)hydroxylamine.
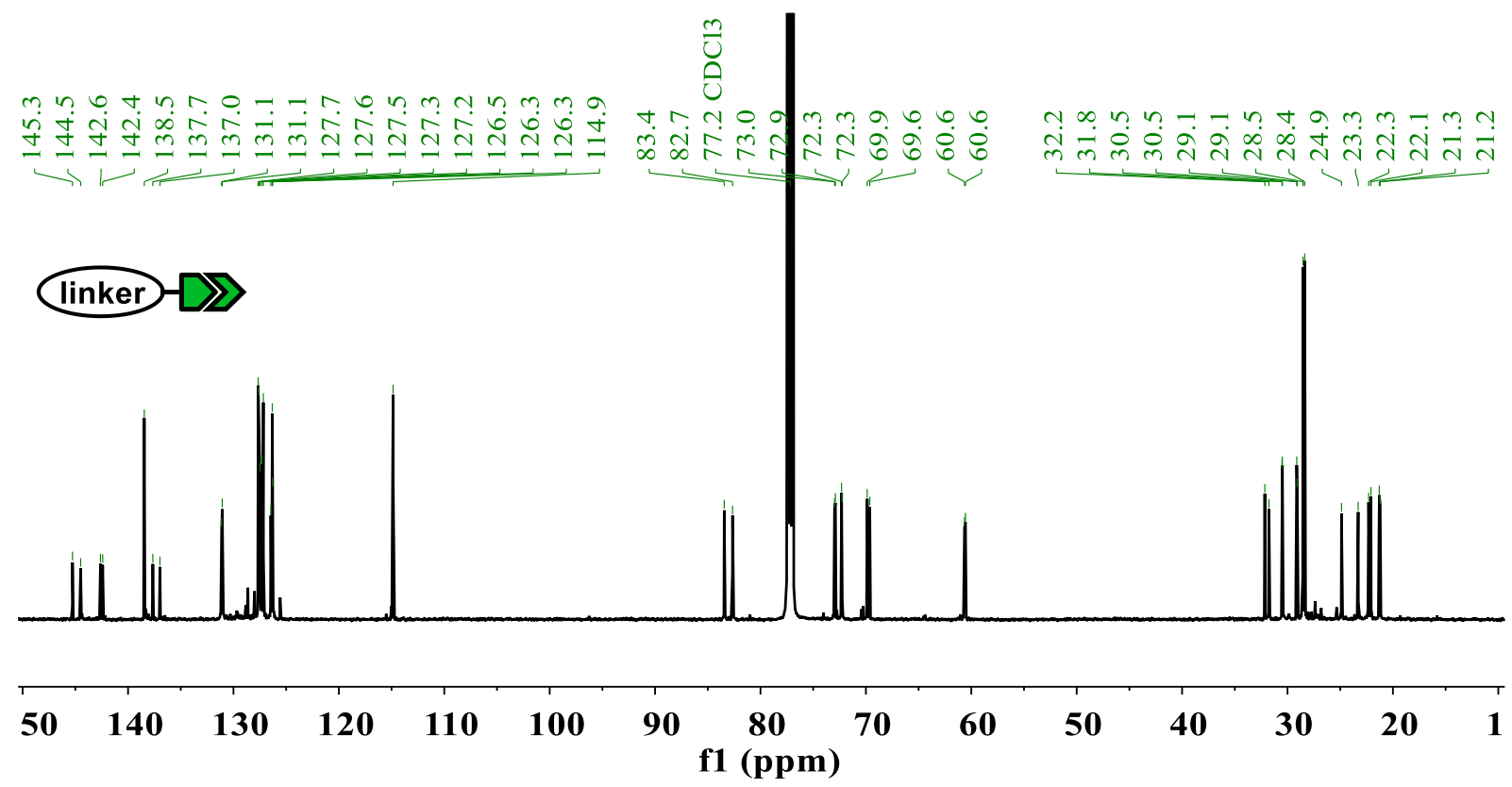

Figure S18: ${ }^{13} \mathrm{C} \mathrm{NMR}$ spectrum $\left(150 \mathrm{MHz}, \mathrm{CDCl}_{3}, 300 \mathrm{~K}\right)$ of $N$-(tert-butyl)- $N$-(2-methyl-1phenylpropyl)-O-(1-(4-((pent-4-en-1-yloxy)methyl)phenyl)ethyl)hydroxylamine. 


\subsubsection{N-(tert-Butyl)-O-(1-(4-(((5-(diethylsilyl)pentyl)oxy)methyl)phenyl)ethyl)- $N$-(2- methyl-1-phenylpropyl)hydroxylamine (alkoxyamine modified CTA, 1)}

We rationalized that the desired alkoxyamine modified CTA (1) was accessible by hydrosilylation of $\mathrm{N}$-(tert-butyl)- $\mathrm{N}$-(2-methyl-1-phenylpropyl)-O-(1-(4-((pent-4-en-1-yloxy)methyl)phenyl)ethyl)hydroxylamine with diethylsilane. Thus the hydrosilylation catalyst needed to be capable of hydrosilylation with diethylsilane without twofold reaction on the same silane, leaving one intact silicon hydride bond. The Wilkinson catalyst $\left[\mathrm{RhCl}\left(\mathrm{PPh}_{3}\right)_{3}\right]$ meets these requirements. However, it is crucial to keep reaction times short, since formation of disilanes (dimers) by reaction of two product molecules was observed for longer reaction times. This dehydrogenative coupling has been previously observed for secondary silanes. ${ }^{21}$

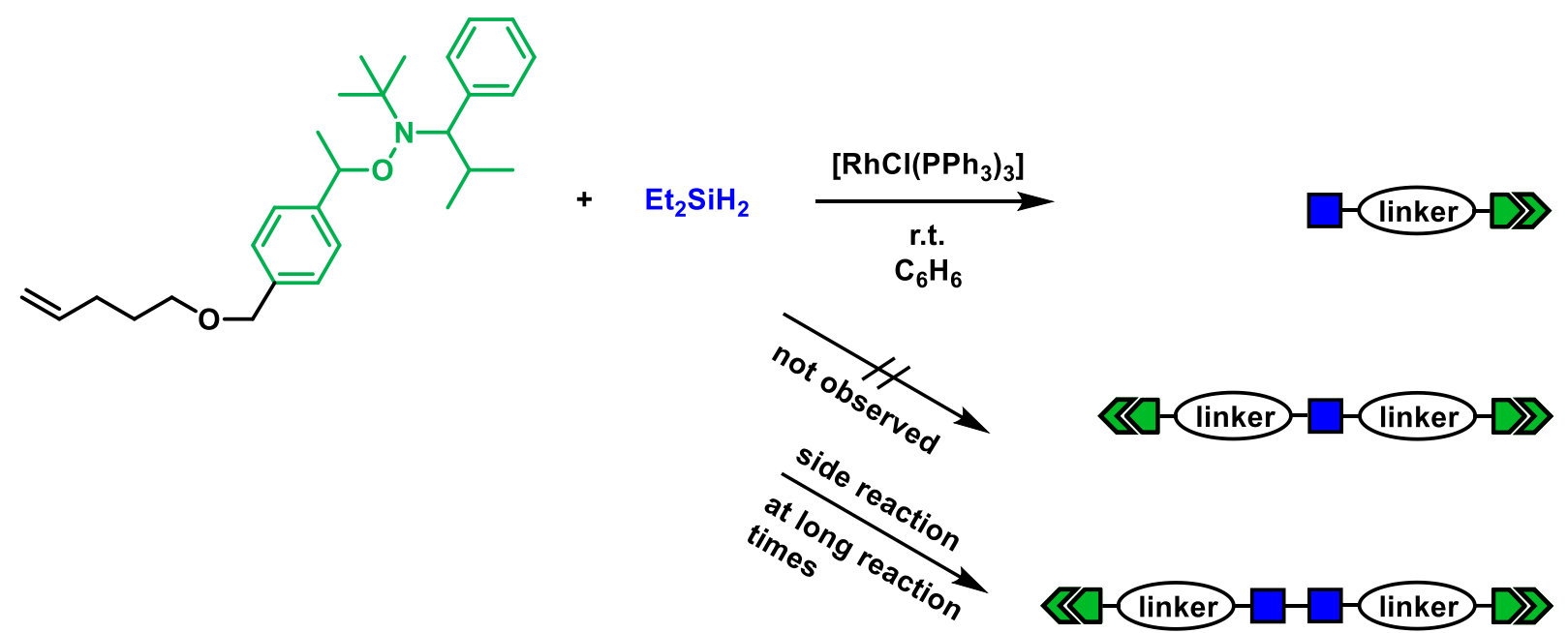

To $1.35 \mathrm{~g}$ (3.2 mmol, 1.0 equiv.) of $N$-(tert-Butyl)- $N$-(2-methyl-1-phenylpropyl)-O-(1-(4((pent-4-en-1-yloxy)methyl)-phenyl)ethyl)hydroxylamine $\quad 0.42 \mathrm{~g} \quad(4.8 \mathrm{mmol}, \quad 1.5$ equiv.) diethylsilane dissolved in benzene was added. The Wilkinson catalyst $\left[\mathrm{RhCl}\left(\mathrm{PPh}_{3}\right)_{3}\right](6 \mathrm{mg}$, $6.4 \mu \mathrm{mol}, 0.002$ equiv.) suspended in benzene (dissolves slowly in benzene, yellow solution) was added to the reaction mixture. After 10 min the yellow reaction mixture was removed from the glovebox and immediately filtered over silica under air. Benzene (circa $10 \mathrm{~mL}$, p.a., not dry and degassed) was used to rinse the silica. The solvent was removed from the filtrate and a clear, slightly yellow oil was obtained (97\% yield, $3.1 \mathrm{mmol}, 1.59 \mathrm{~g})$.

The desired product was obtained as a mixture of diastereomers (Figure S19 and Figure S20). The assignment of ${ }^{1} \mathrm{H}$ and ${ }^{13} \mathrm{C}$ spectra were established by additional 2D NMR experiments $\left({ }^{1} \mathrm{H}-{ }^{1} \mathrm{H}\right.$ gCOSY (Figure S22), ${ }^{1} \mathrm{H}-{ }^{13} \mathrm{C}$ gHSQC (Figure S23) and ${ }^{1} \mathrm{H}^{-13} \mathrm{C}$ gHMBC). 


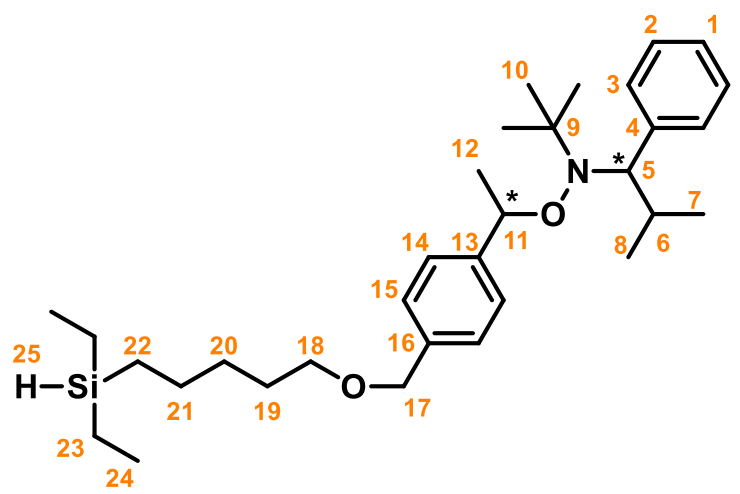

${ }^{1} \mathbf{H}$ NMR $\left(400 \mathrm{MHz}, \mathrm{C}_{6} \mathrm{D}_{6}, 300 \mathrm{~K}\right): \delta=0.41,0.66,1.10,1.39\left(\mathrm{~d},{ }^{3} \mathrm{~J}_{\mathrm{H}, \mathrm{H}}=6.6 \mathrm{~Hz}, 3 \mathrm{H}\right.$ each, H-7, H-7 $\left.{ }^{`}, \mathrm{H}-8, \mathrm{H}-8^{\circ}\right), 0.56\left(\mathrm{dq}^{3} J_{\mathrm{H}, \mathrm{H}}=7.9 \mathrm{~Hz},{ }^{3} J_{\mathrm{H}, \mathrm{H}}=3.2 \mathrm{~Hz}, 12 \mathrm{H}, \mathrm{H}-22 / 22^{`}, \mathrm{H}-23 / 23^{\circ}\right), 0.88$ (s, $9 \mathrm{H}, \mathrm{H}-10), 0.99\left(\mathrm{t},{ }^{3} J_{\mathrm{H}, \mathrm{H}}=7.9 \mathrm{~Hz}, 12 \mathrm{H}, \mathrm{H}-24 / 24^{\circ}\right), 1.10\left(\mathrm{~s}, 9 \mathrm{H}, \mathrm{H}-10^{\circ}\right), 1.54,1.60(\mathrm{~d}$, ${ }^{3} J_{\mathrm{H}, \mathrm{H}}=6.6 \mathrm{~Hz}, 3 \mathrm{H}$ each, H-12, H-12'), $1.31-1.71$ (m, 13H, H-6‘, H-19/19', H-20/20`, $\mathrm{H}-21 / 21^{\circ}$ ), 2.43 (m, 1H, H-6), 3.34 (m, 5H, H-5', H-18/18'), 3.42 (d, ${ }^{3} J_{\mathrm{H}, \mathrm{H}}=10.6 \mathrm{~Hz}, 1 \mathrm{H}, \mathrm{H}-$ 5), 3.93 (vsept, ${ }^{3} J_{\mathrm{H}, \mathrm{H}}=3.2 \mathrm{~Hz}, 2 \mathrm{H}, \mathrm{H}-25 / 25^{\circ}$ ), 4.35, 4.38 (s, $2 \mathrm{H}$ each, H-17, H-17'), 4.95 (q, $\left.{ }^{3} J_{\mathrm{H}, \mathrm{H}}=6.6 \mathrm{~Hz}, 2 \mathrm{H}, \mathrm{H}-11 / 11^{\circ}\right), 7.04-7.56\left(\mathrm{~m}, 18 \mathrm{H}, \mathrm{H}-1 / 1^{`}, \mathrm{H}-2 / 2^{`}, \mathrm{H}-3 / 3^{`}, \mathrm{H}-14 / 14^{`}, \mathrm{H}-\right.$ $\left.15 / 15^{\circ}\right) \mathrm{ppm}$.

${ }^{13} \mathbf{C}\left\{{ }^{1} \mathbf{H}\right\}$ NMR $\left(100 \mathrm{MHz}, \mathrm{C}_{6} \mathrm{D}_{6}, 300 \mathrm{~K}\right): \delta=3.2\left(\mathrm{C}-23 / 23^{\circ}\right), 8.5\left(\mathrm{C}-24 / 24^{\circ}\right), 11.0\left(\mathrm{C}-22 / 22^{\circ}\right)$, 21.4, 21.4, 22.3, 22.6, 23.4, 24.9 (C-7/7` $\left., \mathrm{C}-8 / 8^{\circ}, \mathrm{C}-12 / 12^{\circ}\right), 28.5$ (C-10), 28.7 (C-10`), 25.0, 25.0, 30.4, $30.4\left(\mathrm{C}-20 / 20^{\circ}, \mathrm{C}-21 / 21^{\circ}\right), 30.0,30.0\left(\mathrm{C}-19 / 19^{\circ}\right), 32.1\left(\mathrm{C}-6^{\circ}\right), 32.4(\mathrm{C}-6), 60.7$ (C-9), 60.8 (C-9 $\left.^{\circ}\right), 70.4,70.6\left(\mathrm{C}-18 / 18^{\circ}\right), 72.8,72.8,72.8,72.9\left(\mathrm{C}-5 / 5^{\circ}, \mathrm{C}-17 / 17^{\circ}\right), 83.2,83.9$ (C-11/11'), $126.5-127.9,131.3,131.3\left(\mathrm{C}-1 / 1^{\circ}, \mathrm{C}-2 / 2^{`}, \mathrm{C}-3 / 3^{\circ}, \mathrm{C}-14 / 14^{`}, \mathrm{C}-15 / 15^{\circ}\right), 138.2$, 138.8 (C-16, C-16'), 142.6, 142.8 (C-4, C-4`), 144.5, 145.2 (C-13, C-13`) ppm.

${ }^{29} \mathrm{Si}$ NMR $\left(80 \mathrm{MHz}, \mathrm{C}_{6} \mathrm{D}_{6}, 300 \mathrm{~K}\right): \delta=-2.2 \mathrm{ppm}$.

ESI-HRMS: found 512.3921 [M+H $]^{+},\left(\right.$calcd. $\left.512.3918[\mathrm{M}+\mathrm{H}]^{+}\right)$. 


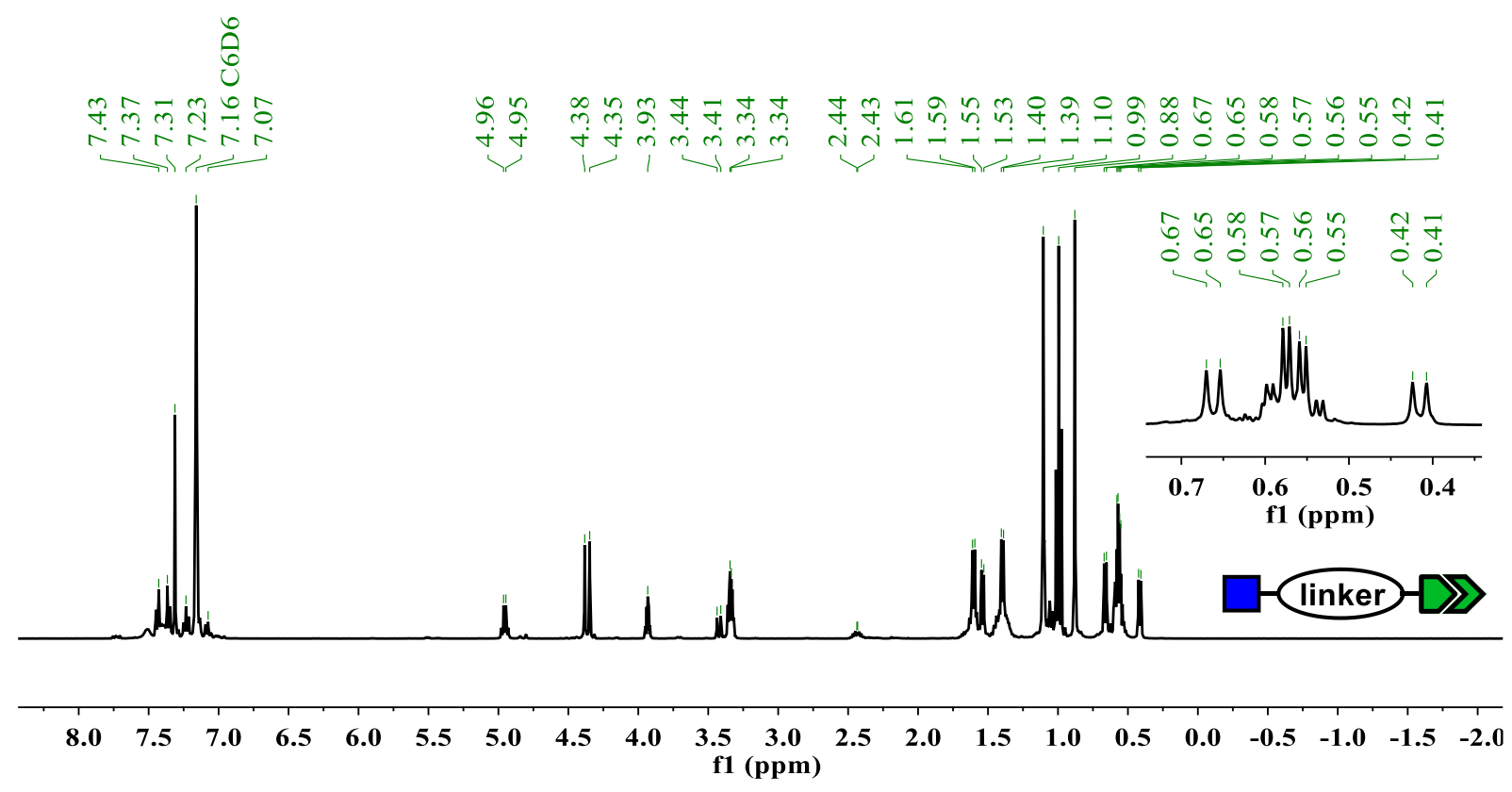

Figure S19: ${ }^{1} \mathrm{H}$ NMR spectrum $\left(400 \mathrm{MHz}, \mathrm{C}_{6} \mathrm{D}_{6}, 300 \mathrm{~K}\right)$ of $N$-(tert-butyl)-O-(1-(4-(((5(diethylsilyl)pentyl)oxy)methyl)phenyl)ethyl)- $N$-(2-methyl-1-phenylpropyl)hydroxylamine (alkoxyamine modified CTA, 1).
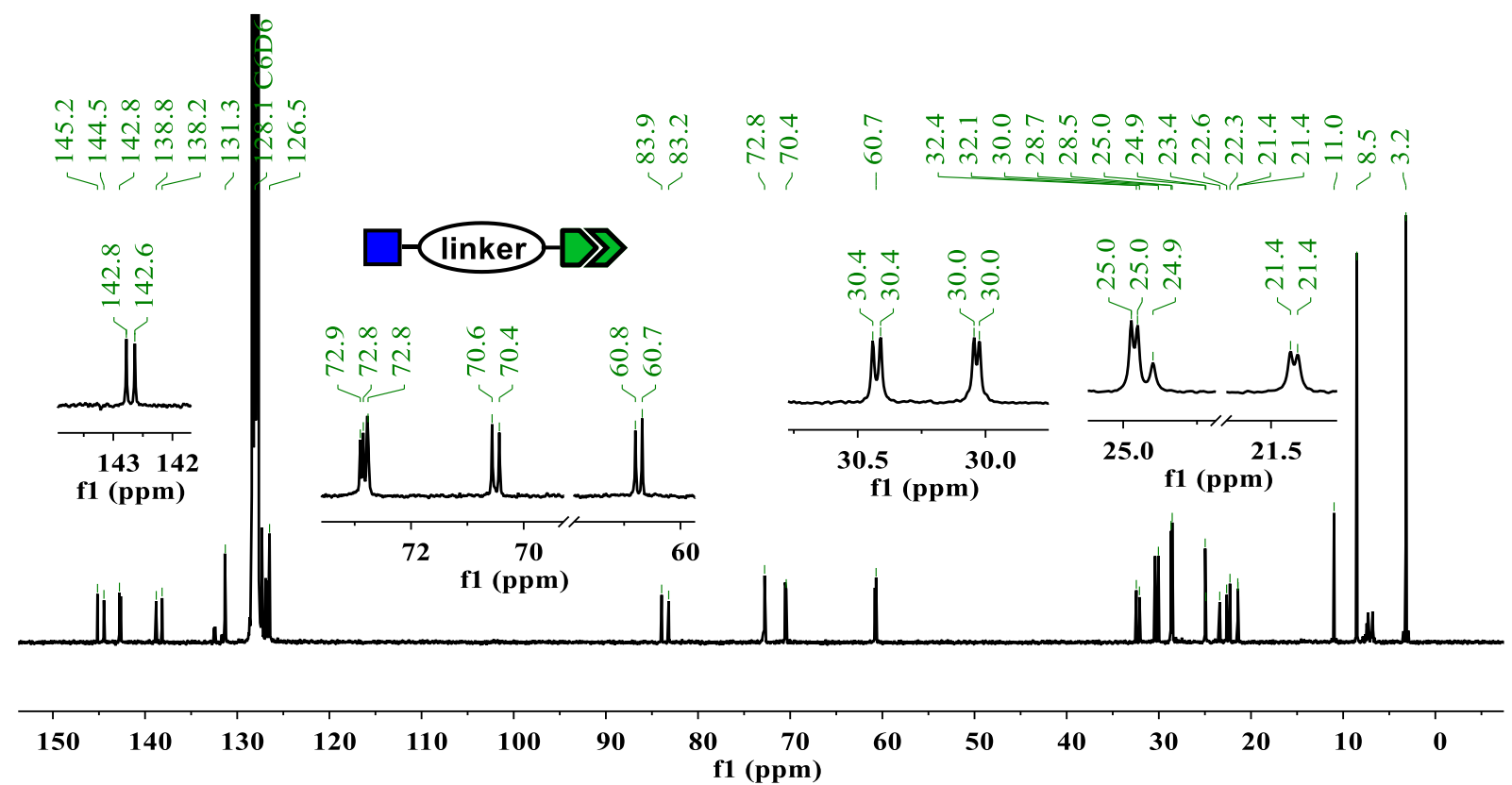

Figure S20: ${ }^{13} \mathrm{C}$ NMR spectrum $\left(100 \mathrm{MHz}, \mathrm{C}_{6} \mathrm{D}_{6}, 300 \mathrm{~K}\right)$ of $\mathrm{N}$-(tert-butyl)-O-(1-(4-(((5(diethylsilyl)pentyl)oxy)methyl)phenyl)ethyl)- $N$-(2-methyl-1-phenylpropyl)-hydroxylamine (alkoxyamine modified CTA, 1). 


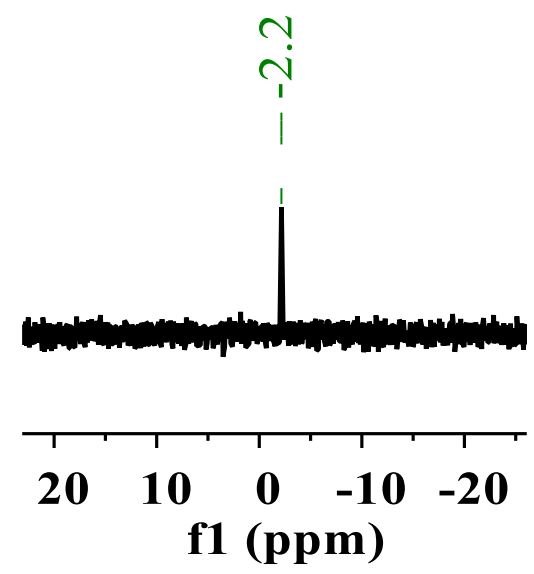

Figure S21: ${ }^{29} \mathrm{Si}$ NMR spectrum $\left(80 \mathrm{MHz}, \mathrm{C}_{6} \mathrm{D}_{6}, 300 \mathrm{~K}\right)$ of $\mathrm{N}$-(tert-butyl)-O-(1-(4-(((5(diethylsilyl)pentyl)oxy)methyl)phenyl)ethyl)- $N$-(2-methyl-1-phenylpropyl)hydroxylamine (alkoxyamine modified CTA, 1).

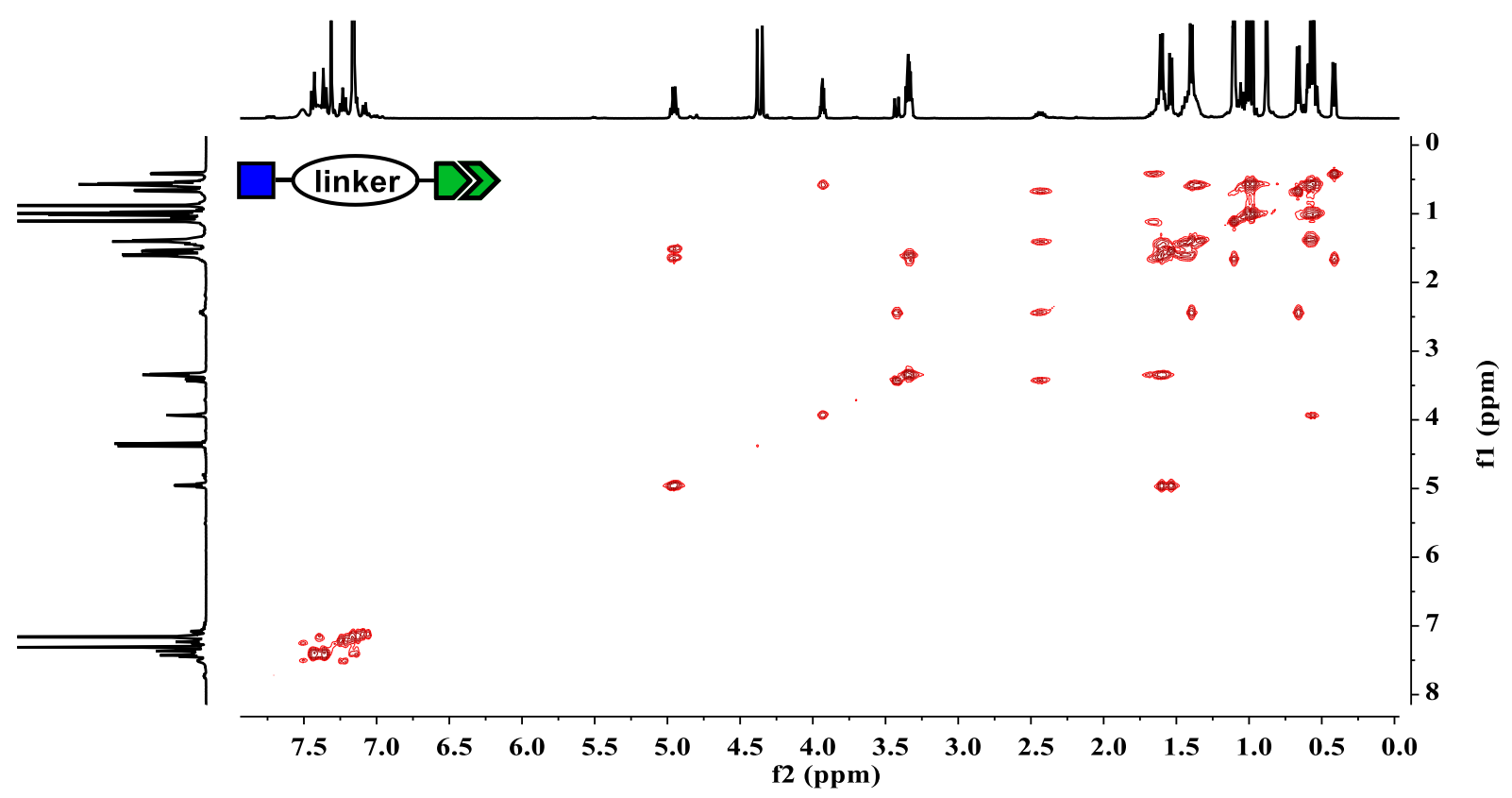

Figure S22: $\quad{ }^{1} \mathrm{H}-{ }^{1} \mathrm{H}$ gCOSY NMR spectrum $\left(400 \mathrm{MHz}, \mathrm{C}_{6} \mathrm{D}_{6}, 300 \mathrm{~K}\right)$ of $\mathrm{N}$-(tert-butyl)-O-(1(4-(((5-(diethylsilyl)pentyl)oxy)methyl)phenyl)ethyl)- $N$-(2-methyl-1-phenylpropyl)-hydroxylamine (alkoxyamine modified CTA, 1). 


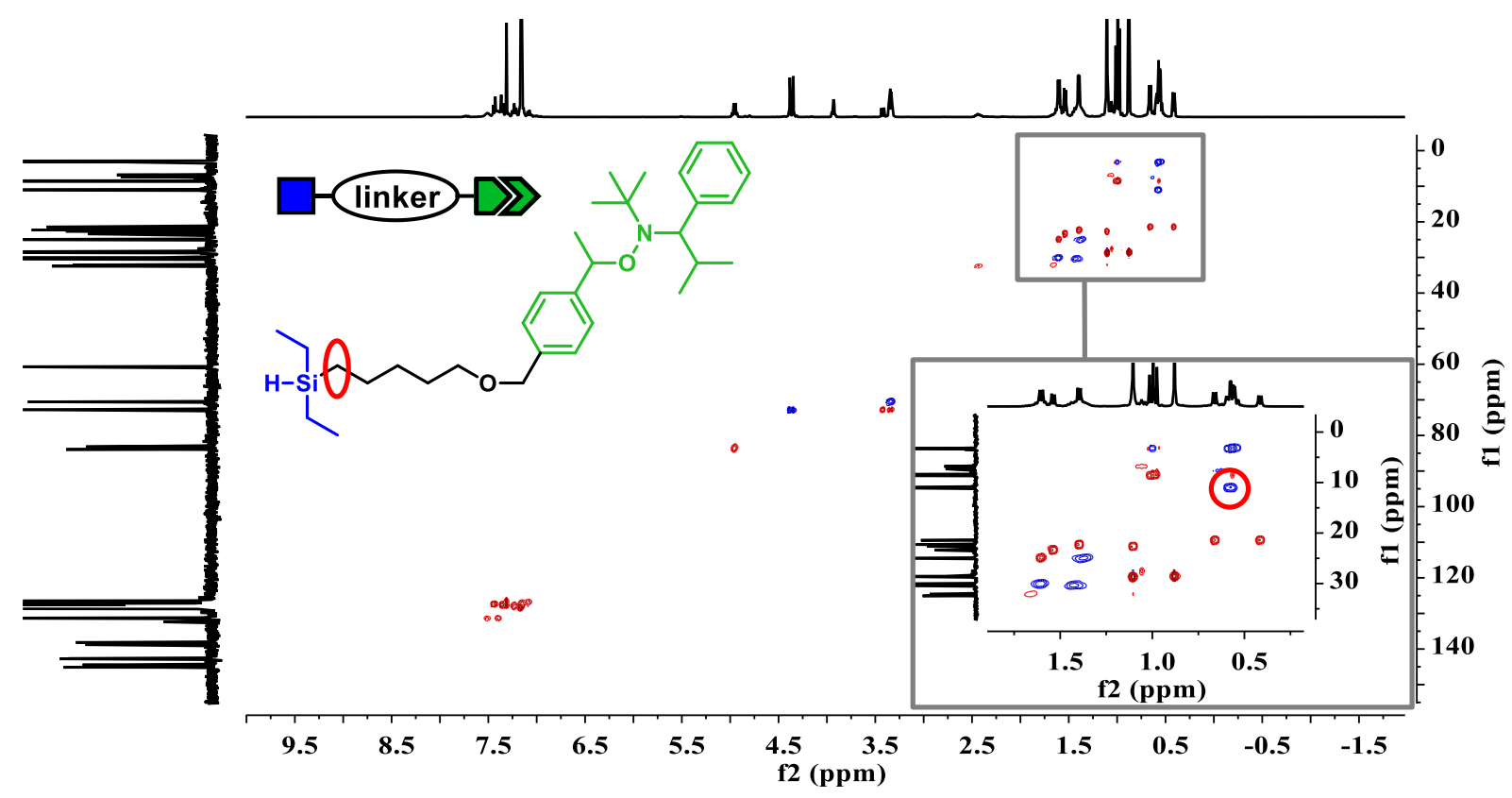

Figure S23: $\quad{ }^{1} \mathrm{H}_{-}{ }^{13} \mathrm{C}$ gHSQC NMR spectrum (400 MHz, $\left.\mathrm{C}_{6} \mathrm{D}_{6}, 300 \mathrm{~K}\right)$ of $\mathrm{N}$-(tert-butyl)- $\mathrm{O}-(1-$ (4-(((5-(diethylsilyl)pentyl)oxy)methyl)phenyl)ethyl)- $N$-(2-methyl-1-phenylpropyl)-hydroxylamine (alkoxyamine modified CTA, 1).

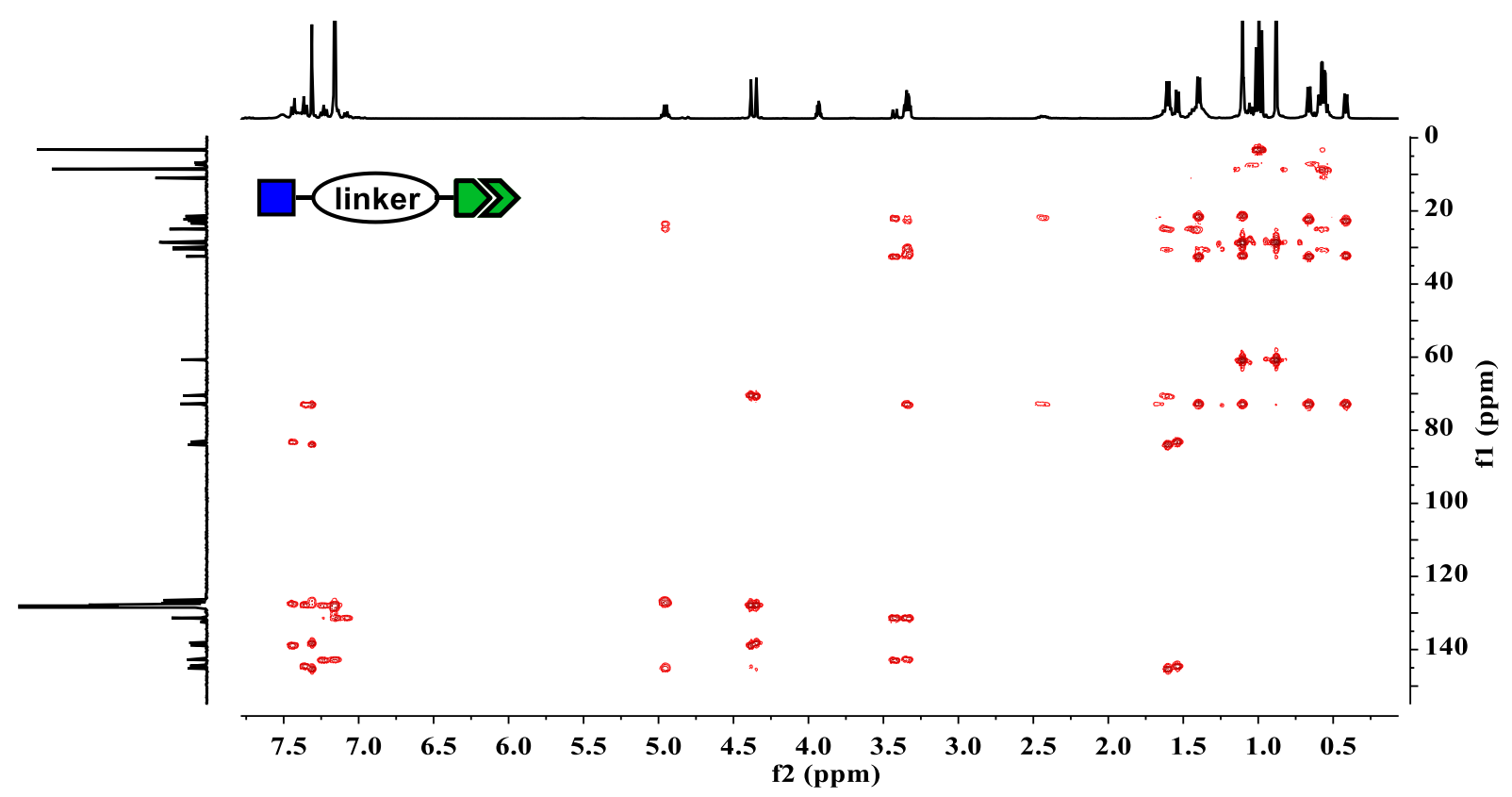

Figure S24: $\quad{ }^{1} \mathrm{H}_{-}{ }^{13} \mathrm{C}$ gHMBC NMR spectrum $\left(400 \mathrm{MHz}, \mathrm{C}_{6} \mathrm{D}_{6}, 300 \mathrm{~K}\right)$ of $\mathrm{N}$-(tert-butyl)- $O$ (1-(4-(((5-(diethylsilyl)pentyl)oxy)methyl)phenyl)ethyl)- $N$-(2-methyl-1phenyl-propyl)-hydroxylamine (alkoxyamine modified CTA, 1). 


\section{Investigation of the Chain Transfer Mechanism}

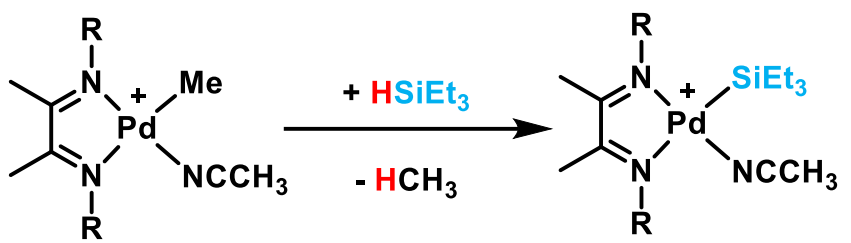

$\mathrm{R}=\mathbf{2 , 6}-\mathrm{iPrC}{ }_{6} \mathrm{H}_{3}$

Scheme S7: Reaction of Pd-Me complex 3 with triethylsilane yielded methane and a Pd$\mathrm{SiEt}_{3}$ complex.

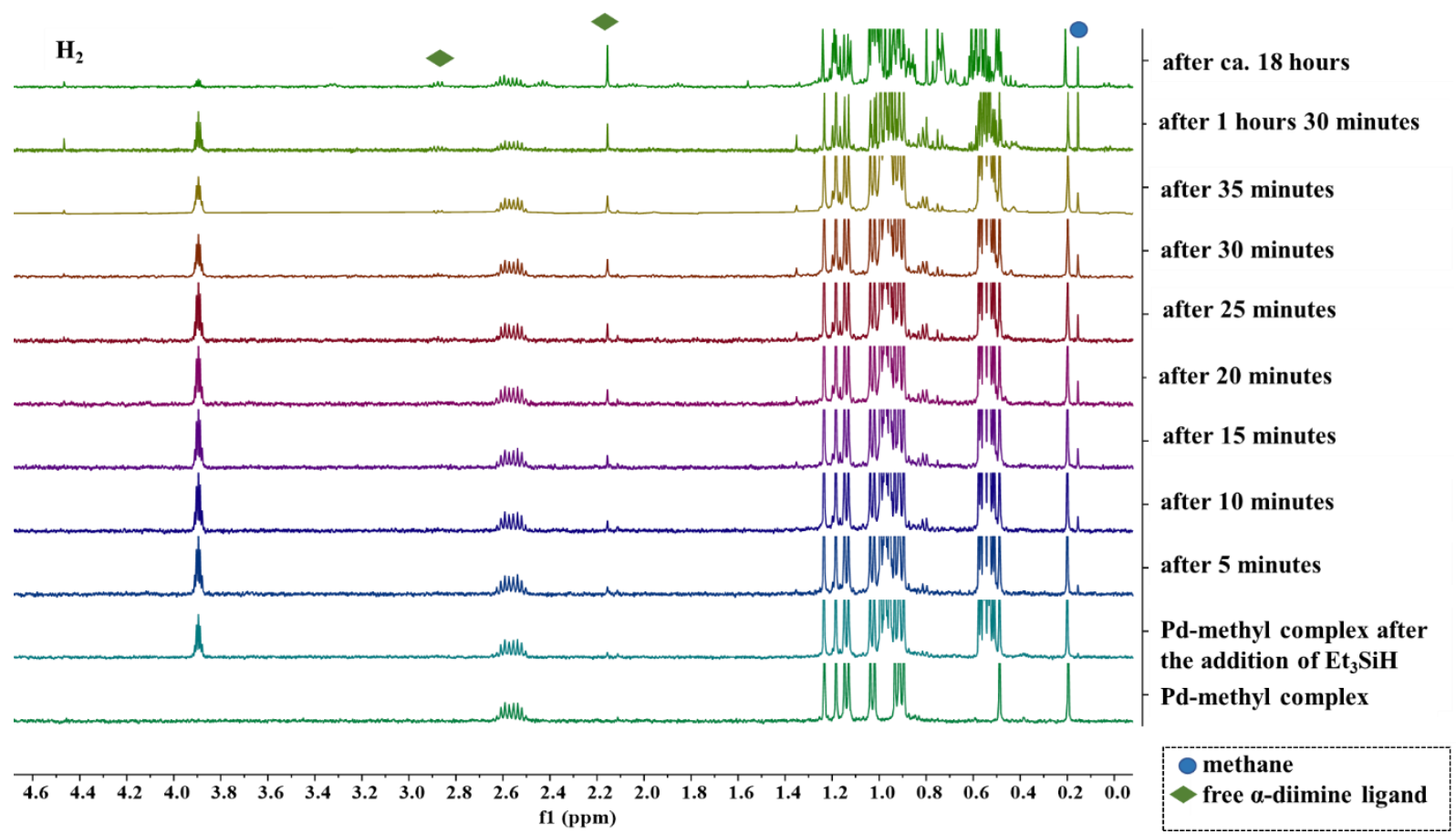

Figure S25: $\quad{ }^{1} \mathrm{H}$ NMR spectrum $\left(400 \mathrm{MHz}, \mathrm{C}_{6} \mathrm{D}_{6}, 300 \mathrm{~K}\right)$ of the Pd-methyl complex 3 and spectra acquired after the addition of 1 equivalent of triethylsilane. Formation of methane is observed. 


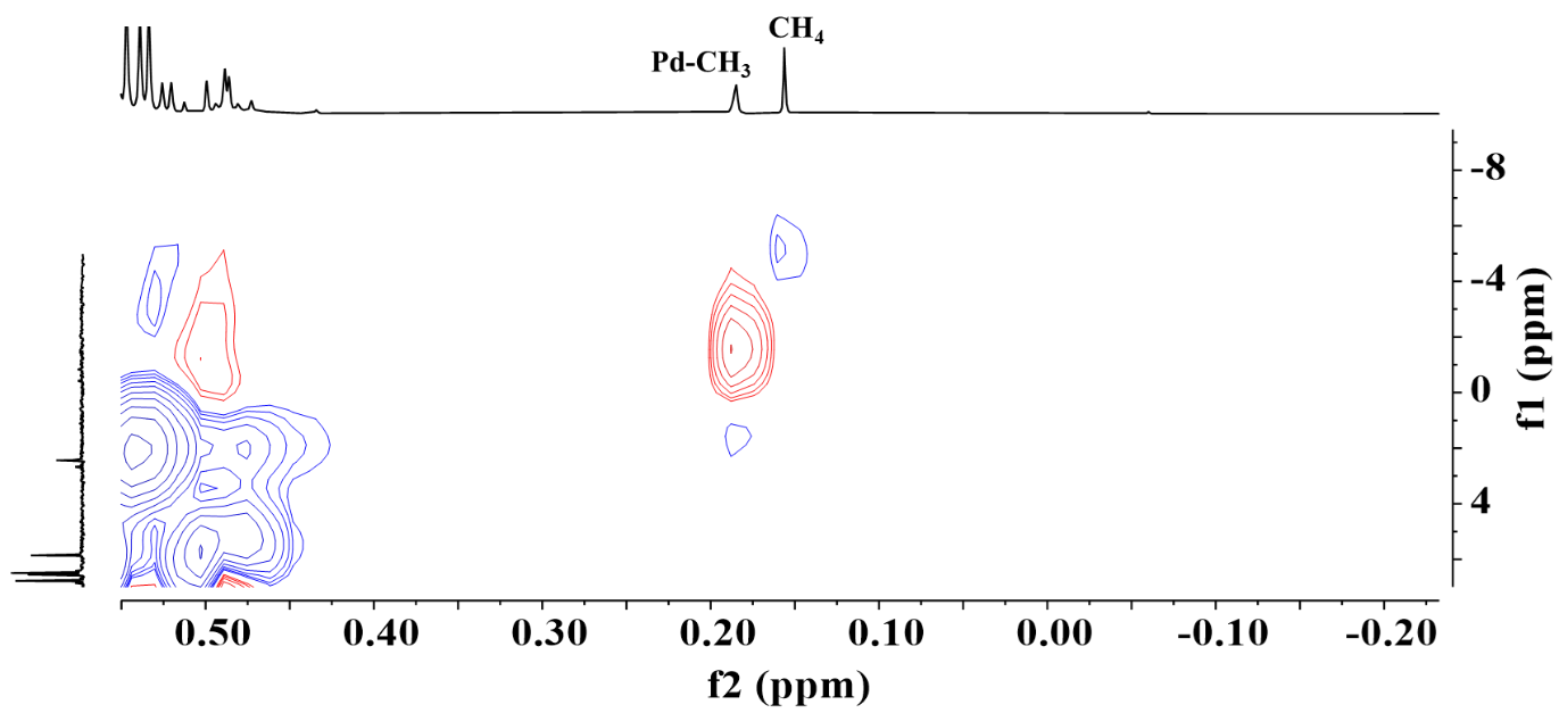

Figure S26: Enlargement of ${ }^{1} \mathrm{H},{ }^{13} \mathrm{C}$ gHSQC spectrum $\left(600 \mathrm{MHz}, \mathrm{C}_{6} \mathrm{D}_{6}, 300 \mathrm{~K}\right)$ after the addition of 1 equiv. triethylsilane to 1 equiv. Pd-methyl complex $\mathbf{3}$. The signal at $0.15 \mathrm{ppm}$ shows a correlation to a carbon at $-5 \mathrm{ppm}$ thus confirming the assignment to methane.
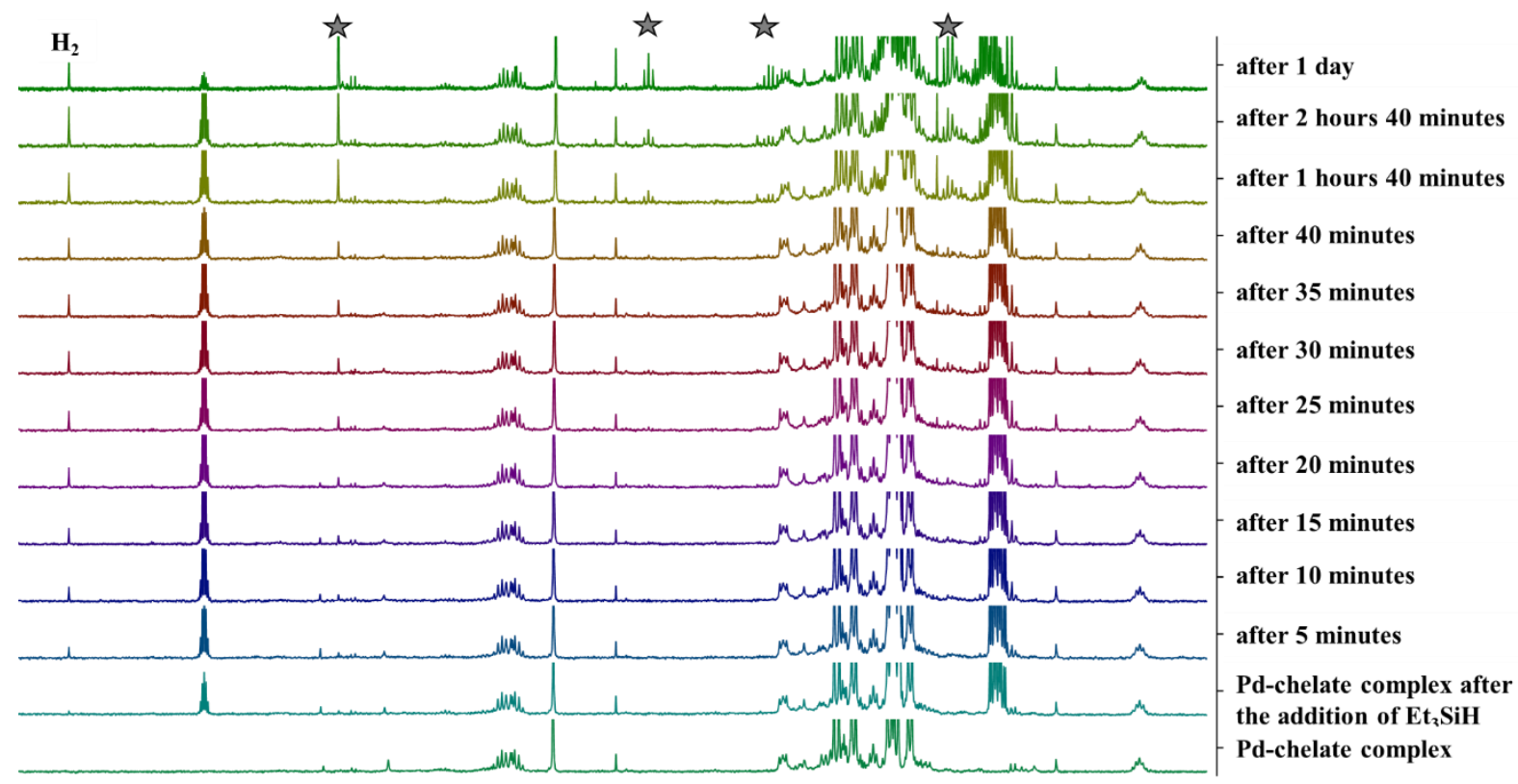

methylbutyrate

Figure S27: ${ }^{1} \mathrm{H}$ NMR spectrum $\left(400 \mathrm{MHz}, \mathrm{C}_{6} \mathrm{D}_{6}, 300 \mathrm{~K}\right)$ of the Pd-chelate complex 2 and spectra acquired after the addition of triethylsilane. Formation of methyl butyrate is observed while no indication for 4-triethylsilanyl butyric acid is visible.

Formation of hydrogen most likely originates from the Pd-catalyzed dimerization of silanes. While hydrogen could possibly also act as a chain transfer agent, the observation of silyl end groups in the polymers and their increase with increasing amount of added silane as well as the good correlation of molecular weight and amount of silane show, that chain transfer by hydrogen is at most a minor pathway. 


\section{Standard Polymerization Procedures}

\subsection{CTP Procedure}

Polymerization experiments were conducted in a Büchi miniclave reactor equipped with a $200 \mathrm{~mL}$ stainless steel double mantle vessel and a magnetically coupled overhead stirrer. An external thermostat unit connected to a thermocouple inside the reactor was used for temperature control during the polymerizations. Ethylene mass flow was monitored by Bronkhorst mass flow meters.

The reactor was prepared by repeated evacuation and refilling with inert gas at $\geq 60{ }^{\circ} \mathrm{C}$. After cooling to $10^{\circ} \mathrm{C}, 100 \mathrm{~mL}$ of dry and degassed toluene was cannula-transferred into the reactor. Catalyst precursor complex (10 $\mu \mathrm{mol}, 1$ equiv.) and if applicable silane as CTA were weighed into separate vials in a glovebox. The solution of the desired amount of silane $(5,10,20,50$ or 100 equiv.) in toluene $(2 \mathrm{~mL})$ was transferred into the reactor followed by the solution of catalyst precursor complex in dichloromethane $(2 \mathrm{~mL})$ using Hamilton syringes. Under stirring with $1000 \mathrm{rpm}$ the reactor was pressurized with ethylene to $15 \mathrm{bar}$ and the temperature was adjusted to reach the desired polymerization temperature (here $15^{\circ} \mathrm{C}$ ). The pressure was kept constant for the duration of the polymerization experiment and the ethylene mass flow was recorded. After three hours ethylene flow was cut and the pressure was released. Immediate evaporation of the solvent yielded palladium containing polymer. The polymer was dried under reduced pressure in order to determine the yield. The polymer was subsequently dissolved in toluene ( $8 \mathrm{~mL}$, analysis grade, not dried or degassed) by heating to $80{ }^{\circ} \mathrm{C}$ if triethylsilane and $55^{\circ} \mathrm{C}$ if the alkoxyamine modified CTA (1) was used. The solution was filtered through celite. After concentration of the solution by evaporation, methanol $(20 \mathrm{~mL})$ was added dropwise followed by the rapid addition of additional methanol $(80 \mathrm{~mL})$ yielding precipitated polymer which was manually removed from the liquid phase. The resulting polymer was dried at $50{ }^{\circ} \mathrm{C}$ under reduced pressure.

\subsection{NMP Procedure}

Polymerizations were conducted under nitrogen atmosphere in a tightly closed $8 \mathrm{~mL}$ vial in an aluminum heating block equipped with a strong ( $\mathrm{Nd}$ core) stirring bar inside a glovebox.

a) For homopolymerizations Styryl-TIPNO ( $2 \mu \mathrm{mol}, 1$ equiv.), the respective monomer (styrene, $n$ - or tert-butyl acrylate; $8 \mathrm{mmol}, 4000$ equiv.) and if applicable TIPNO free radical $\left(0.01,0.02,0.05,0.10\right.$ or 0.20 equiv, using a stock solution with $\mathrm{c}=2.2 \times 10^{-4} \mathrm{mg} / \mathrm{mg}$ in the respective monomer) was weighed into an $8 \mathrm{~mL}$ vial inside the glovebox. b) For polymerizations with macroinitiators, the end-functionalized polymer $(2 \mu \mathrm{mol}, 1$ equiv. $)$ was weighed into an $8 \mathrm{~mL}$ vial and introduced into the glovebox. Monomer ( $8 \mathrm{mmol}, 4000$ equiv.) and TIPNO free radical $(0.1 \mu \mathrm{mol}, 0.05$ equiv., using a stock solution) were added to the macroinitiator. The vial was closed tightly and placed in the preheated aluminum heating block $\left(120^{\circ} \mathrm{C}\right)$. After stirring for the intended amount of time ( 1 or 4 hours) the vial was removed from the glovebox and opened to allow quenching with oxygen. The vial was thereafter closed 
again and cooled to room temperature using water. The remaining monomer was removed from the resulting polymer under reduced pressure at $40-60{ }^{\circ} \mathrm{C}$.

\section{Additional Chain Transfer Polymerization Experiments}

The viability of CTPs using $\alpha$-diimine Pd complexes in combination with silanes was insinuated by Brookhart et al. ${ }^{22}$ and proven by Guironnet et al. ${ }^{23}$ As reference experiments for comparison with the functionalized, silane-based CTA the capability and efficiency of $\alpha$-diimine palladium complexes $\mathbf{2}$ and $\mathbf{3}$ (Figure 2) for a chain transfer polymerization of ethylene was studied with triethylsilane as model silane.

For all complexes the respective polymer yield was constant with increasing amount of added CTA (Table S2), showing that there is no adverse effect. The molecular weight however decreased with increasing amounts of triethylsilane, as expected for a chain transfer polymerization (Table S2, Figure S28-S31).

Table S2: $\quad$ Polymerization results with catalyst precursors $\mathbf{2}$ and $\mathbf{3}$ using various equivalents of $\mathrm{Et}_{3} \mathrm{SiH}$ or 100 equivalents of compound $\mathbf{1}$ as CTA.

\begin{tabular}{lllllllll}
\hline entry & complex $^{\mathbf{a})}$ & $\begin{array}{l}\text { equiv. } \\
\text { silane }\end{array}$ & $\begin{array}{l}\text { yield } \\
{[\mathbf{g}]}\end{array}$ & $\begin{array}{l}\mathbf{M}_{\mathbf{n}}(\mathbf{G P C})^{\mathbf{b})} \\
{\left[\mathbf{1 0}^{\mathbf{3}} \mathbf{g} / \mathbf{m o l}\right]}\end{array}$ & $\begin{array}{l}\mathbf{M}_{\mathbf{n}}(\mathbf{N M R})^{\mathbf{c})} \\
{\left[\mathbf{1 0}^{\mathbf{3}} \mathbf{g} / \mathbf{m o l}\right]}\end{array}$ & $\mathbf{M}_{\mathrm{w}} / \mathbf{M}_{\mathbf{n}}$ & $\begin{array}{l}\text { silyl : } \\
\text { methoxy } \\
\text { end groups }\end{array}$ & $\begin{array}{l}\text { chains } \\
\text { per Pd } \\
(\mathbf{N M R})^{\mathbf{d})}\end{array}$ \\
\hline $\mathbf{1}$ & 2 & 0 & 0.93 & 143.4 & $128.8^{\mathrm{e})}$ & $\left.1.03^{\mathrm{f}}\right)$ & n.a. & 0.7 \\
$\mathbf{2}$ & 2 & 10 & 0.90 & 91.9 & $66.0^{\mathrm{g})}$ & 1.4 & 0.8 & $1.8^{\mathrm{h})}$ \\
$\mathbf{3}$ & 2 & 50 & 0.88 & 51.6 & $34.4^{\mathrm{g})}$ & 1.5 & 2.4 & $3.4^{\mathrm{h})}$ \\
$\mathbf{4}$ & 2 & 100 & 0.83 & 40.3 & $23.3^{\mathrm{g})}$ & 1.5 & 4.0 & $5.0^{\mathrm{h})}$ \\
$\mathbf{5}$ & 3 & 0 & 1.02 & 140.7 & n.d..$^{\mathrm{i})}$ & $1.06^{\mathrm{f}}$ & n.a. & n.d. \\
$\mathbf{6}$ & 3 & 5 & 0.97 & 131.9 & 159.5 & 1.1 & n.a. & 0.6 \\
$\mathbf{8}$ & 3 & 10 & 0.99 & 108.0 & 155.6 & 1.2 & n.a. & 0.6 \\
$\mathbf{9}$ & 3 & 20 & 1.08 & 101.4 & 108.3 & 1.2 & n.a. & 1.0 \\
\hline $\mathbf{1 0}$ & 3 & 50 & 1.03 & 63.7 & 49.2 & 1.3 & n.a. & 2.1 \\
\hline $\mathbf{1 1}$ & 3 & 100 & 0.90 & 41.4 & 24.6 & 1.4 & n.a. & 3.7 \\
\hline
\end{tabular}

Polymerizations in $100 \mathrm{~mL}$ toluene at $15^{\circ} \mathrm{C}$ and 15 bar ethylene pressure for $180 \mathrm{~min}$. a) $10 \mu \mathrm{mol}$ of catalyst precursor were used. b) Determined by GPC (THF, $\left.35^{\circ} \mathrm{C}\right)$ versus PS standards. c) Determined by ${ }^{1} \mathrm{H}$ NMR spectroscopic end group analysis. For details cf. chapter 11. d) Calculated by $\mathrm{m}_{\text {Polymer }} /\left(\mathrm{M}_{\mathrm{n}}(\mathrm{NMR}) \times \mathrm{n}_{\mathrm{Pd}}\right)$. e) Determined by ${ }^{1} \mathrm{H}$ NMR spectroscopy using methoxy end groups, as the polymerization without CTA is living. f) Excluding a small fraction at twice the molecular weight (resulting from bimolecular termination) not considered. ${ }^{24} \mathbf{g}$ ) 
Determined by ${ }^{1} \mathrm{H}$ NMR spectroscopic quantification of both methoxy and silane end groups. h) Calculated as sum of silyl and methoxy terminated chains. i) Only aliphatic end groups expected in this case. These are not detected in ${ }^{1} \mathrm{H}$ NMR spectra due to overlap with polymer backbone signals. j) In this entry compound $\mathbf{1}$ was used as CTA.

\subsection{NMR Spectra}

Due to their hyperbranched structure the obtained polymers could be easily dissolved in chloroform- $d_{1}$ and analyzed by NMR spectroscopy. Silane end groups originating from chain transfer were detected in the polymers. In contrast, olefinic signals caused by $\beta$-hydride elimination were not detected in the ${ }^{1} \mathrm{H}$ NMR spectra indicating that chain transfer proceeds exclusively by reaction of palladium polymeryls with the added silane. Intensity of signals at $0.51 \mathrm{ppm}$, characteristic for ethyl groups bound to a silicon atom, increased with increasing amounts of CTA used in the formation of the polymers (Figure S28). Two-dimensional NMR analysis by gHSQC further shows that the overlapping quartett at $0.51 \mathrm{ppm}$ in the ${ }^{1} \mathrm{H}$ NMR is an overlay of two different signals corresponding to methylene moieties adjacent to a silicon atom (PE-CH$\left.-\mathrm{Si}\left(\mathrm{CH}_{2} \mathrm{CH}_{3}\right)_{3}\right)$, i.e. a triethylsilyl terminated polyethylene chain with respective ${ }^{13} \mathrm{C} \mathrm{NMR}$ resonances at $3.6 \mathrm{ppm}\left(\mathrm{PE}-\mathrm{CH}_{2}-\mathrm{Si}\left(\mathrm{CH}_{2} \mathrm{CH}_{3}\right)_{3}\right)$ and at $11.1 \mathrm{ppm}\left(\mathrm{PE}-\mathrm{CH}_{2}-\mathrm{Si}\right.$ ) (Figure S37, Figure S38).
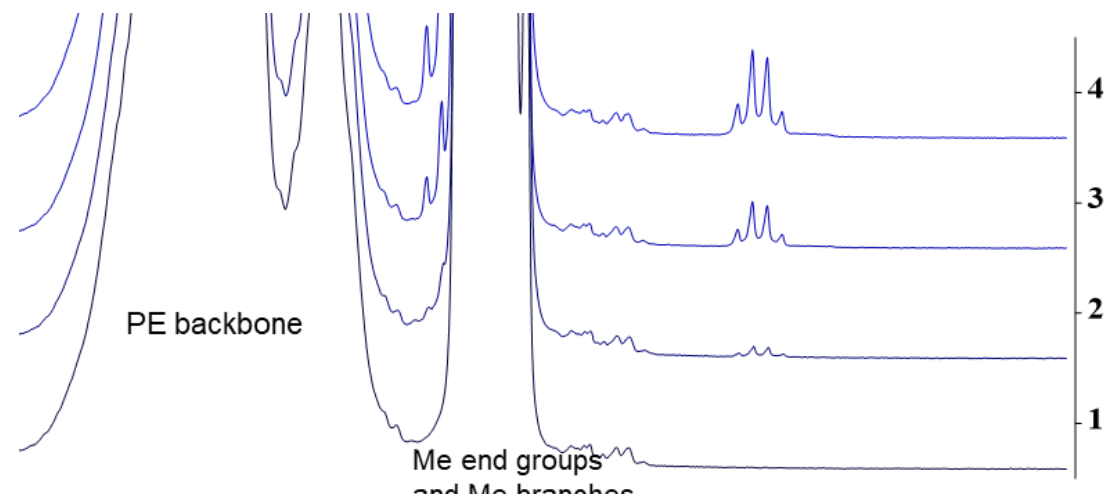

and Me branches
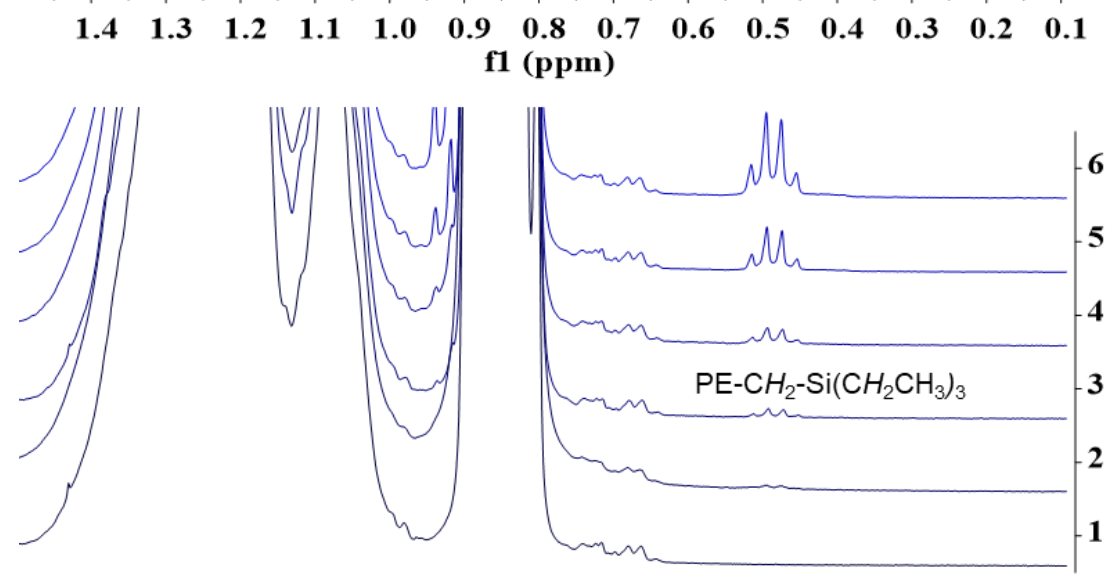

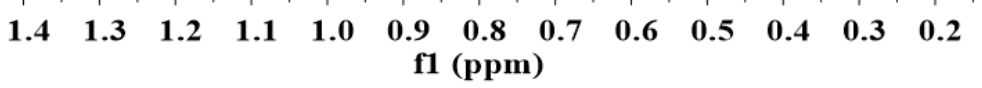

Figure S28: $\quad{ }^{1} \mathrm{H} \mathrm{NMR}$ spectra $\left(400 \mathrm{MHz}, \mathrm{CDCl}_{3}, 300 \mathrm{~K}\right)$ of polymers obtained in CTP in the presence of $0,10,50$ and 100 equivalents of triethylsilane using $\alpha$-diimine palladium complexes $\mathbf{2}$ (top) and $\mathbf{3}$ (bottom) respectively. 


\subsection{GPC Data}

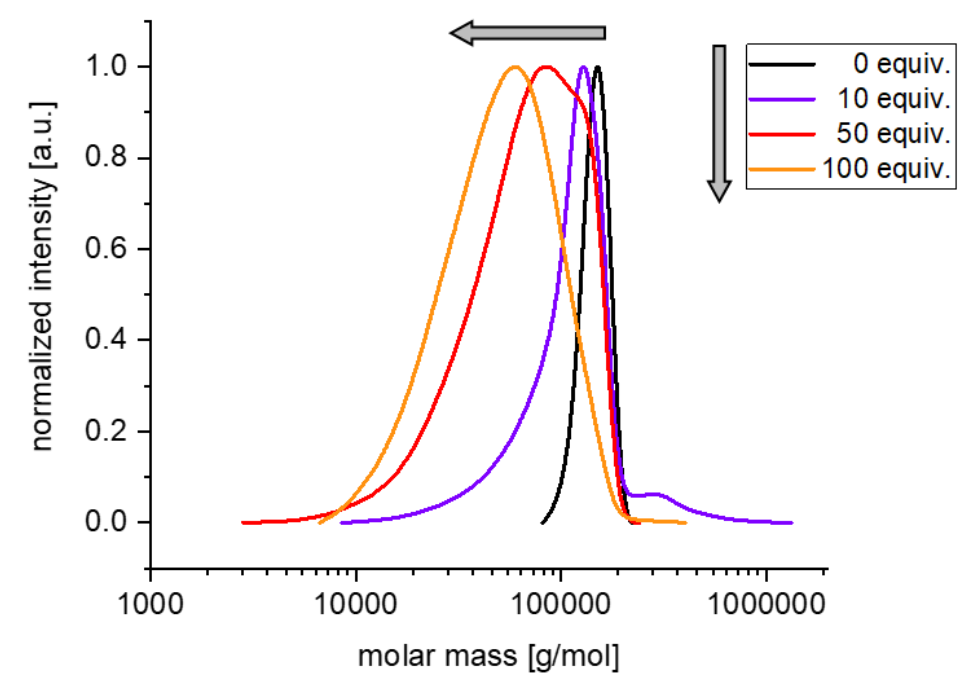

Figure S29: GPC traces for polymers obtained in CTP in the presence of 0, 10, 50 and 100 equivalents of triethylsilane using $\alpha$-diimine palladium complex 2 (cf. Table $S 2$, entries 1-4).

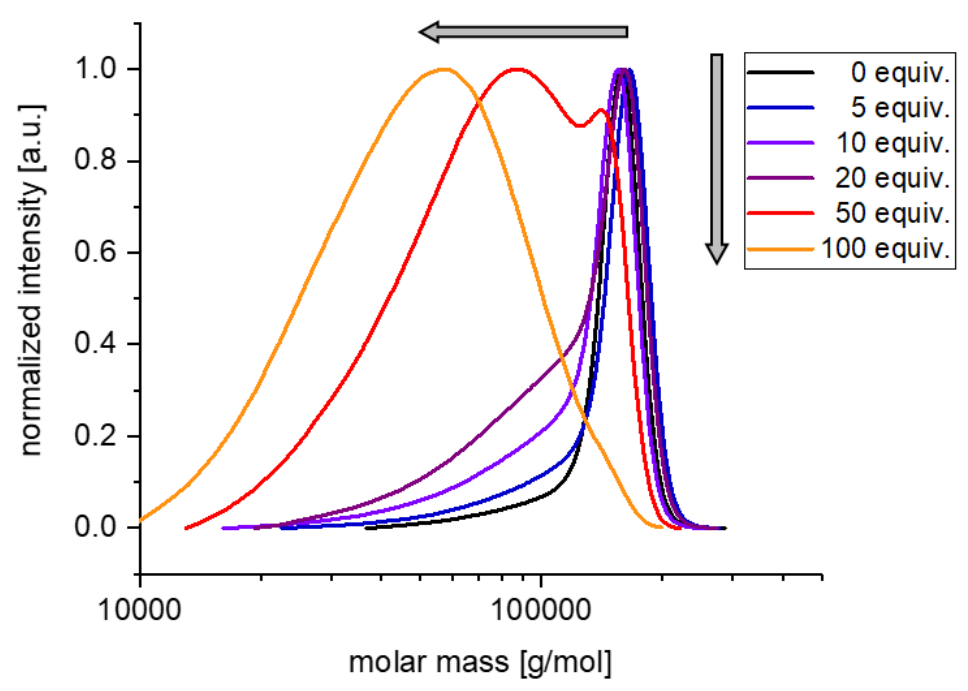

Figure S30: GPC traces for polymers obtained in CTP in the presence of 0, 5, 10, 20, 50 and 100 equivalents of triethylsilane using $\alpha$-diimine palladium complex $\mathbf{3}$ (cf. Table S2, entries 5-10). 


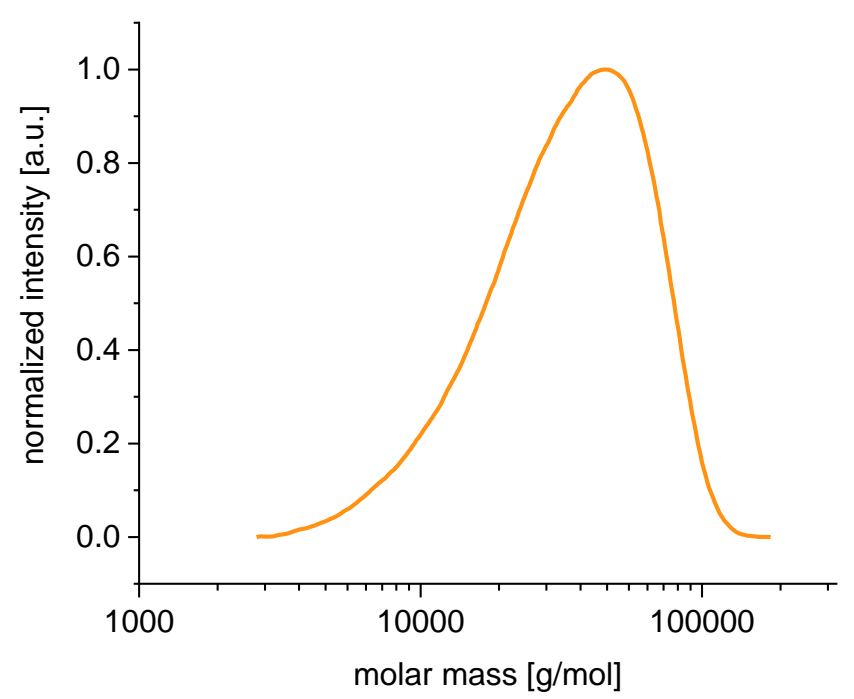

Figure S31: GPC trace for polymer obtained in CTP in the presence of 100 equivalents of the modified CTA (1) using $\alpha$-diimine palladium complex 3 (cf. Table S2, entry 11).

\section{Correlation between Inverse Degree of Molecular Weight and CTA concentration}

A linear correlation between the inverse of the molecular weight and the amount of added CTA is typical for a CTP: ${ }^{25}$

$\frac{1}{M_{n}} \approx A+\frac{k_{t r}[C T A]}{k_{p}[M]^{x}}$

Plotting data obtained with complexes $\mathbf{2}$ and $\mathbf{3}$ and triethylsilane or the alkoxyamine modified CTA (1) respectively, indeed a linear fit was appropriate (Figure S32, Figure S33 and Figure S34). 


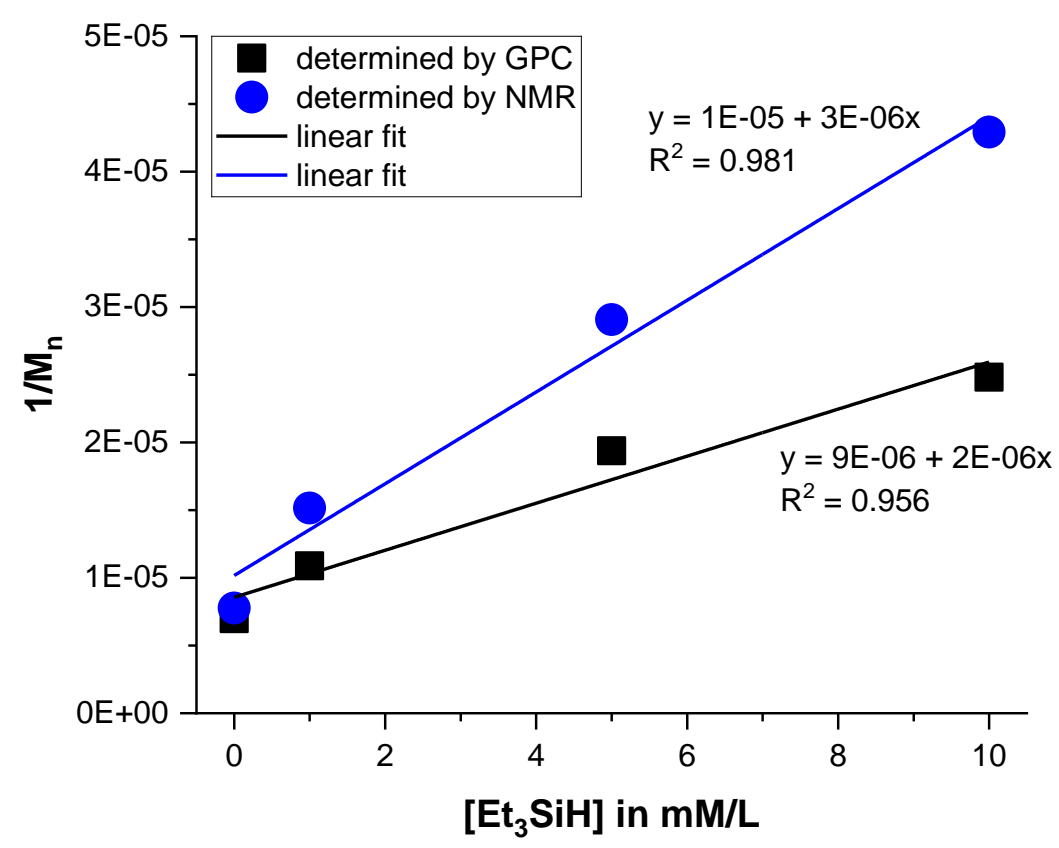

Figure S32: Inverse of the molecular weight plotted against amount of added triethylsilane as CTA in polymerizations with complex 2 (cf. Table S2, entries 1-4).

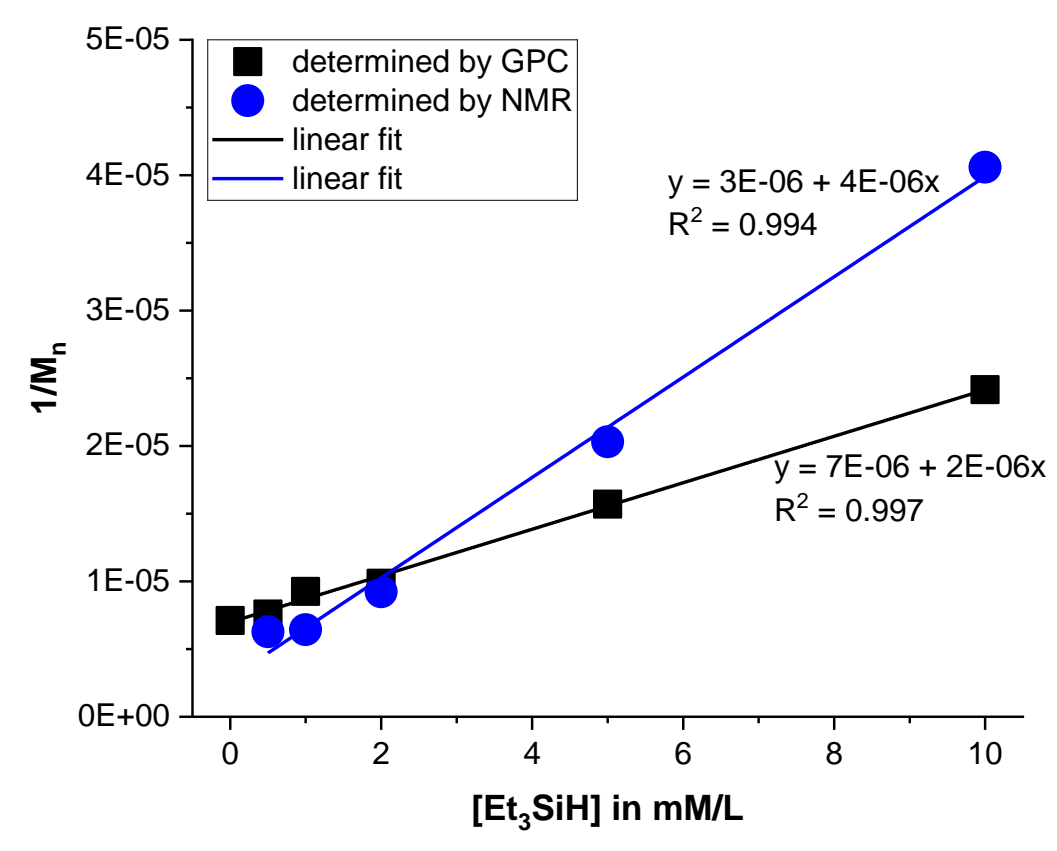

Figure S33: Inverse of the molecular weight plotted against amount of added triethylsilane as CTA in polymerizations with complex 3 (cf. Table S2, entries 5-10). 


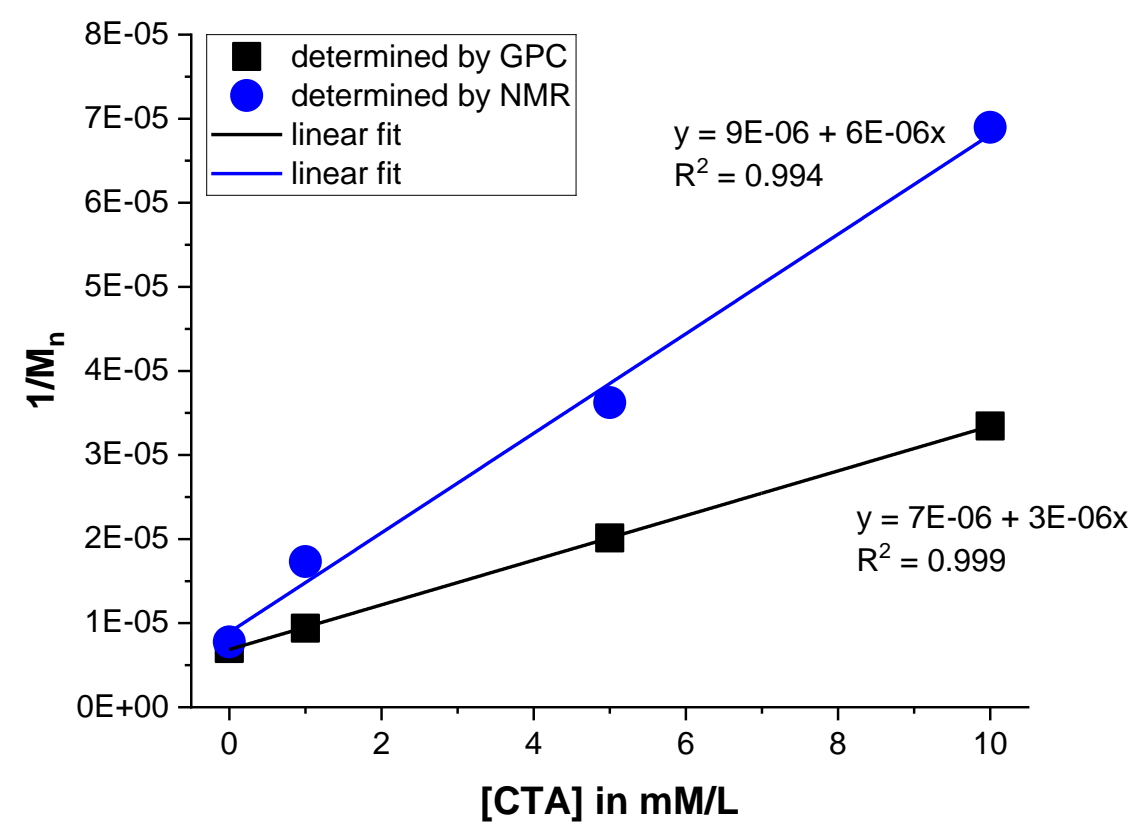

Figure S34: Inverse of the molecular weight plotted against amount of added alkoxyamine modified CTA (1) in polymerizations with complex 2 (cf. Table 1, entries 1-4). 


\section{Exemplary NMR Spectra of Homopolymers Obtained in CTP}

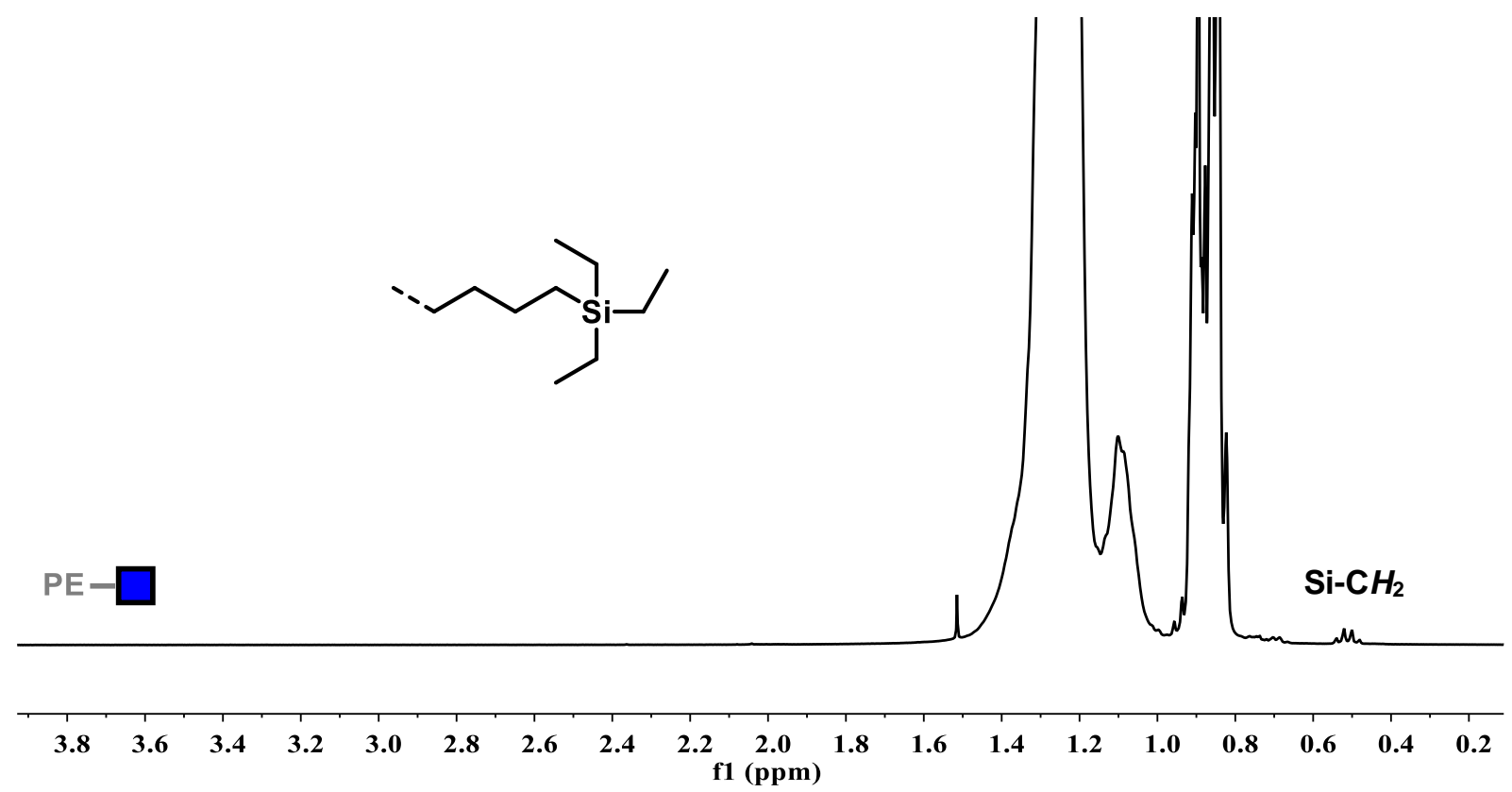

Figure S35: ${ }^{1} \mathrm{H}$ NMR spectrum $\left(400 \mathrm{MHz}, \mathrm{CDCl}_{3}, 300 \mathrm{~K}\right)$ of polymer obtained with complex 3 and 50 equivalents of triethylsilane showing signals for triethylsilyl end groups.
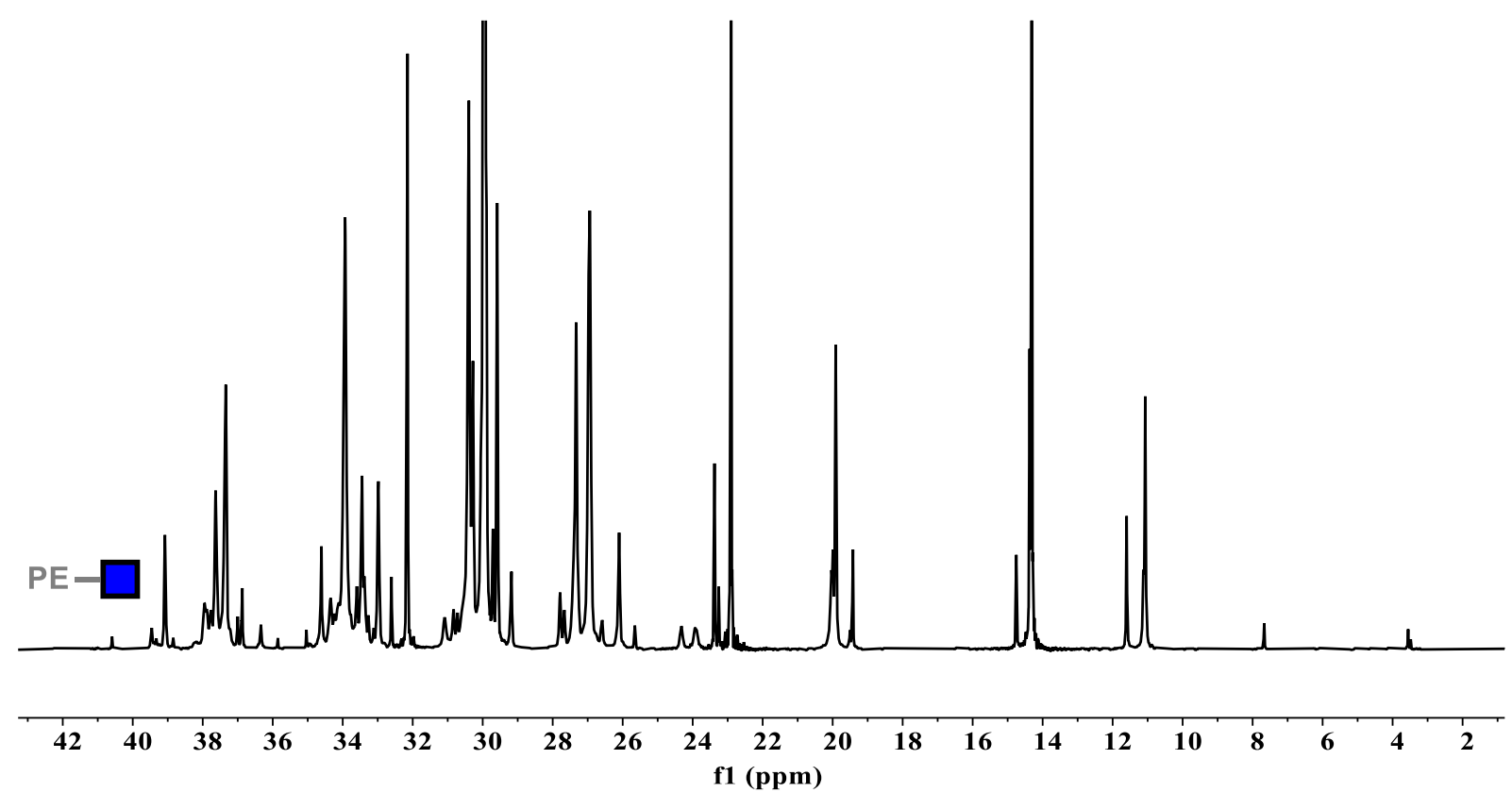

Figure S36: ${ }^{13} \mathrm{C}\left\{{ }^{1} \mathrm{H}\right\}$ NMR spectrum $\left(100 \mathrm{MHz}, \mathrm{CDCl}_{3}, 300 \mathrm{~K}\right)$ of polymer obtained with complex 3 and 50 equivalents of triethylsilane showing signals for triethylsilyl end groups. 


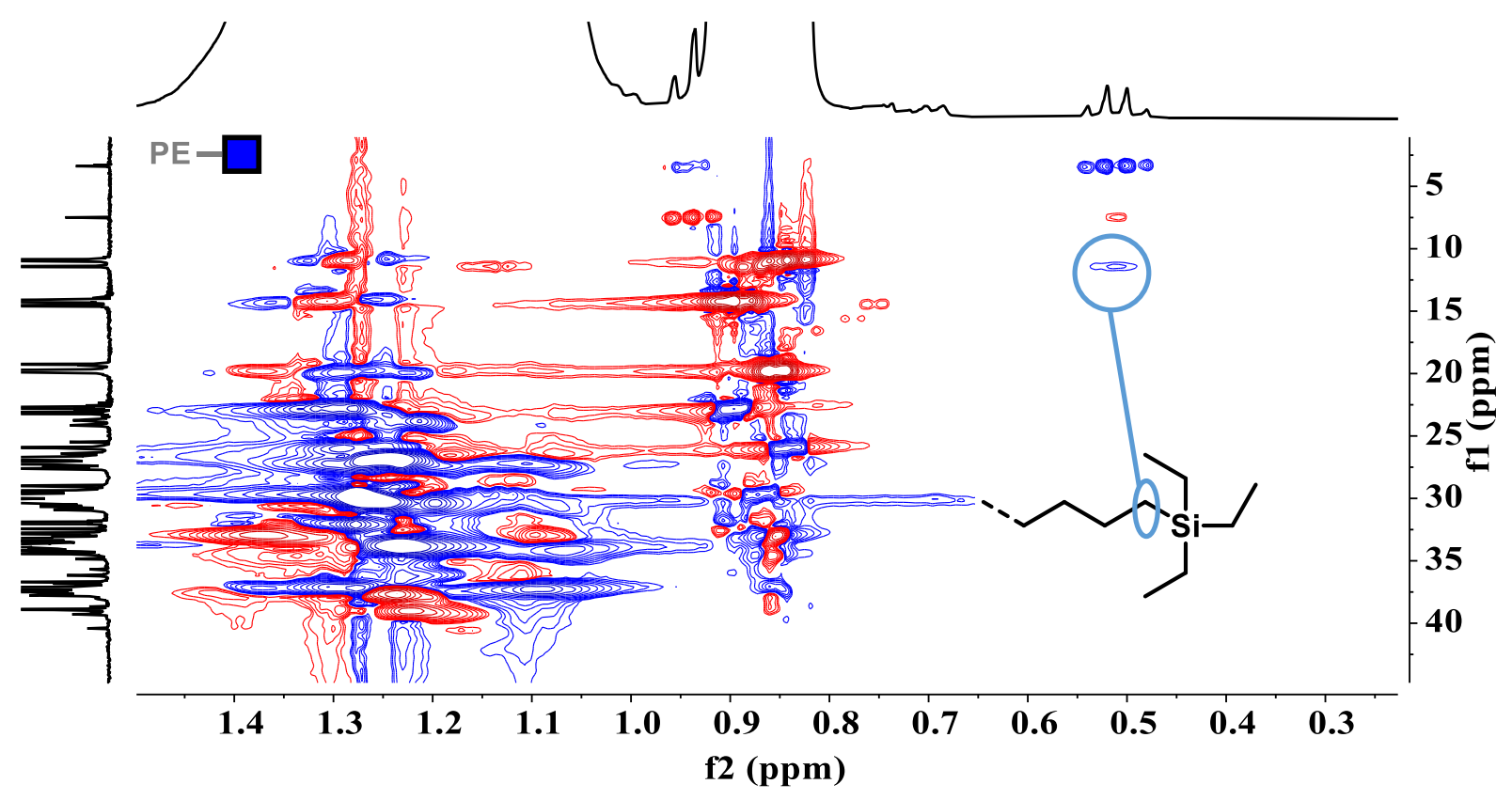

Figure S37: ${ }^{1} \mathrm{H}-{ }^{13} \mathrm{C}$ gHSQC NMR spectrum (400 MHz, $\mathrm{CDCl}_{3}, 300 \mathrm{~K}$ ) of polymer obtained with complex 3 and 50 equivalents of triethylsilane showing signals for triethylsilyl end groups.

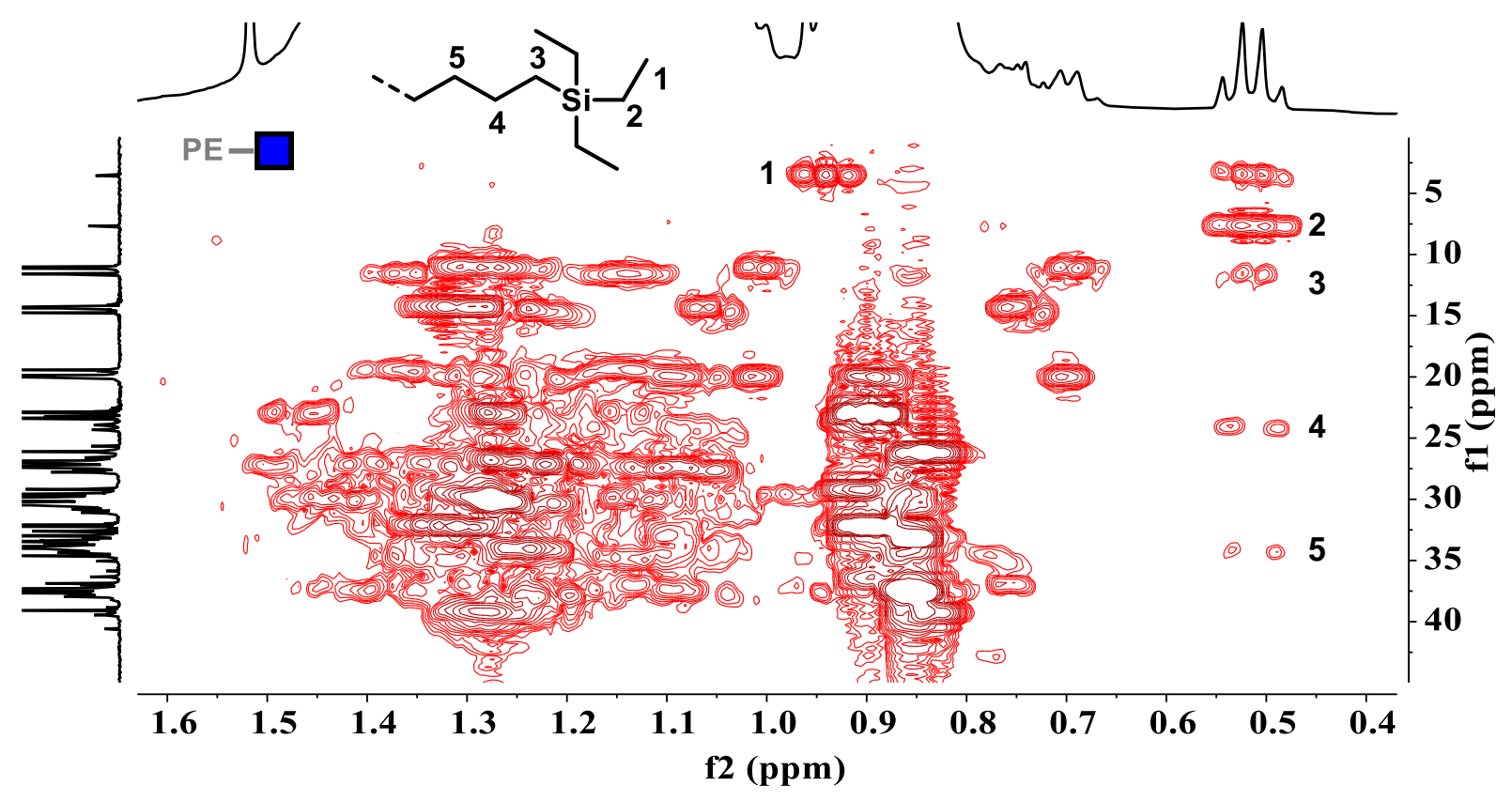

Figure S38: $\quad{ }^{1} \mathrm{H}_{-}{ }^{13} \mathrm{C}$ gHMBC NMR spectrum $\left(400 \mathrm{MHz}, \mathrm{CDCl}_{3}, 300 \mathrm{~K}\right)$ of polymer obtained with complex $\mathbf{3}$ and 50 equivalents of triethylsilane showing signals for triethylsilyl end groups. 

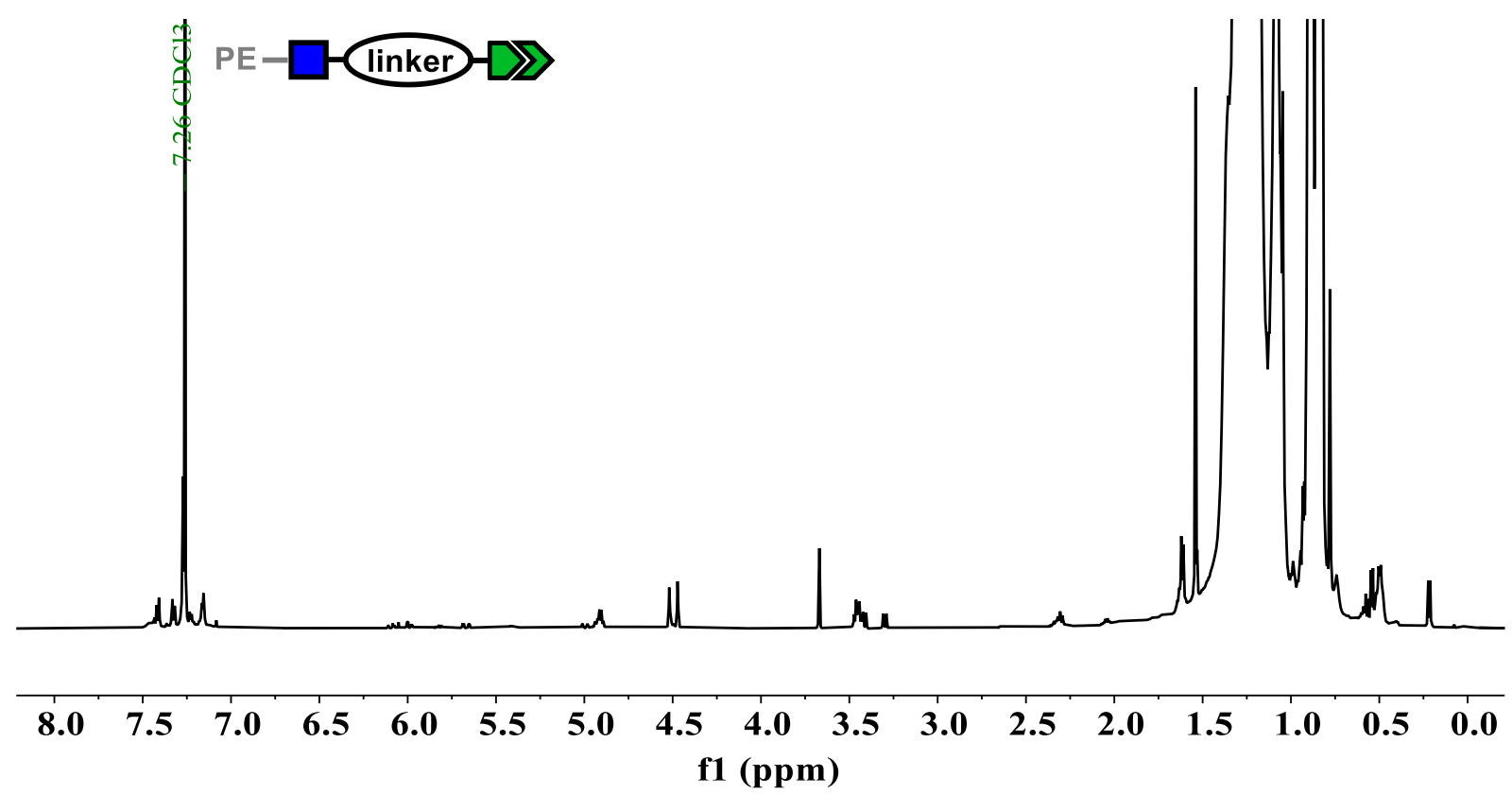

Figure S39: $\quad{ }^{1} \mathrm{H}$ NMR spectrum (400 $\mathrm{MHz}, \mathrm{CDCl}_{3}, 300 \mathrm{~K}$ ) of polymer obtained with complex $\mathbf{2}$ and 100 equivalents of the alkoxyamine modified CTA (1).

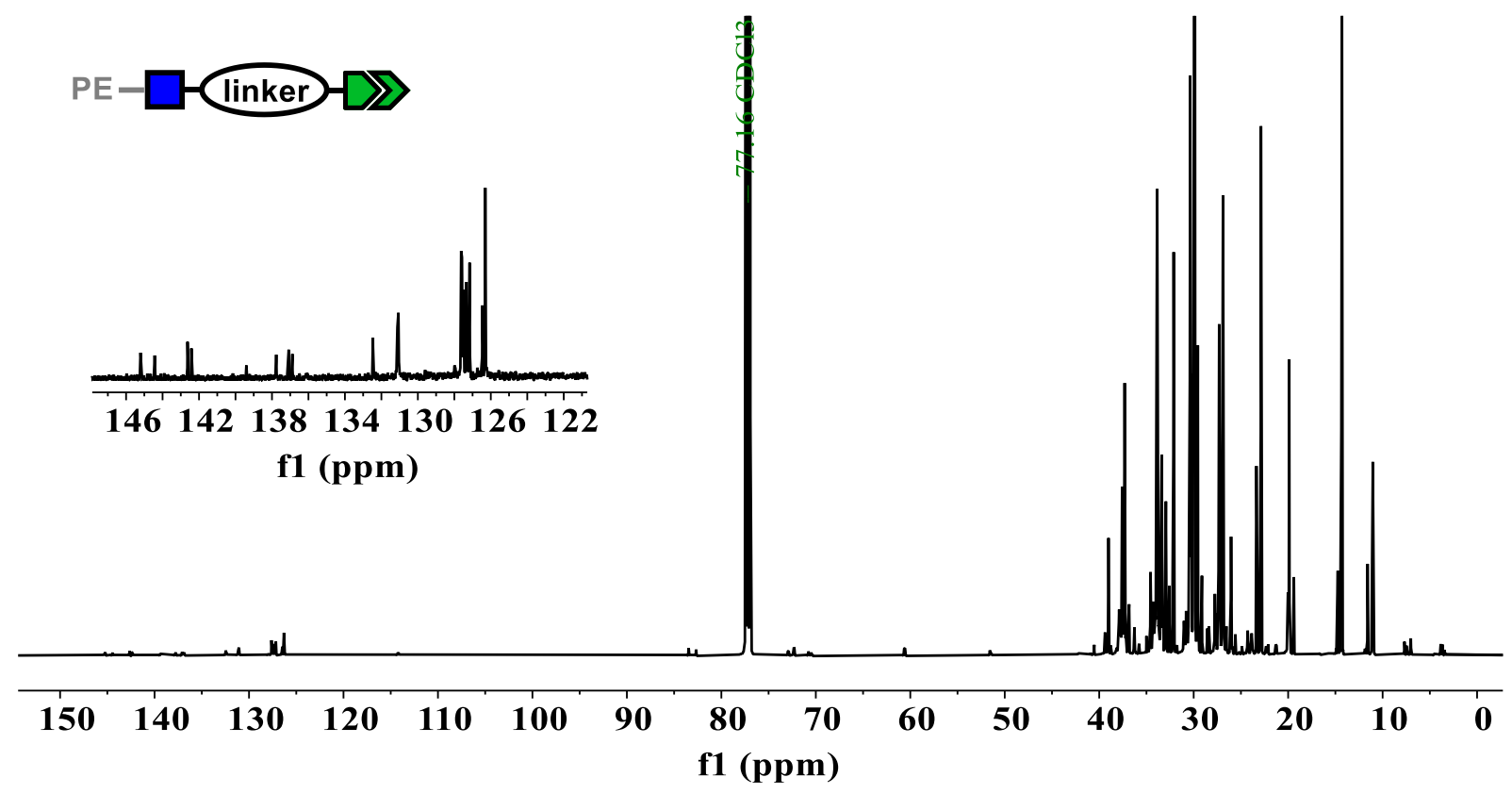

Figure S40: ${ }^{13} \mathrm{C}\left\{{ }^{1} \mathrm{H}\right\}$ NMR spectrum $\left(150 \mathrm{MHz}, \mathrm{CDCl}_{3}, 298 \mathrm{~K}\right)$ of polymer obtained with complex $\mathbf{2}$ and 100 equivalents of the alkoxyamine modified CTA (1). 


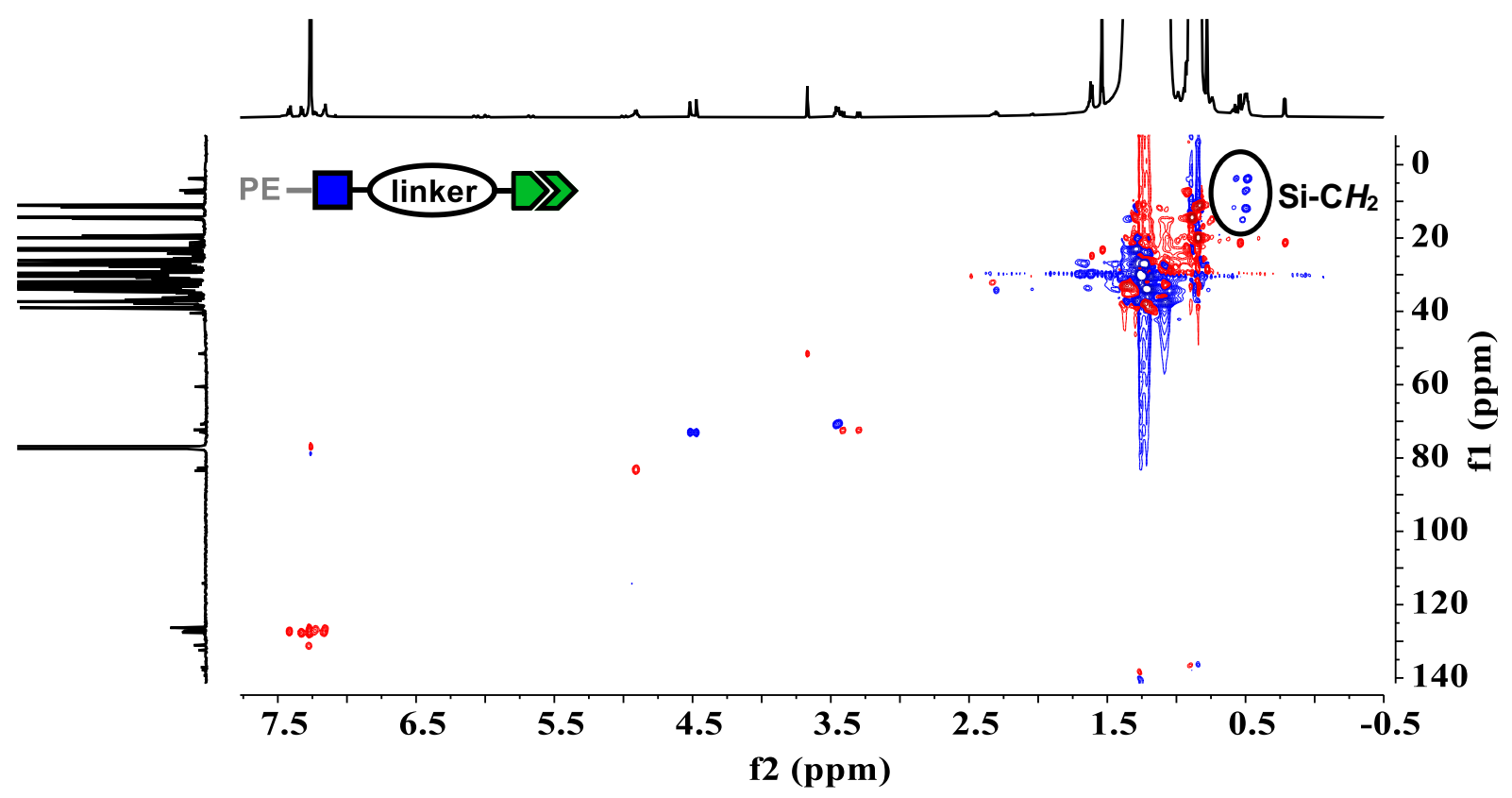

Figure S41: ${ }^{1} \mathrm{H}_{-}{ }^{13} \mathrm{C}$ gHSQC NMR spectrum $\left(600 \mathrm{MHz}, \mathrm{CDCl}_{3}, 298 \mathrm{~K}\right)$ of polymer obtained with complex 2 and 100 equivalents of the alkoxyamine modified CTA (1) showing signals for different silicon-bound methylene groups.

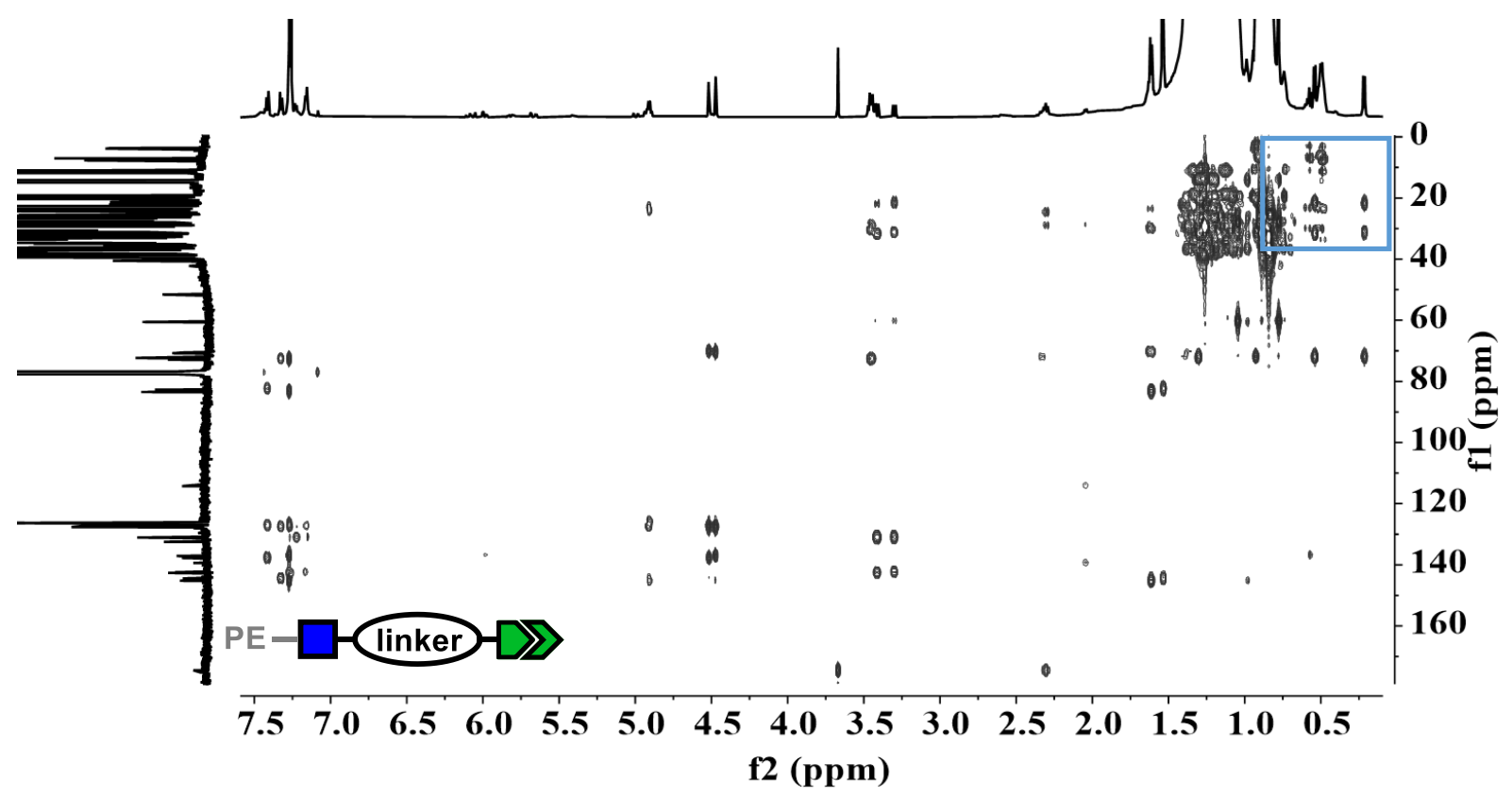

Figure S42: $\quad{ }^{1} \mathrm{H}_{-}{ }^{13} \mathrm{C}$ gHMBC NMR spectrum $\left(600 \mathrm{MHz}, \mathrm{CDCl}_{3}, 298 \mathrm{~K}\right)$ of polymer obtained with complex 2 and 100 equivalents of the alkoxyamine modified CTA (1). 


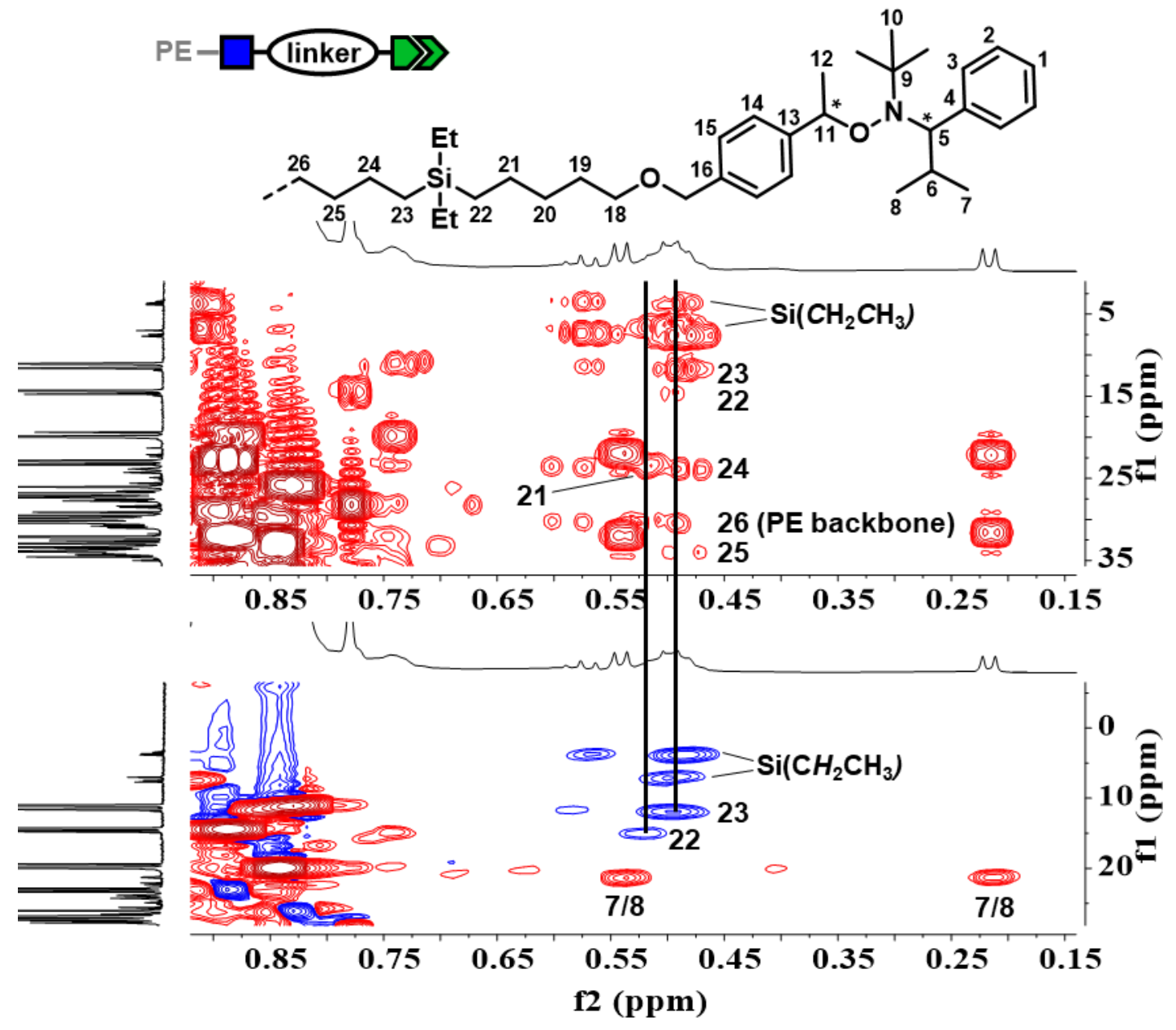

Figure S43: Enlargement of the ${ }^{1} \mathrm{H}_{-}{ }^{13} \mathrm{C}$ gHSQC NMR and ${ }^{1} \mathrm{H}-{ }^{13} \mathrm{C}$ gHMBC NMR spectra $\left(600 \mathrm{MHz}, \mathrm{CDCl}_{3}, 298 \mathrm{~K}\right)$ of polymer obtained with complex 2 and 100 equivalents of the alkoxyamine modified CTA (1) showing the connection between the silicon-bound methylene and the polyethylene backbone. 

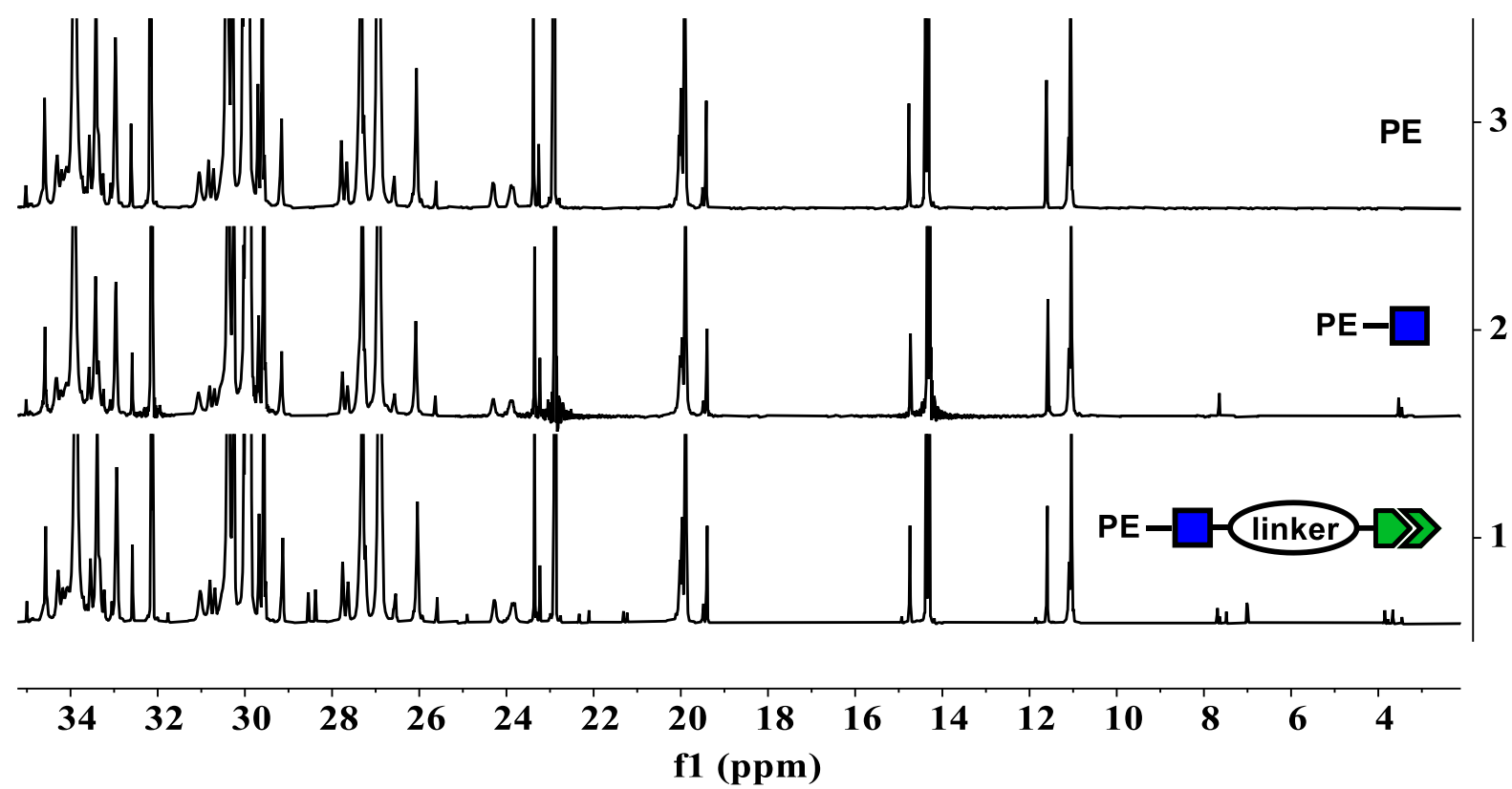

Figure S44: Enlargement of the ${ }^{13} \mathrm{C}\left\{{ }^{1} \mathrm{H}\right\}$ NMR spectra (150 MHz, $\mathrm{CDCl}_{3}, 298 \mathrm{~K}$ ) of polymer obtained with complex 2 and 100 equivalents of the alkoxyamine modified CTA (bottom), of polymer obtained with complex $\mathbf{3}$ and 50 equivalents of triethylsilane (center, $100 \mathrm{MHz}, \mathrm{CDCl}_{3}, 300 \mathrm{~K}$ ), and of polymer obtained with complex 3 without addition of CTA (top).

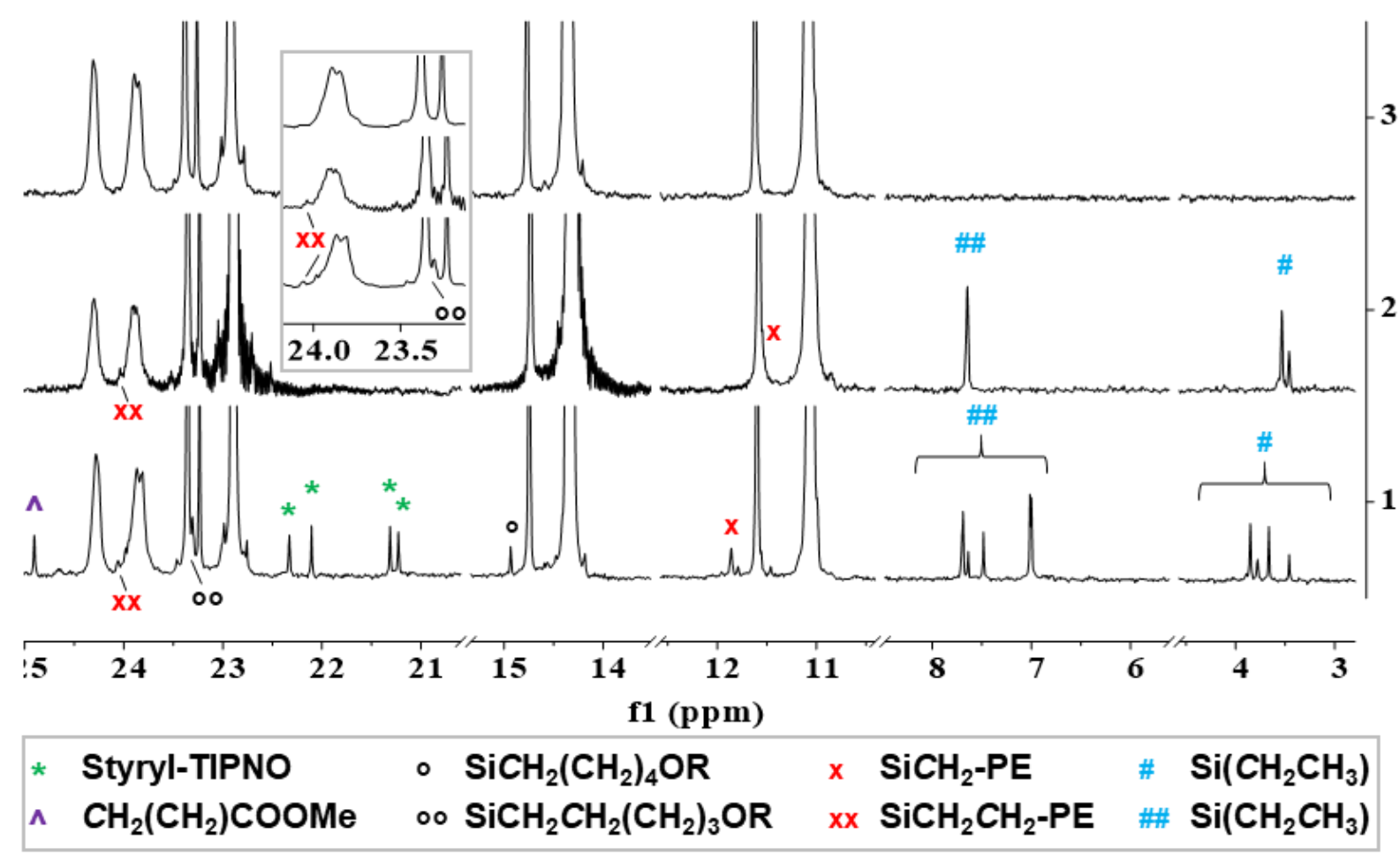

Figure S45: Further enlargement of the ${ }^{13} \mathrm{C}\left\{{ }^{1} \mathrm{H}\right\}$ NMR spectra (150 MHz, $\mathrm{CDCl}_{3}, 298 \mathrm{~K}$ ) of polymer obtained with complex 2 and 100 equivalents of the alkoxyamine modified CTA (bottom), of polymer obtained with complex $\mathbf{3}$ and 50 equivalents of triethylsilane (center, $100 \mathrm{MHz}, \mathrm{CDCl}_{3}, 300 \mathrm{~K}$ ), and of polymer obtained with complex 3 without addition of CTA (top). 


\section{Controlled Free Radical Polymerization of Styrene, $n$-and tert-Butyl Acrylate}

For our concept pursued here, a direct spectroscopic observation of the initiator-derived end groups is crucial. One example for a detailed analysis of end groups in NMP is the elaborate work by Hawker et. al.: Using chromophore-labeled initiators and measuring the absorbance of the resulting polymers, they were able to determine end group fidelity in NMP of styrene and butyl acrylate. ${ }^{26}$ Targeting the formation of block copolymers, the attachment of the initiating end group is of utmost importance, thus homopolymers of styrene, $n$ - and tert-butyl acrylate in NMPs were synthesized and analyzed with regard to their end groups. N-tert-Butyl- $N-(2-$ methyl-1-phenylpropyl)-O-(1-phenylethyl)hydroxylamine (Styryl-TIPNO) was employed to initiate NMP of styrene. Note that its dissociation rate is two orders of magnitude higher $\left(1.2 \times 10^{-4} \mathrm{~s}^{-1}\right.$ at $\left.90{ }^{\circ} \mathrm{C}\right)$ compared to for example Styryl-TEMPO $\left(1.8 \times 10^{-6} \mathrm{~s}^{-1} \text { at } 90{ }^{\circ} \mathrm{C}\right)^{27,28}$ and it is commercially available. Polymerization at $120^{\circ} \mathrm{C}$ in bulk yielded narrowly dispersed polymer $\left(\mathrm{M}_{\mathrm{w}} / \mathrm{M}_{\mathrm{n}}=1.1\right.$,Table $\left.\mathrm{S} 3\right)$.

Table S3: $\quad$ Polymerization results for NMP of styrene, $n$ - and tert-butyl acrylate using Styryl-TIPNO as initiator.

\begin{tabular}{llllllll}
\hline entry & $\begin{array}{l}\text { mono- } \\
\text { mer }\end{array}$ & $\begin{array}{l}\text { initiator } \\
\text { amount } \\
{[\mu \mathbf{m o l}]}\end{array}$ & $\begin{array}{l}\text { initiator to } \\
\text { monomer to } \\
\text { TIPNO ratio }\end{array}$ & $\begin{array}{l}\text { yield } \\
{[\mathbf{g}]}\end{array}$ & $\begin{array}{l}\text { time } \\
{[\mathbf{h}]}\end{array}$ & $\begin{array}{l}\mathbf{M}_{\mathbf{n}}(\mathbf{G P C})^{\mathbf{a})} \\
{\left[\mathbf{1 0}^{3} \mathbf{g} / \mathbf{m o l}\right]}\end{array}$ & $\mathbf{M}_{\mathbf{w}} / \mathbf{M}_{\mathbf{n}}$ \\
\hline $\mathbf{1}$ & $\mathrm{S}$ & 150 & $1: 180: 0$ & 0.89 & 4 & 7.4 & 1.2 \\
$\mathbf{2}$ & $\mathrm{S}$ & 75 & $1: 500: 0$ & 1.39 & 4 & 22.0 & 1.1 \\
$\mathbf{3}$ & $n \mathrm{BA}$ & 2 & $1: 4000: 0.05$ & 0.05 & 4 & 32.8 & 1.3 \\
$\mathbf{4}$ & $t \mathrm{BA}$ & 2 & $1: 4000: 0.05$ & 0.04 & 4 & 31.7 & 1.4 \\
\hline
\end{tabular}

Polymerizations in bulk at $120{ }^{\circ} \mathrm{C}$. a) Determined by GPC $\left(\mathrm{THF}, 35^{\circ} \mathrm{C}\right)$ versus PS standards.

Note that in all the polymerizations, and also in polymerizations with functionalized PE initiator, of acrylate or styrene monomer respectively, conversions were low, (circa 1 to $8 \%$ for acrylates and 12 to $48 \%$ for styrene), that is the free radical polymerization occurs under steady state conditions indeed. According to the mechanism of NMP the growing polymer chain should bear a styryl moiety as initiating chain end, while the TIPNO group should be attached to the terminal chain end. NMR spectroscopy of the formed polystyrene shows signals at 3.1, 3.3 and $4.1 \mathrm{ppm}$ corresponding to the TIPNO motif (Figure S46). Their connectivity to the backbone was established by ${ }^{1} \mathrm{H}-{ }^{1} \mathrm{H}$ gCOSY and TOCSY NMR experiments (Figure S47, Figure S48). In addition a DOSY NMR spectrum showed the same diffusion behavior for these signals and the polystyrene backbone, further proving the attachment of TIPNO at the chain end (Figure S49). 


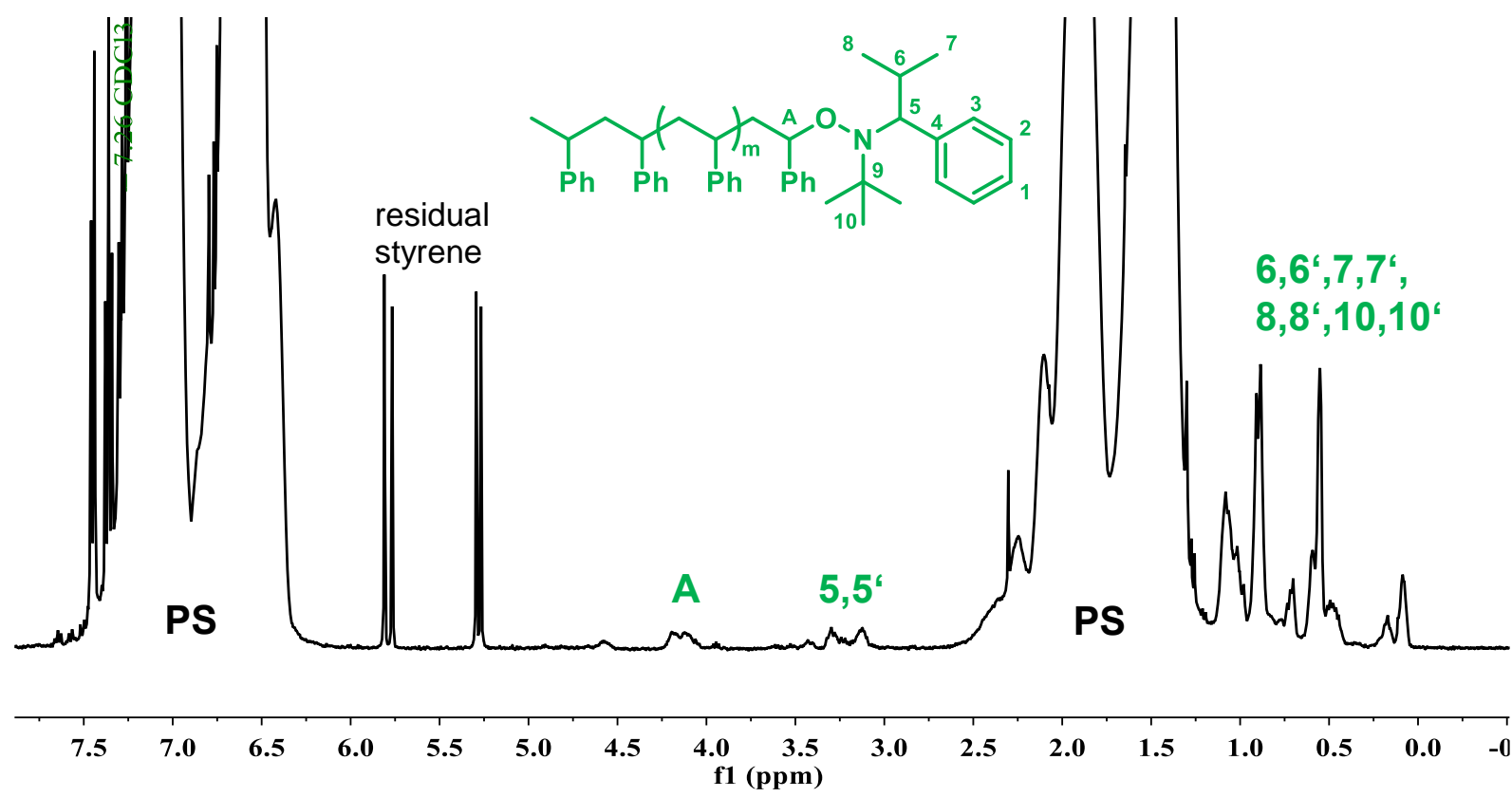

Figure S46: $\quad{ }^{1} \mathrm{H}$ NMR spectrum $\left(400 \mathrm{MHz}, \mathrm{CDCl}_{3}, 300 \mathrm{~K}\right)$ of polystyrene obtained in NMP with Styryl-TIPNO as initiator (Table S3, entry 1) showing signals for the TIPNO motif.

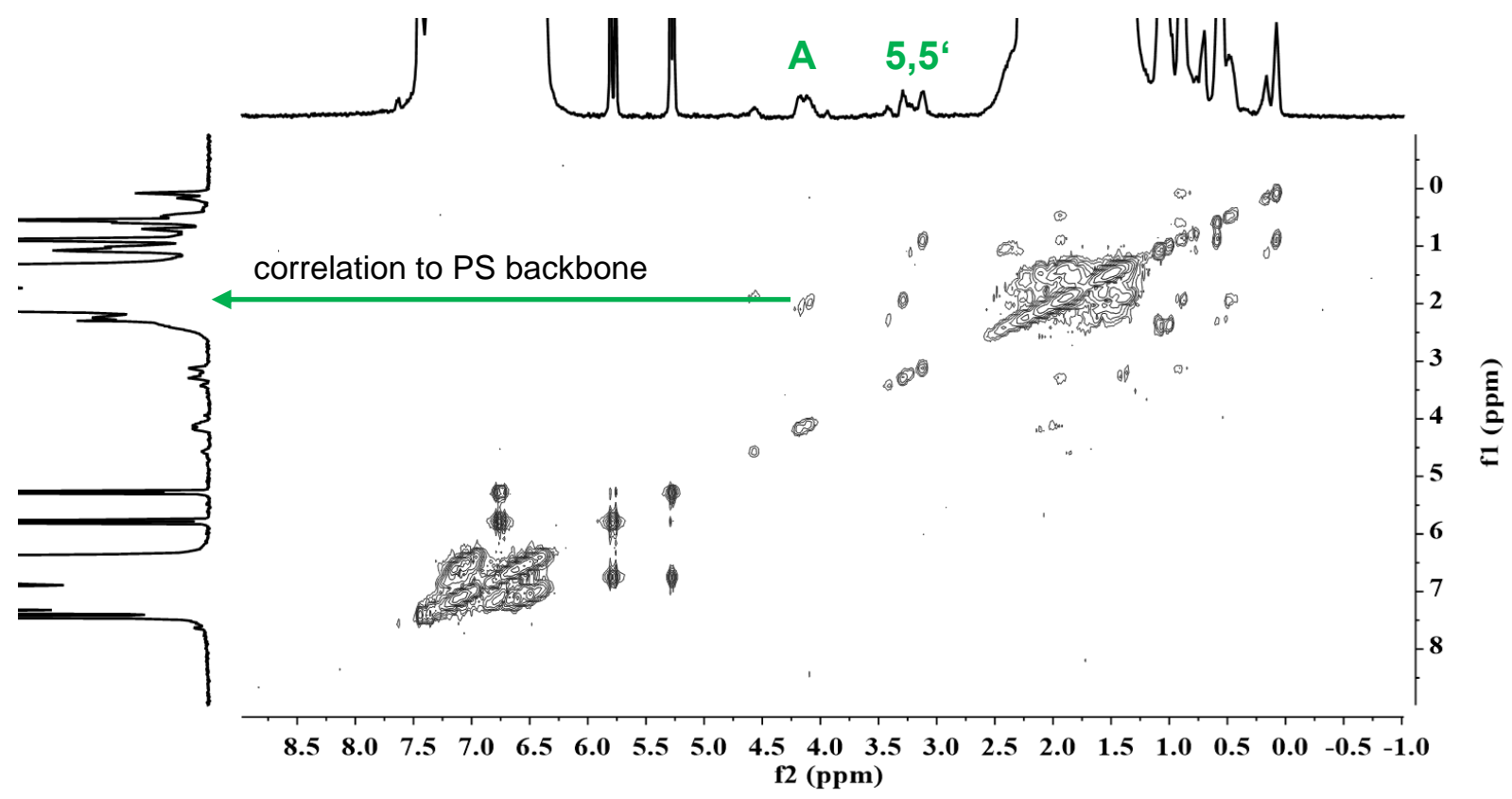

Figure S47: ${ }^{1} \mathrm{H}-{ }^{1} \mathrm{H}$ gCOSY NMR spectrum (400 $\mathrm{MHz}, \mathrm{CDCl}_{3}, 300 \mathrm{~K}$ ) of polystyrene obtained in NMP with Styryl-TIPNO as initiator (Table S3, entry 1). The correlation between signals corres-ponding to the TIPNO motif and the polystyrene backbone is visible. 

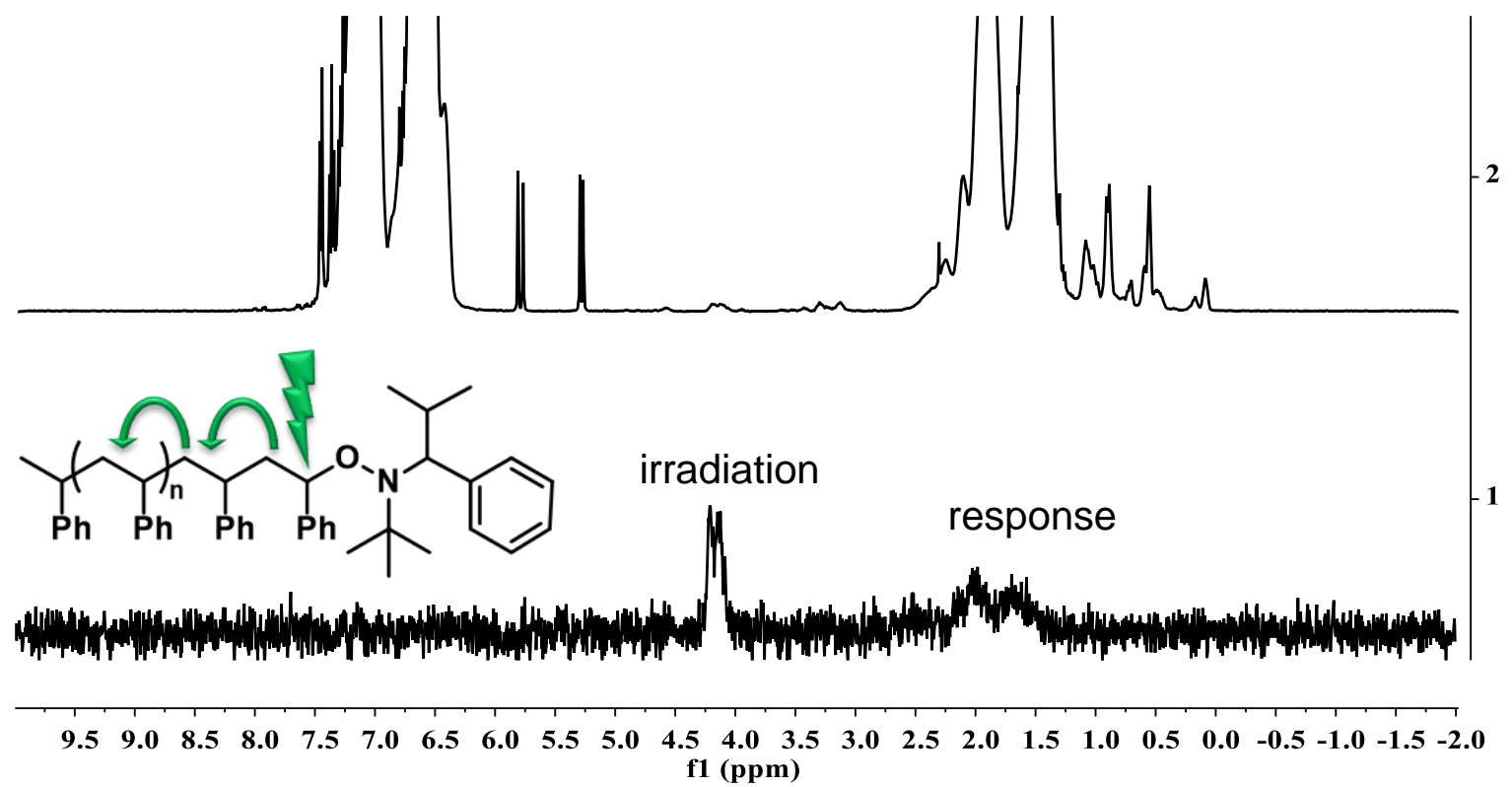

Figure S48: TOCSY NMR spectrum (bottom) and ${ }^{1} \mathrm{H}$ NMR spectrum (top, $400 \mathrm{MHz}, \mathrm{CDCl}_{3}$, $300 \mathrm{~K}$ ) of polystyrene obtained in NMP with Styryl-TIPNO as initiator (Table $\mathrm{S} 3$, entry 1). Irradiation at $4.2 \mathrm{ppm}$ results in a signal response of the polystyrene backbone.

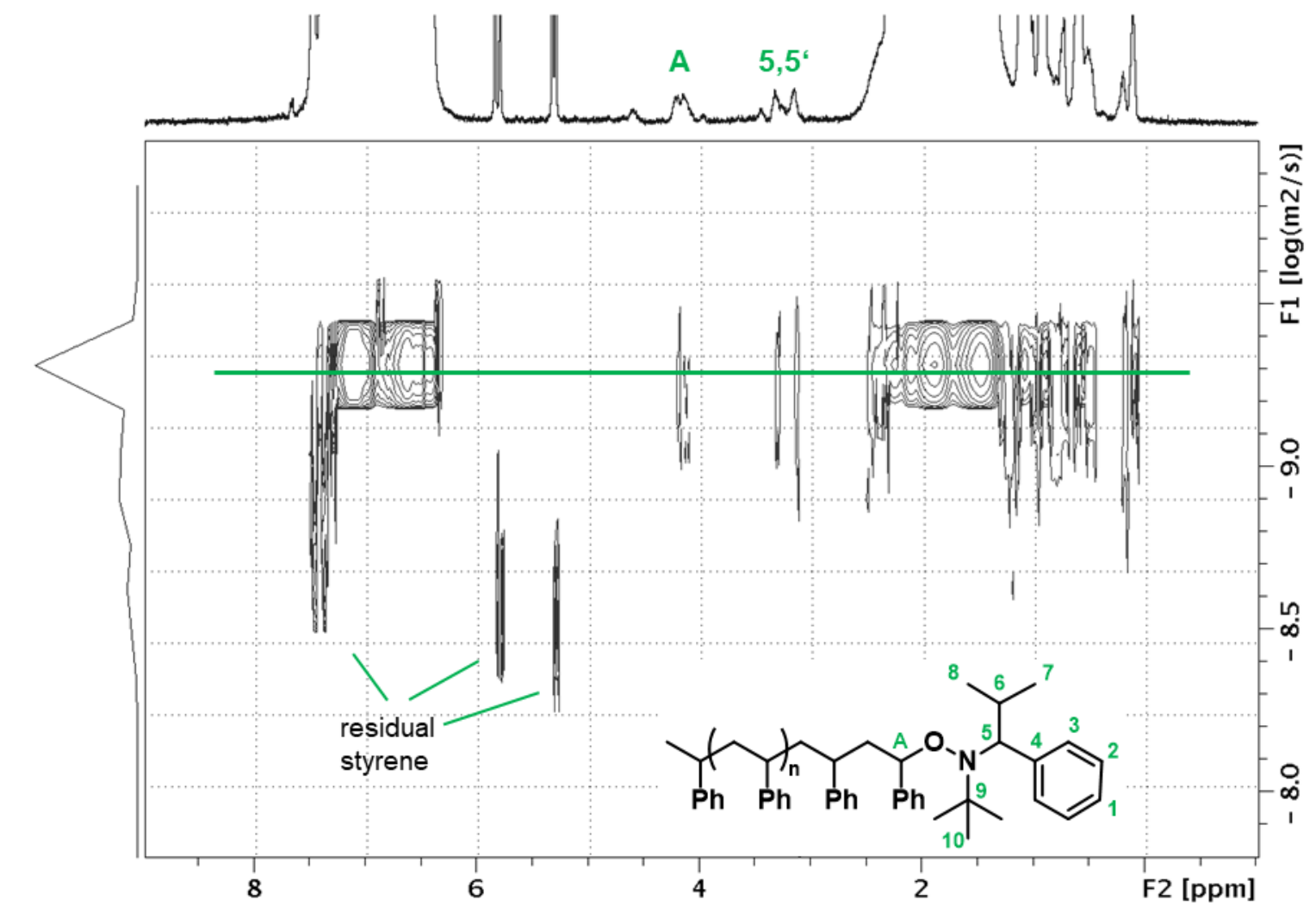

Figure S49: DOSY NMR spectrum (400 MHz, $\mathrm{CDCl}_{3}, 300 \mathrm{~K}$ ) of polystyrene obtained in NMP with Styryl-TIPNO as initiator. Signals corresponding to the TIPNO motif and the polystyrene backbone show the same diffusion behavior. 
Acrylate monomers like e.g. $n$-and tert-butyl acrylate exhibit faster polymerization rates in radical polymerization methods compared to styrene $\left(\mathrm{k}_{\mathrm{p} \text {, acrylate }}=11000 \mathrm{~L} \mathrm{~mol}^{-1} \mathrm{~s}^{-1}\right.$ at $120{ }^{\circ} \mathrm{C}$, $\mathrm{k}_{\mathrm{p}, \text { styrene }}=1800 \mathrm{~L} \mathrm{~mol}^{-1} \mathrm{~s}^{-1}$ at $\left.120{ }^{\circ} \mathrm{C}\right) .{ }^{13}$ Thus a higher level of control is necessary to afford polyacrylates with narrow molecular weight distribution. Due to the nature of NMP the presence of deliberately added persistent free radical (e.g. 2,2,5-trimethyl-4-phenyl-3azahexane-3-nitroxide, TIPNO) slows the overall polymerization rate, as the polymerization equilibrium is shifted towards the combination product, that is the Polymeryl/Styryl-TIPNOadduct. ${ }^{13,29}$ Polymerizations of $n$-and tert-butyl acrylate with Styryl-TIPNO were conducted varying the amount of TIPNO free radical from 0 to 0.2 equivalents. As anticipated NMP of acrylate in a controlled fashion occurred. The molecular weights decreased with increasing ratios of TIPNO to Styryl-TIPNO while polymers with increasingly narrow $M_{w} / M_{n}$ were obtained (Figure S50). The level of control over the polymer dispersity comes at the expense of conversion. A ratio of NMP initiator to free radical, i.e. Styryl-TIPNO to TIPNO of 1 to 0.05 was determined to be the best compromise (Figure S51). This ratio agrees with data reported by Hawker et al. for a controlled polymerization of $n$-butyl acrylate. ${ }^{13}$
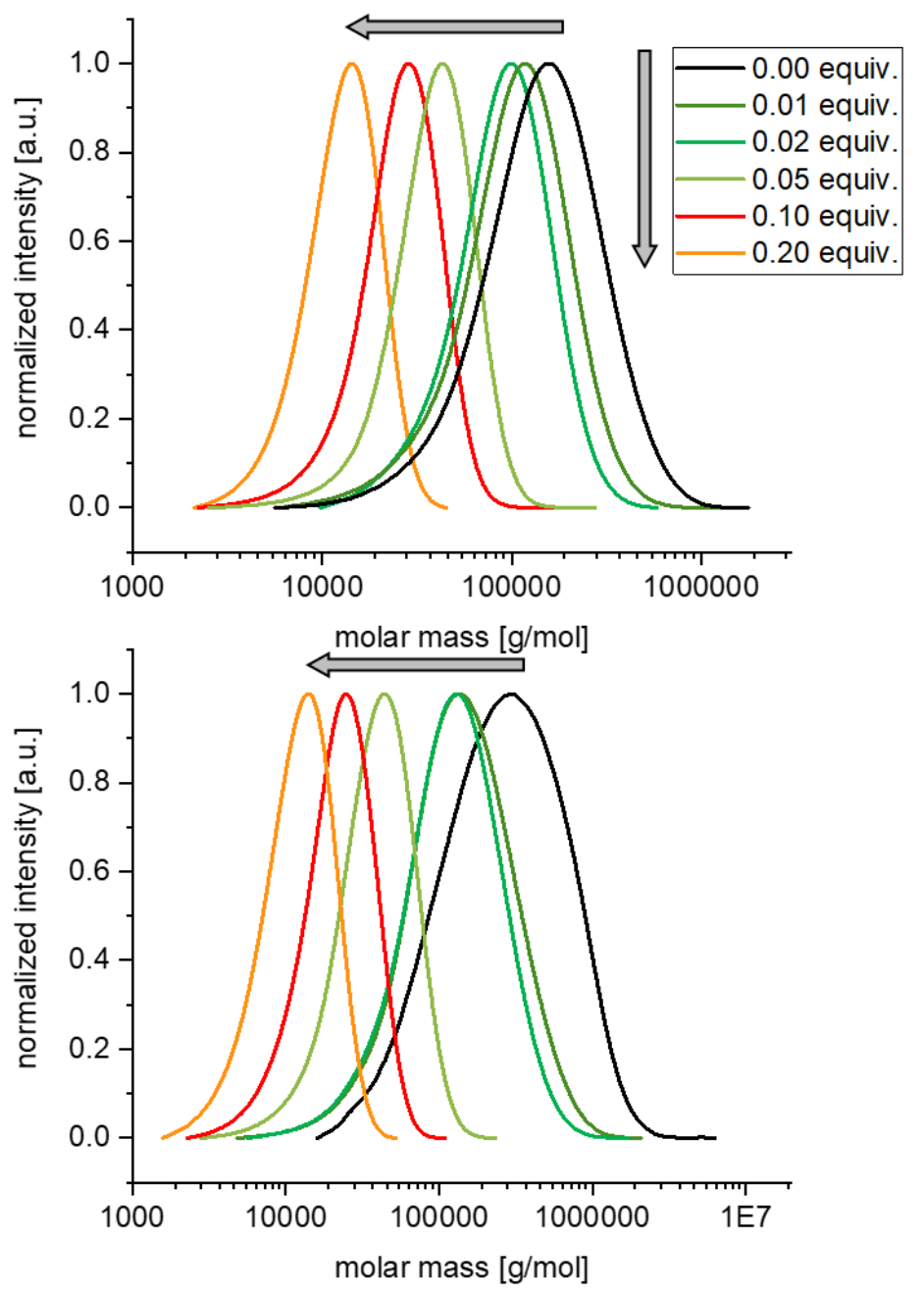

Figure S50: GPC traces for poly(n-butyl acrylates) (top) and poly(tert-butyl acrylates) (bottom) obtained in NMP with Styryl-TIPNO as initiator and 0 to 0.2 equivalents of TIPNO free radical. 


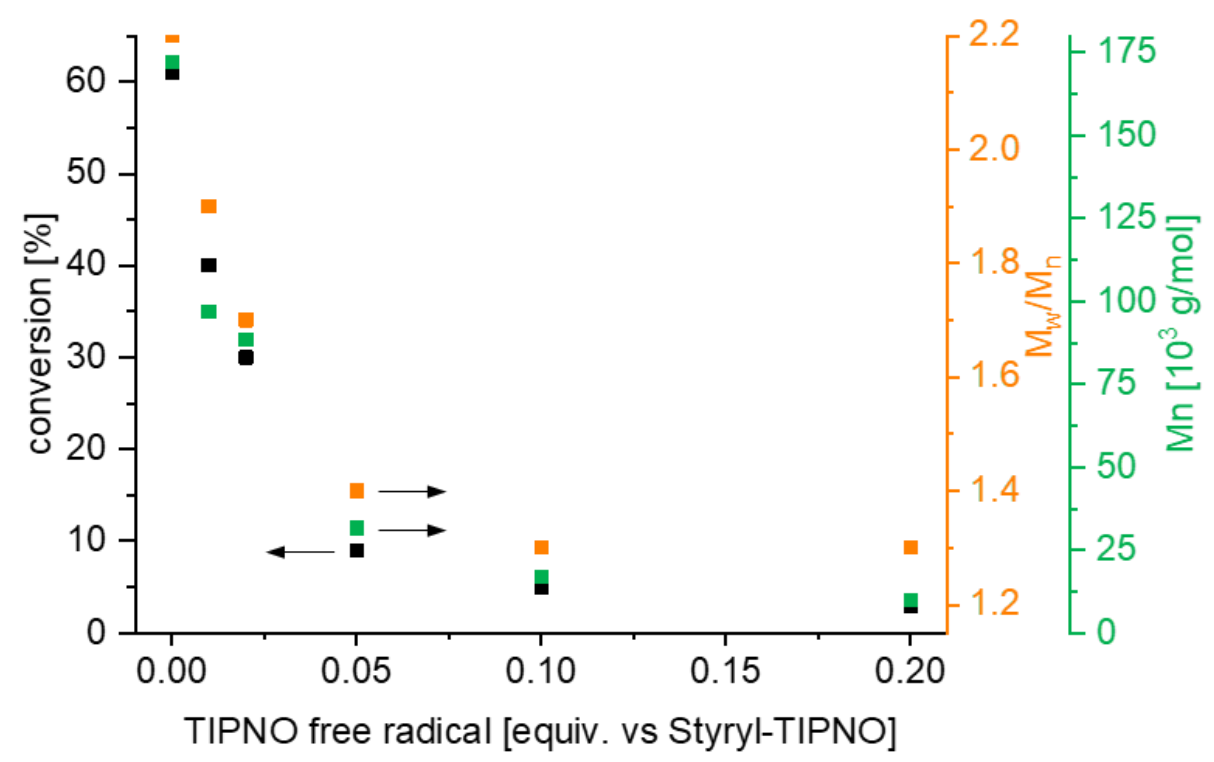

Figure S51: Conversion, polymer dispersity $\mathrm{M}_{\mathrm{w}} / \mathrm{M}_{\mathrm{n}}$ and molecular weight of poly(tert-butyl acrylates) obtained in NMP with Styryl-TIPNO and varying amounts of TIPNO free radical.

The microstructure of the obtained poly(butyl acrylates) was analyzed by ${ }^{1} \mathrm{H}$ NMR revealing characteristic signals for Styryl and TIPNO end groups. Detection and assignment of connecting points between the polymer backbone prove the attachment of the initiator fragments as end groups (Figure S52).
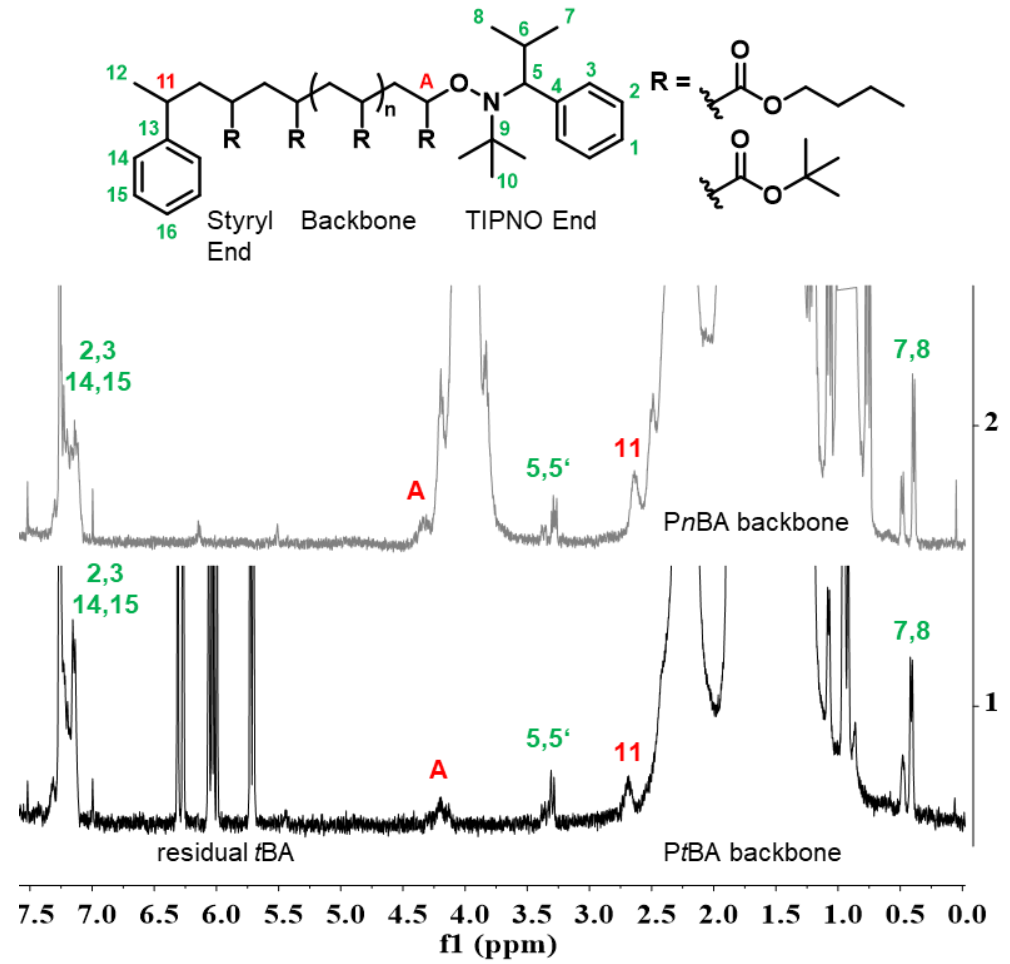

Figure S52: $\quad{ }^{1} \mathrm{H}$ NMR spectra (400 $\mathrm{MHz}, \mathrm{CDCl}_{3}, 300 \mathrm{~K}$ ) of poly(n-butyl acrylate) (bottom) and poly(tert-butyl acrylate) (top) obtained in NMP with Styryl-TIPNO as initiator showing signals for the Styryl and TIPNO motif. 


\subsection{Exemplary NMR Spectra}

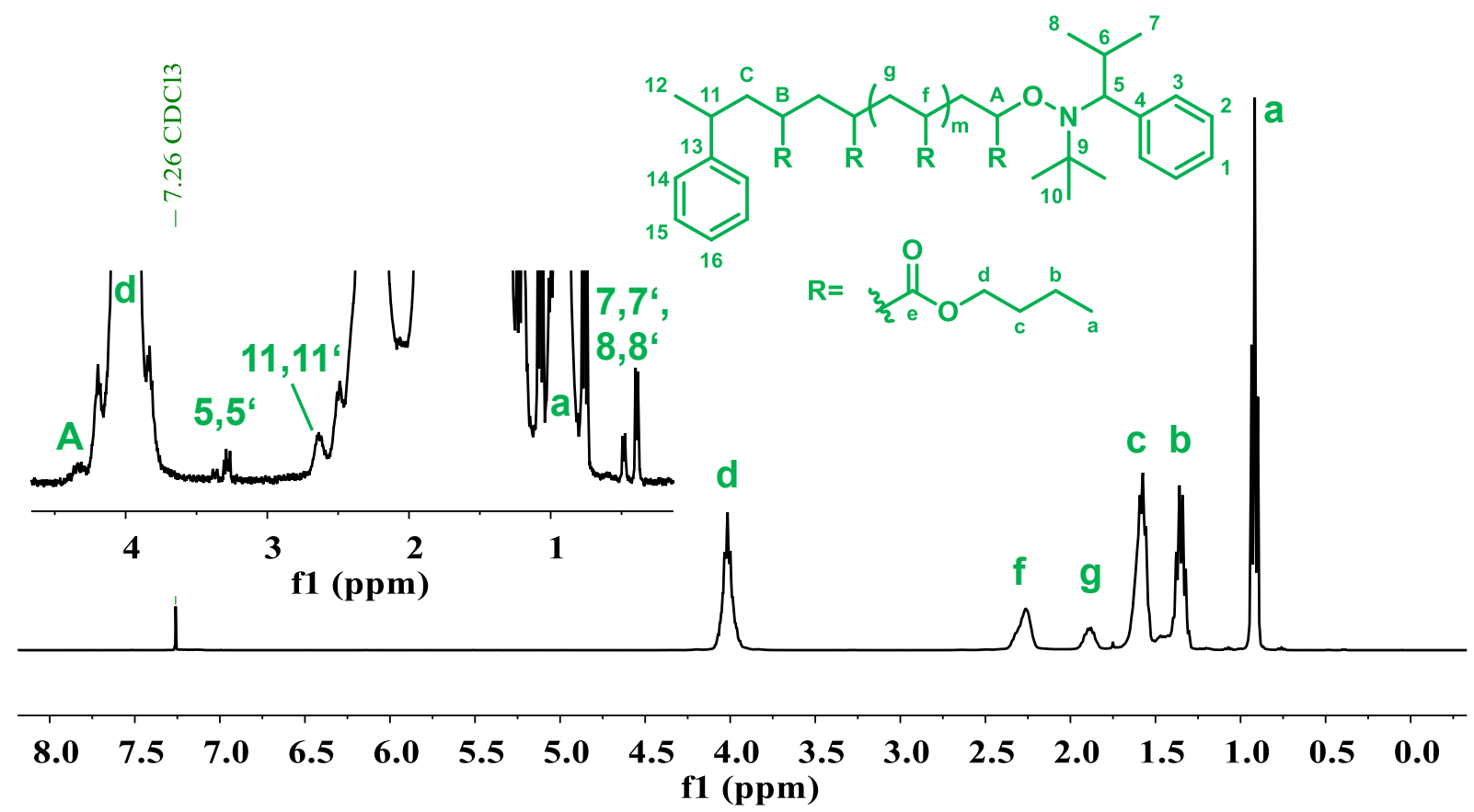

Figure S53: ${ }^{1} \mathrm{H}$ NMR spectrum $\left(400 \mathrm{MHz}, \mathrm{CDCl}_{3}, 300 \mathrm{~K}\right)$ of poly $(n$-butyl acrylate) obtained in NMP with Styryl-TIPNO as initiator (Table S3, entry 3) showing signals for the TIPNO motif.

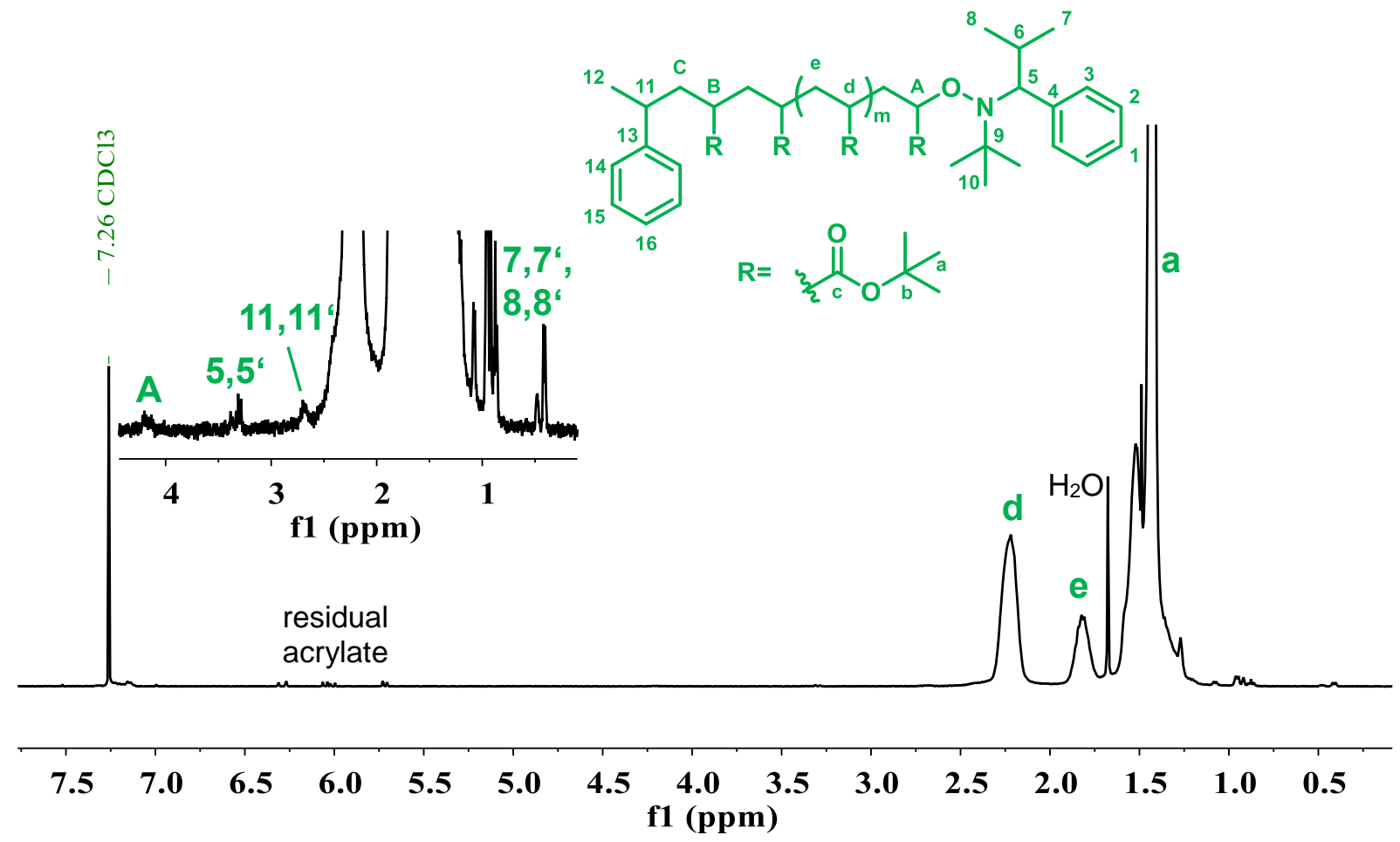

Figure S54: ${ }^{1} \mathrm{H}$ NMR spectrum $\left(400 \mathrm{MHz}, \mathrm{CDCl}_{3}, 300 \mathrm{~K}\right)$ of poly(tert-butyl acrylate) obtained in NMP with Styryl-TIPNO as initiator (Table S3, entry 4) showing signals for the TIPNO motif. 


\subsection{Exemplary GPC Data}

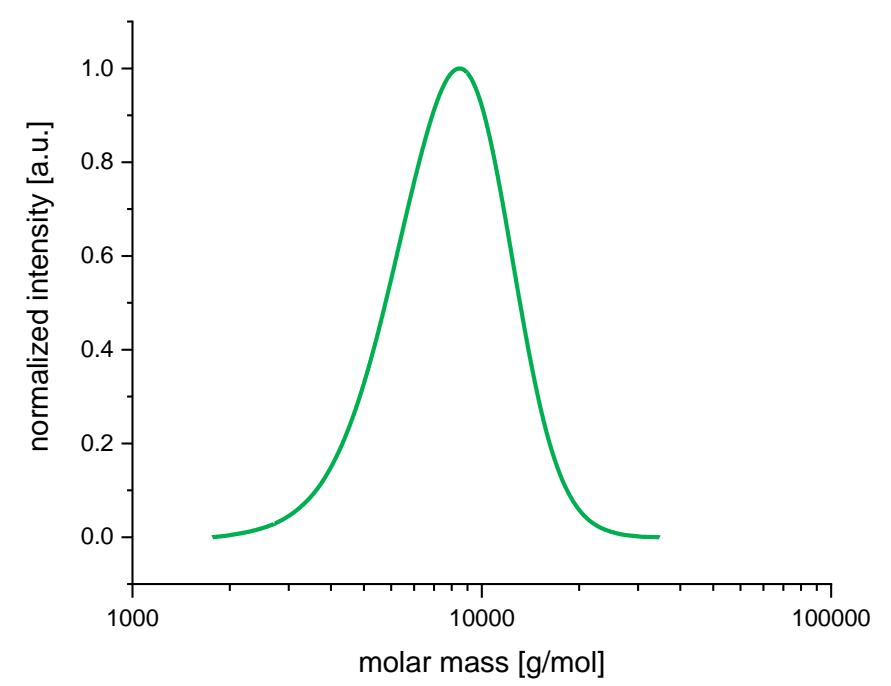

Figure S55: GPC trace detected by RI for polystyrene obtained in NMP with Styryl-TIPNO as initiator (Table S3, entry 1).

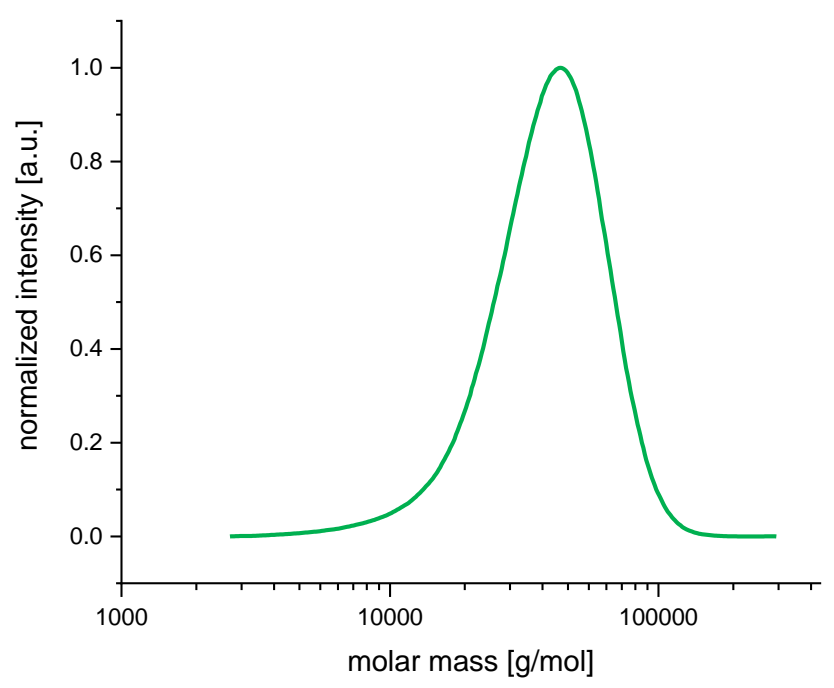

Figure S56: GPC trace detected by RI for poly(n-butyl acrylate) obtained in NMP with Styryl-TIPNO as initiator (Table S3, entry 3). 


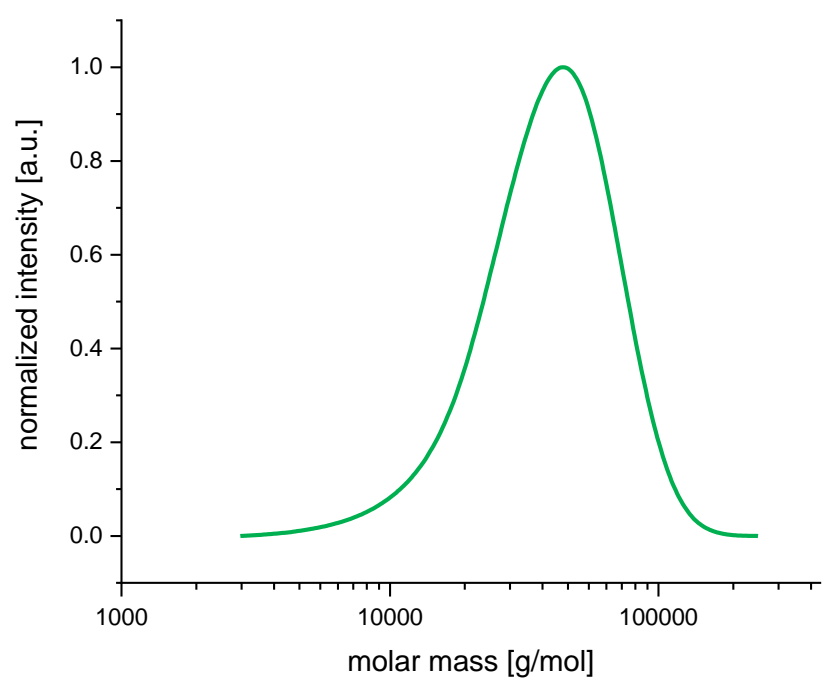

Figure S57: GPC trace detected by RI for poly(tert-butyl acrylate) obtained in NMP with Styryl-TIPNO as initiator (Table S3, entry 4). 


\section{Analytical Data of Obtained Copolymers}

\subsection{Exemplary NMR Spectra}

\section{PE-PS-Block Copolymers}

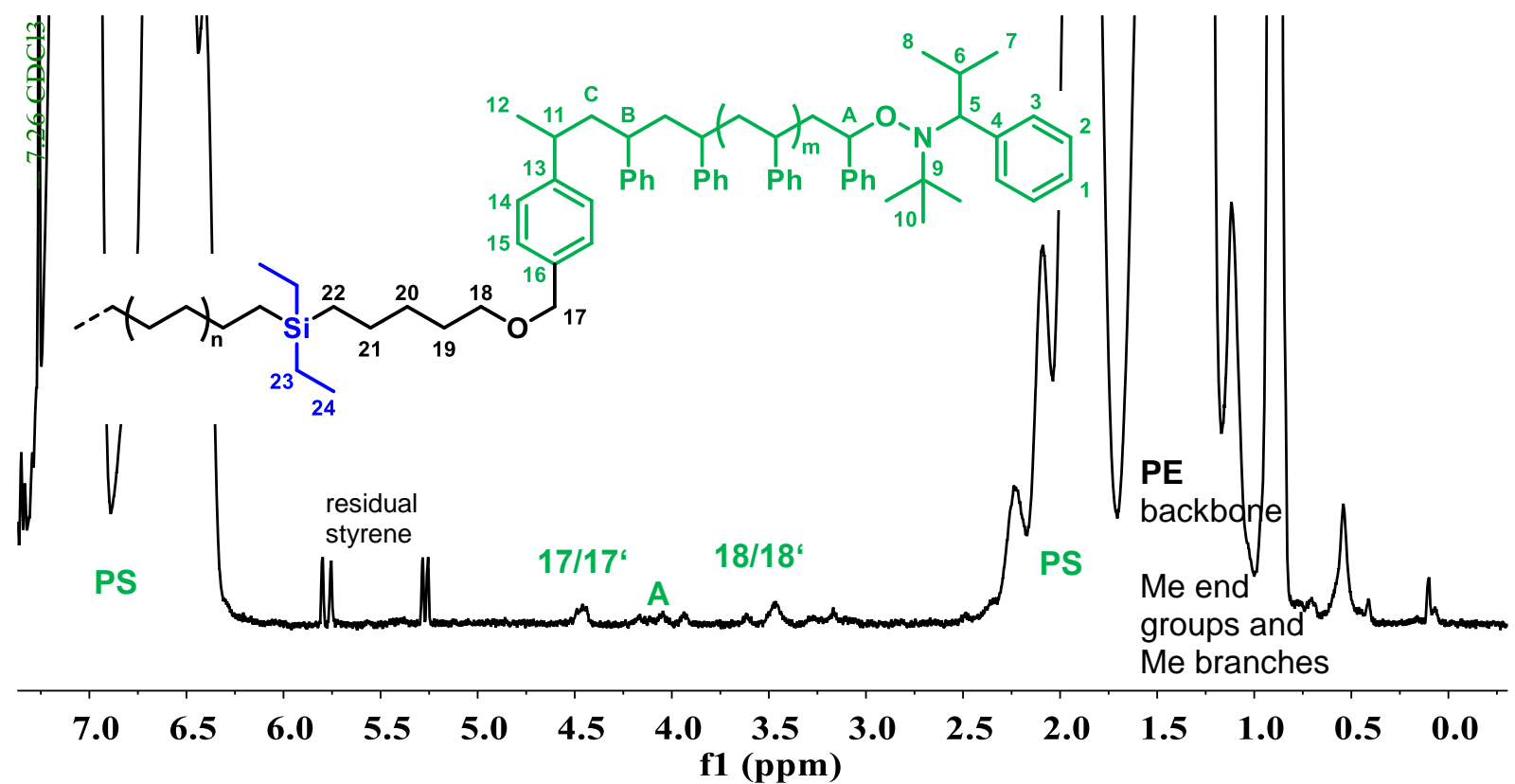

Figure S58: $\quad{ }^{1} \mathrm{H}$ NMR spectrum $\left(400 \mathrm{MHz}, \mathrm{CDCl}_{3}, 300 \mathrm{~K}\right)$ of polymer obtained in NMP of styrene initiated by PE-1 (cf. Table 2, entry 1). Signals corresponding to polyethylene, polystyrene and characteristic signals for the TIPNO end group as well as the linker between the silyl and TIPNO moiety are highlighted.
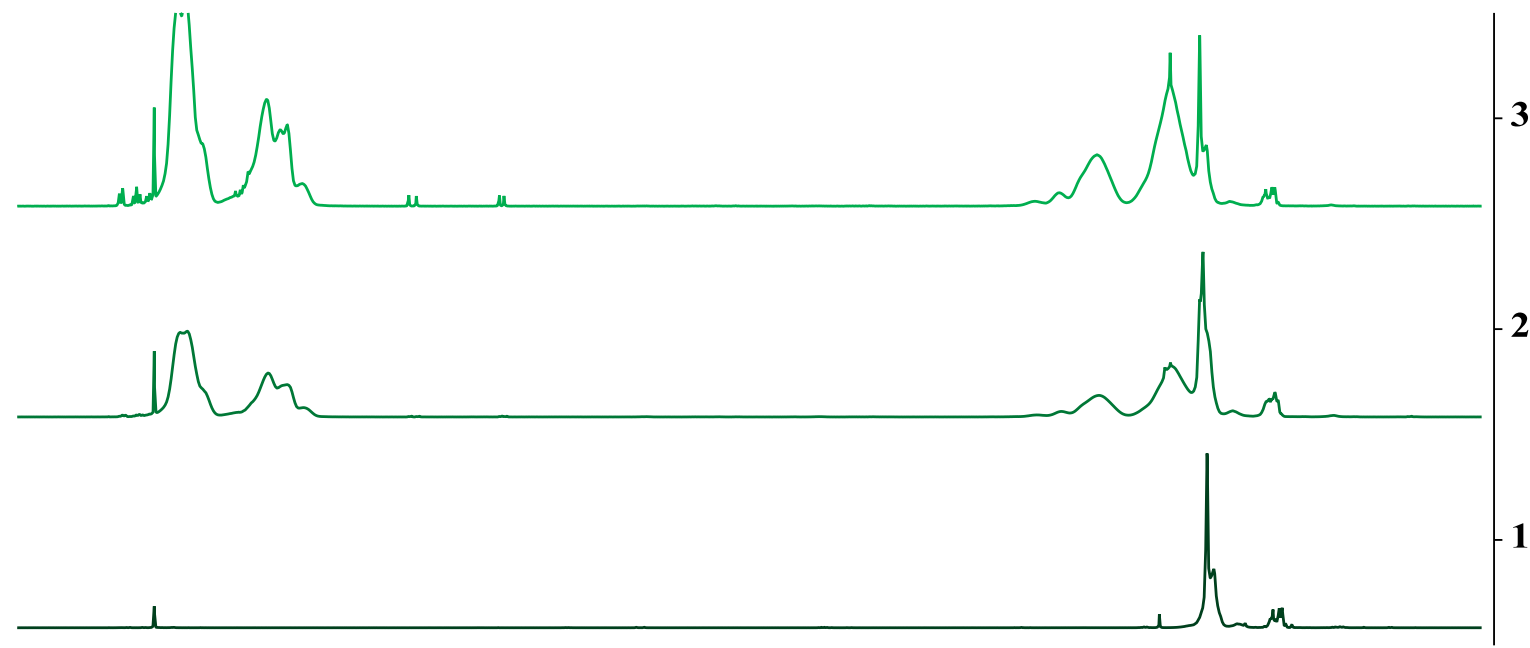

\section{$\begin{array}{llllllllllllllllll}3.0 & 7.5 & 7.0 & 6.5 & 6.0 & 5.5 & 5.0 & 4.5 & 4.0 & 3.5 & 3.0 & 2.5 & 2.0 & 1.5 & 1.0 & 0.5 & 0.0\end{array}$ f1 (ppm)}

Figure S59: $\quad{ }^{1} \mathrm{H}$ NMR spectra $\left(400 \mathrm{MHz}, \mathrm{CDCl}_{3}, 300 \mathrm{~K}\right)$ of the polymer PE-1 (bottom) and polymers obtained after $1 \mathrm{~h}$ (center) and $4 \mathrm{~h}$ (top) NMP of styrene initiated by PE-1 (cf. Table 2, entries 1-2). 
PE-PnBA-Block Copolymers
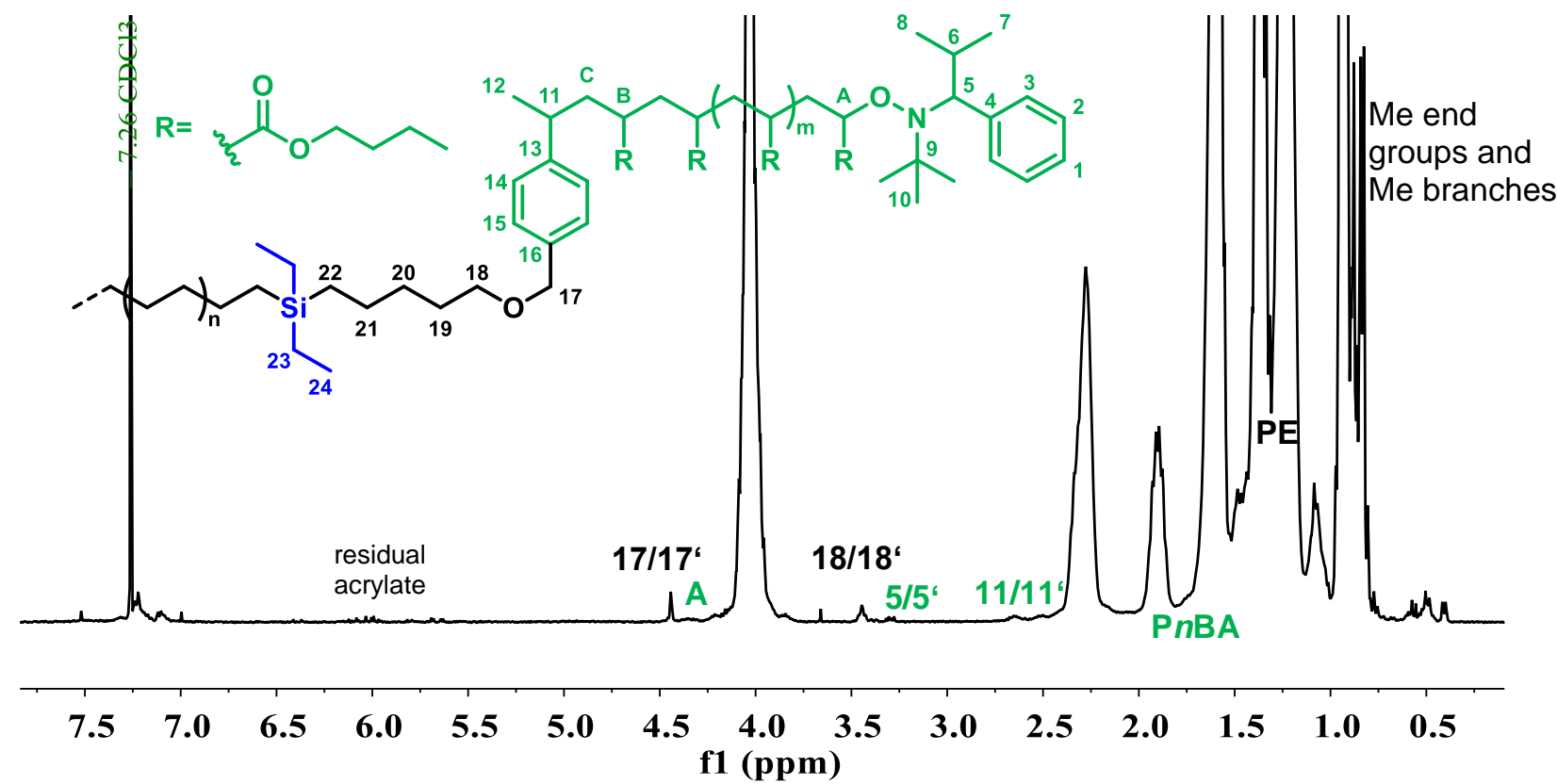

Figure S60: ${ }^{1} \mathrm{H}$ NMR spectrum $\left(400 \mathrm{MHz}, \mathrm{CDCl}_{3}, 300 \mathrm{~K}\right)$ of polymer obtained in NMP of $n$-butyl acrylate initiated by PE-2 (cf. Table 2, entry 4). Signals corresponding to polyethylene, polyacrylate and characteristic signals for the TIPNO end group as well as the linker between the silyl and TIPNO moiety are highlighted.

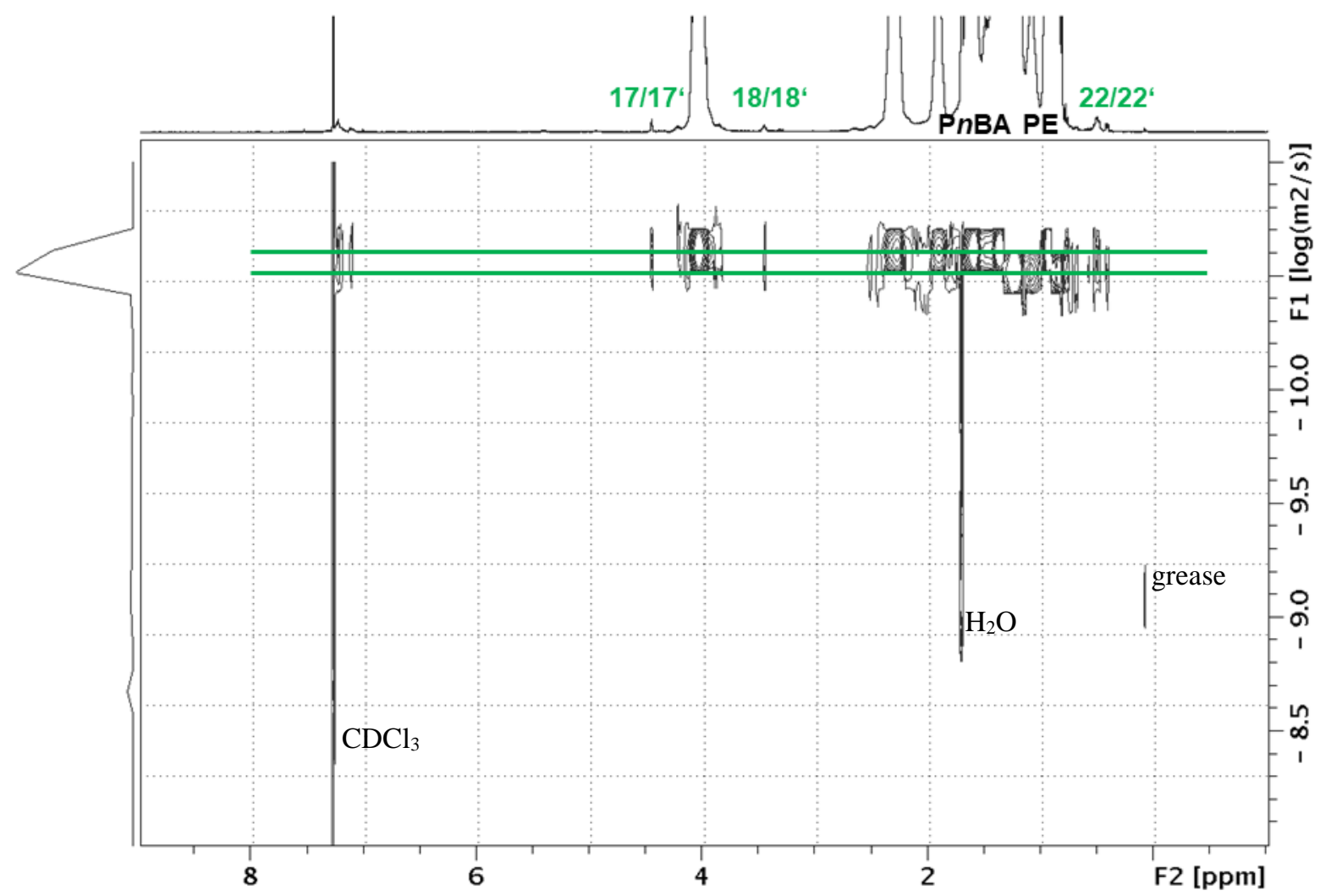

Figure S61: DOSY NMR spectrum $\left(400 \mathrm{MHz}, \mathrm{CDCl}_{3}, 300 \mathrm{~K}\right)$ of polymer obtained in NMP of $n$-butyl acrylate. Signals corresponding to the TIPNO motif, polyethylene and $\operatorname{poly}(n$-butyl acrylate) show similar diffusion behavior. 


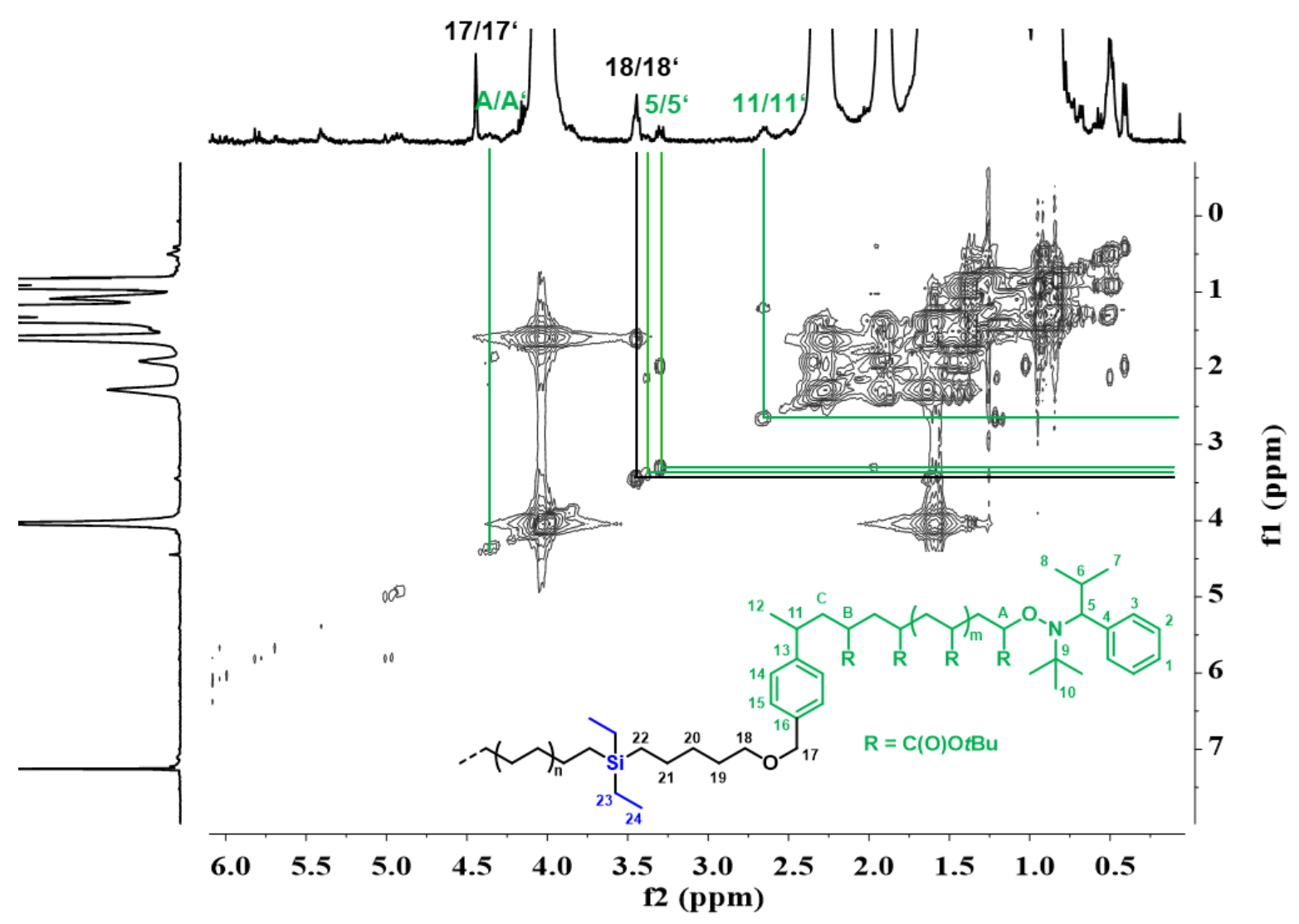

Figure S62: $\quad{ }^{1} \mathrm{H}-{ }^{1} \mathrm{H}$ gCOSY NMR spectrum $\left(600 \mathrm{MHz}, \mathrm{CDCl}_{3}, 298 \mathrm{~K}\right)$ of polymer obtained in NMP of $n$-butyl acrylate. Characteristic signals for the TIPNO end group as well as the linker between the silyl and TIPNO moiety are highlighted.

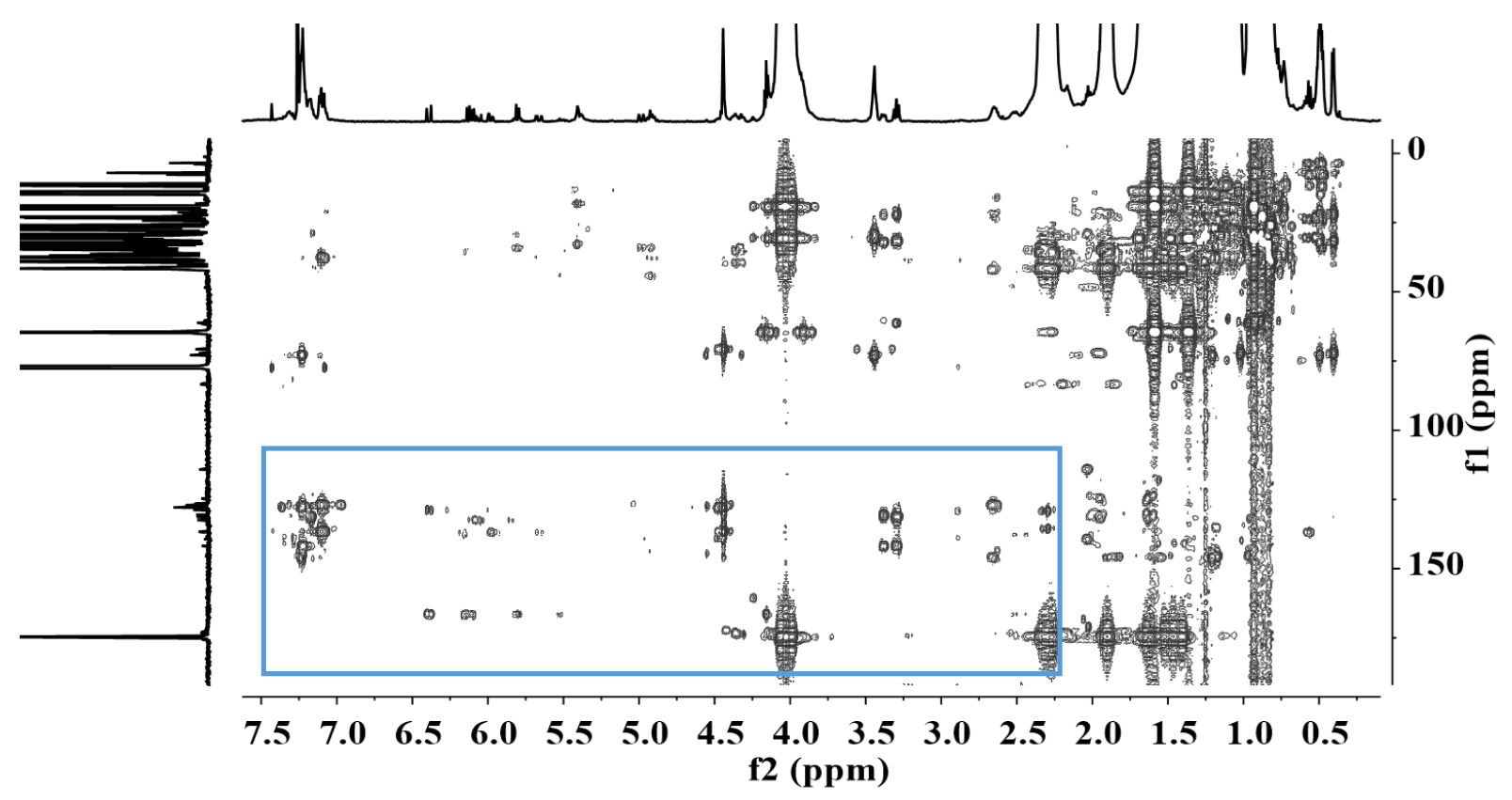

Figure S63: $\quad{ }^{1} \mathrm{H}-{ }^{13} \mathrm{C}$ gHMBC NMR spectrum $\left(600 \mathrm{MHz}, \mathrm{CDCl}_{3}, 298 \mathrm{~K}\right)$ of polymer obtained in NMP of $n$-butyl acrylate. Correlations to aromatic and carbonyl carbons are visible. 


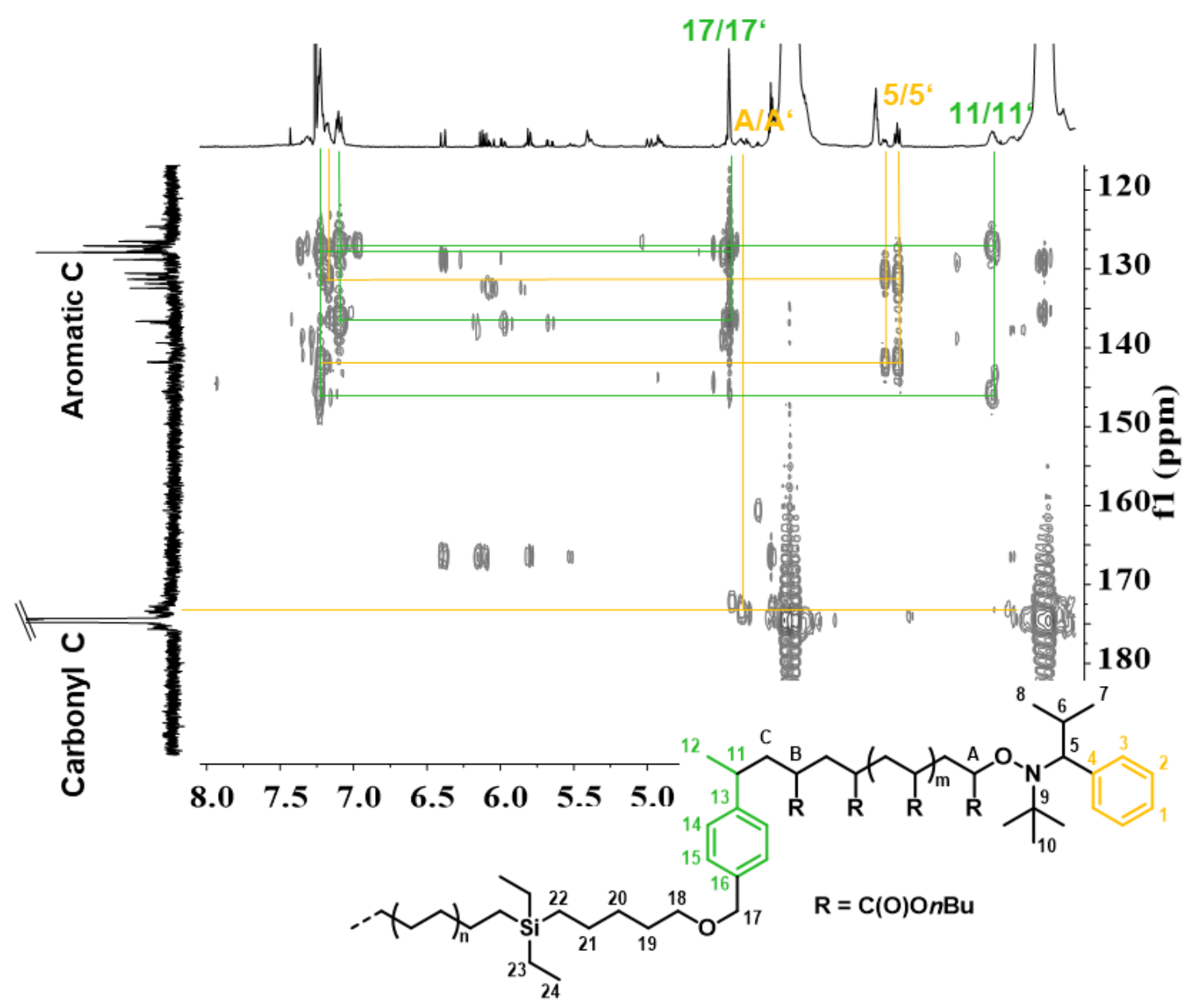

Figure S64: Enlargement of the ${ }^{1} \mathrm{H}^{-13} \mathrm{C}$ gHMBC NMR spectrum $\left(600 \mathrm{MHz}, \mathrm{CDCl}_{3}, 298 \mathrm{~K}\right)$ of polymer obtained in NMP of $n$-butyl acrylate, showing the aromatic motif connecting the polyethylene and polyacrylate blocks. 
PE-PtBA-Block Copolymers

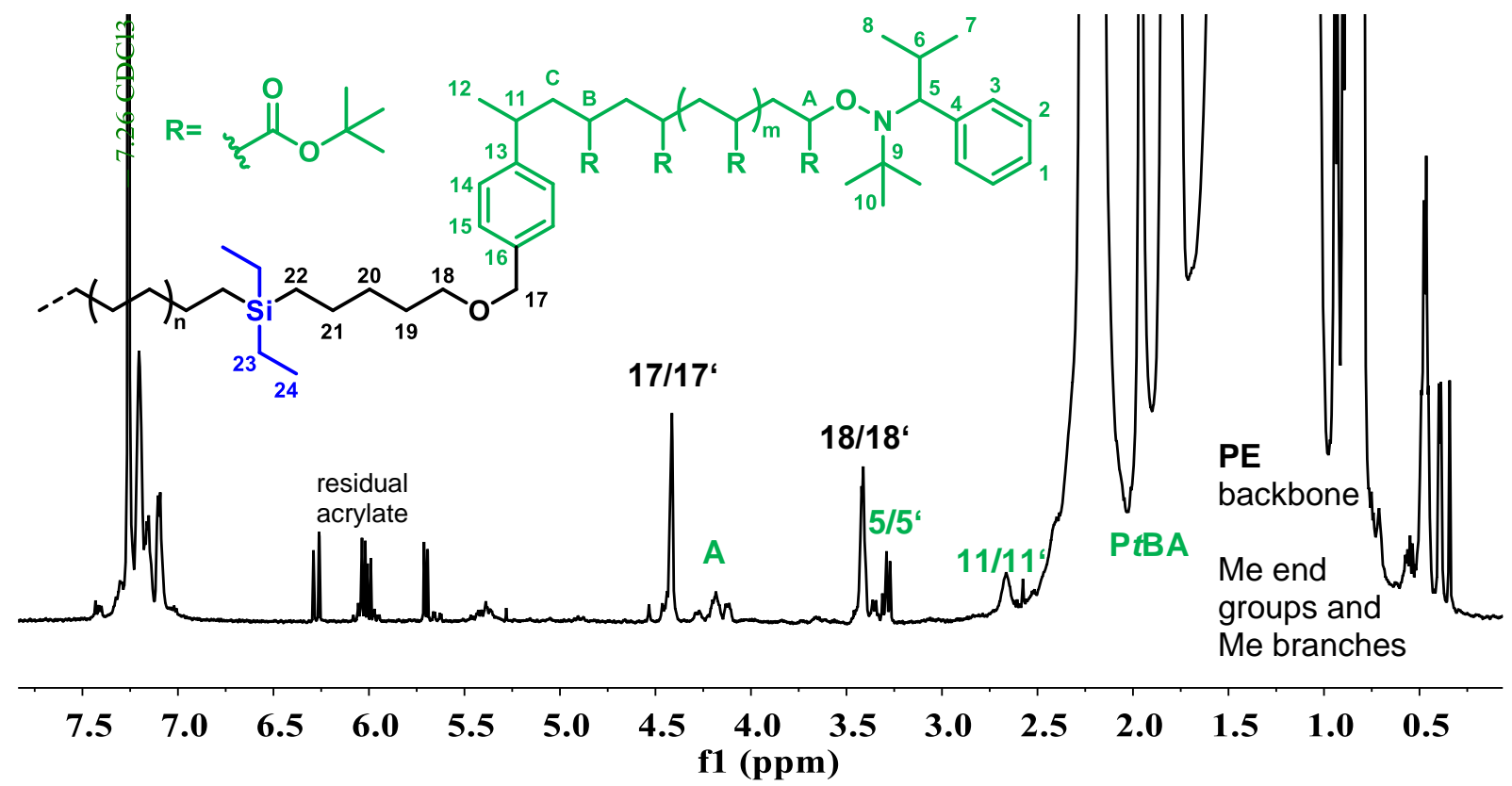

Figure S65: ${ }^{1} \mathrm{H}$ NMR spectrum $\left(600 \mathrm{MHz}, \mathrm{CDCl}_{3}, 298 \mathrm{~K}\right)$ of polymer obtained in NMP of tert-butyl acrylate initiated by PE-1 (cf. Table 2, entry 6). Signals corresponding to polyethylene, polyacrylate and characteristic signals for the TIPNO end group as well as the linker between the silyl and TIPNO moiety are highlighted.
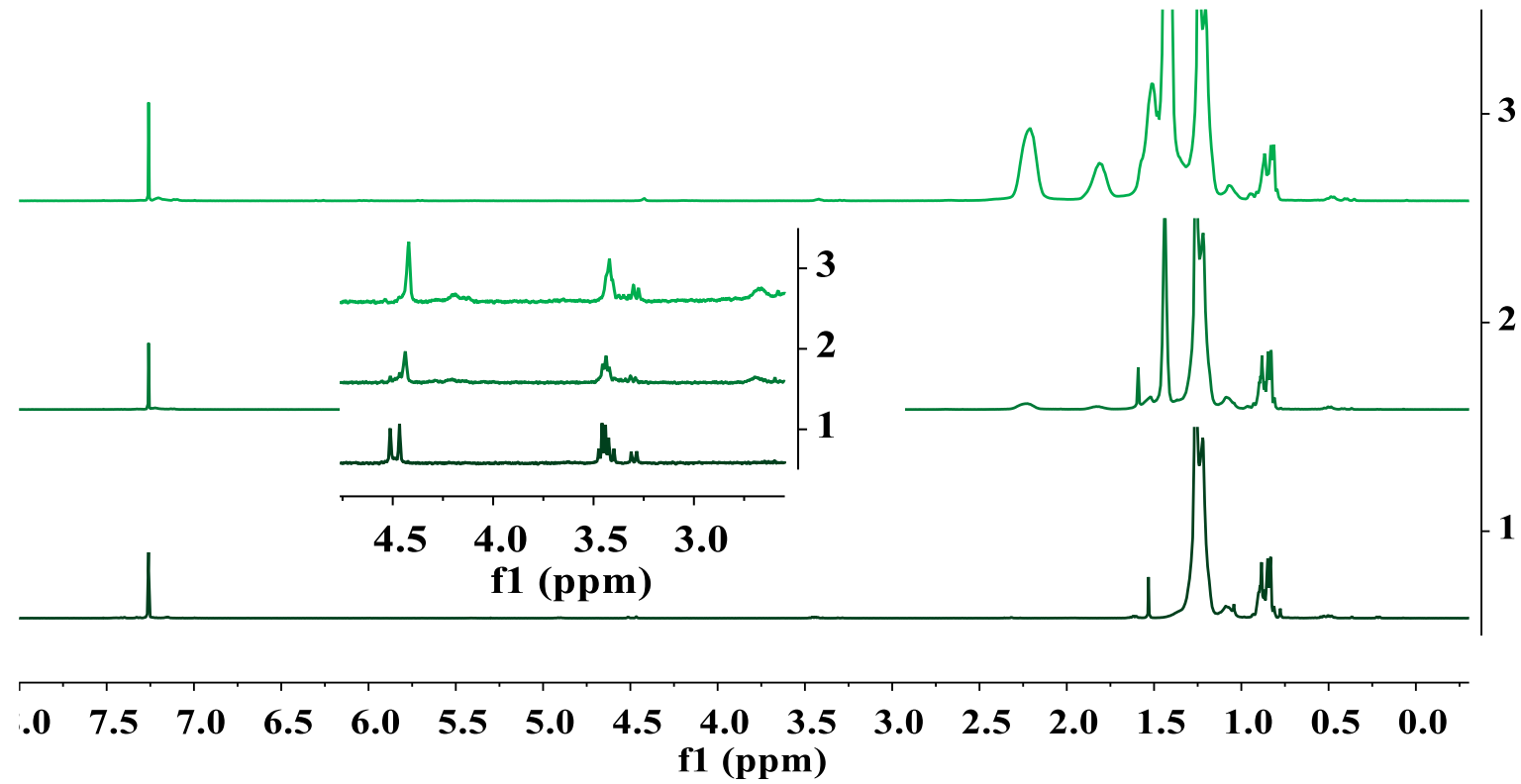

Figure S66: ${ }^{1} \mathrm{H}$ NMR spectra $\left(400 \mathrm{MHz}, \mathrm{CDCl}_{3}, 300 \mathrm{~K}\right)$ of the polymer PE-1 (bottom) and polymers obtained after $1 \mathrm{~h}$ (center) and $4 \mathrm{~h}$ (top) NMP of tert-butyl acrylate initiated by PE-1 (cf. Table 2, entries 5-6). The inset shows signals corresponding to the TIPNO and linking motif. 


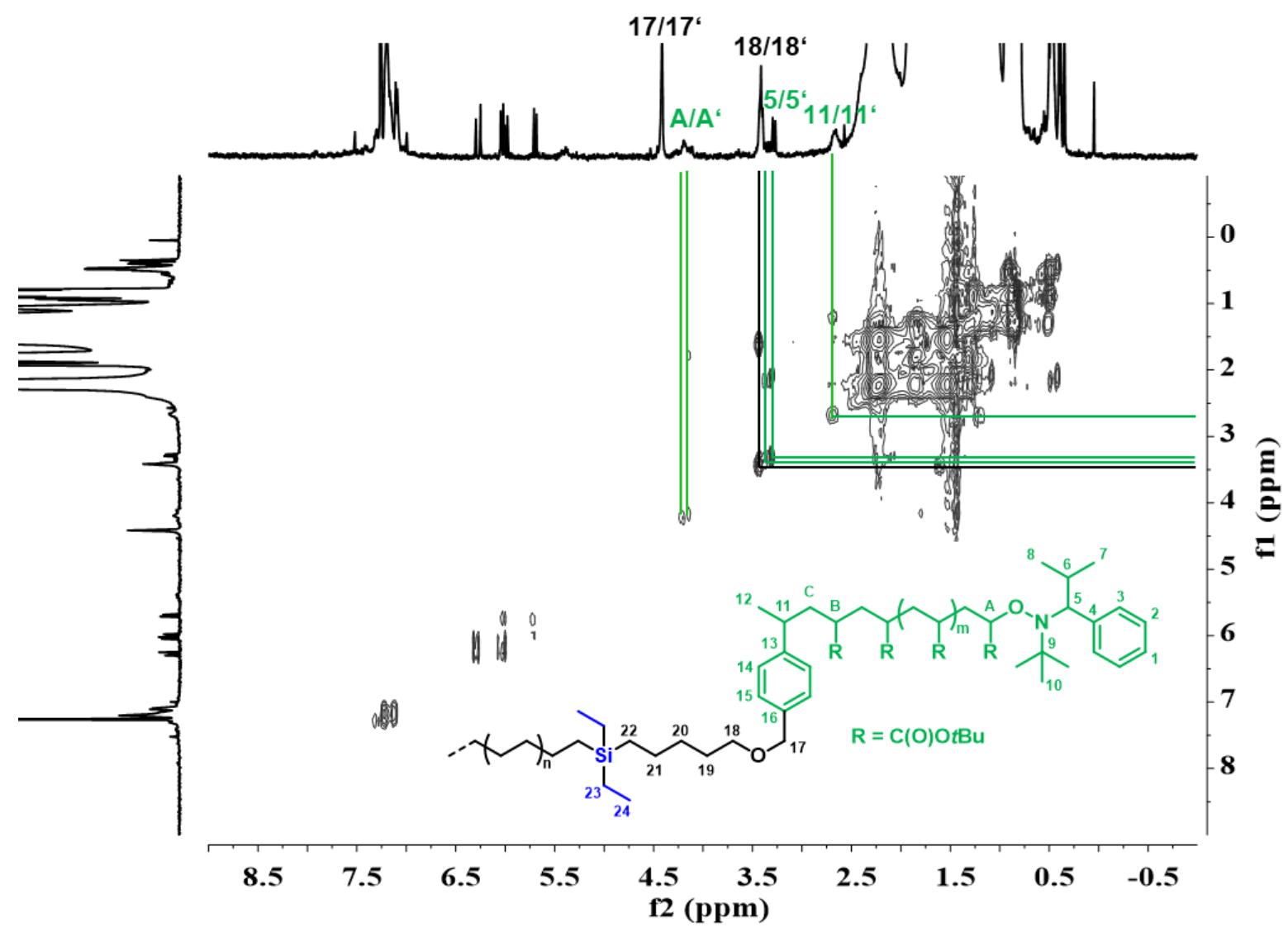

Figure S67: $\quad{ }^{1} \mathrm{H}-{ }^{1} \mathrm{H}$ gCOSY NMR spectrum $\left(600 \mathrm{MHz}, \mathrm{CDCl}_{3}, 298 \mathrm{~K}\right)$ of polymer obtained in NMP of tert-butyl acrylate initiated by PE-1 (cf. Table 2, entry 6). Characteristic signals for the TIPNO end group as well as the linker between the silyl and TIPNO moiety are highlighted.

\subsection{Exemplary GPC Data}

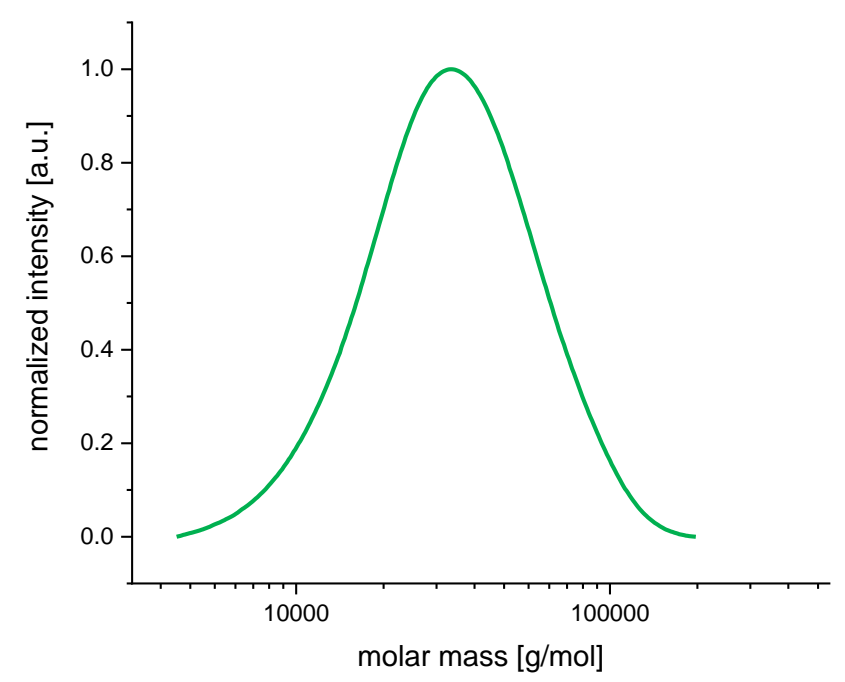

Figure S68: GPC trace detected by RI for poly(n-butyl acrylate) obtained in NMP initiated by PE-2 (Table 2, entry 4). 


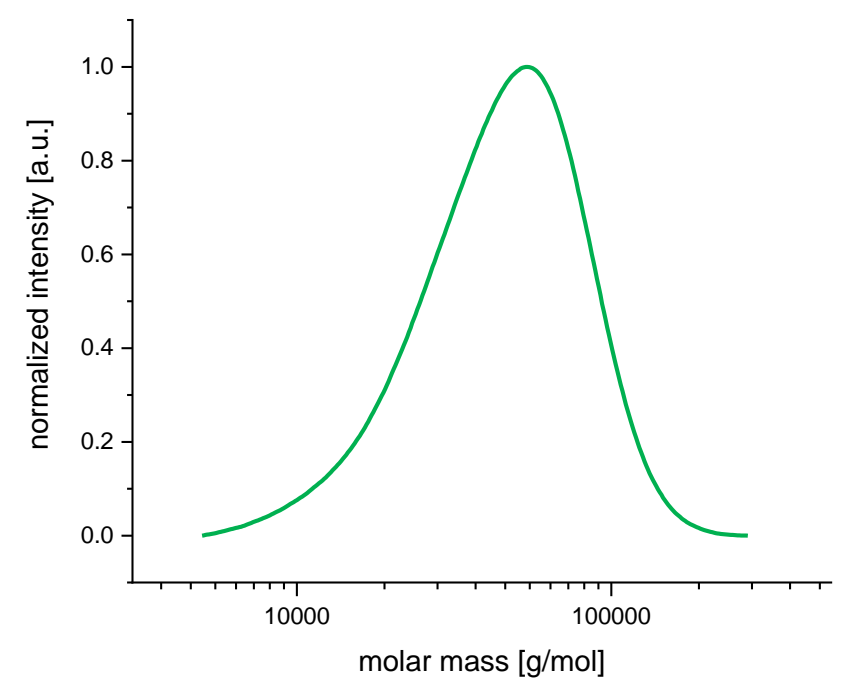

Figure S69: GPC trace detected by RI for poly(tert-butyl acrylate) obtained in NMP initiated by PE-1 (Table 2, entry 6).

\subsection{Exemplary DSC Data}

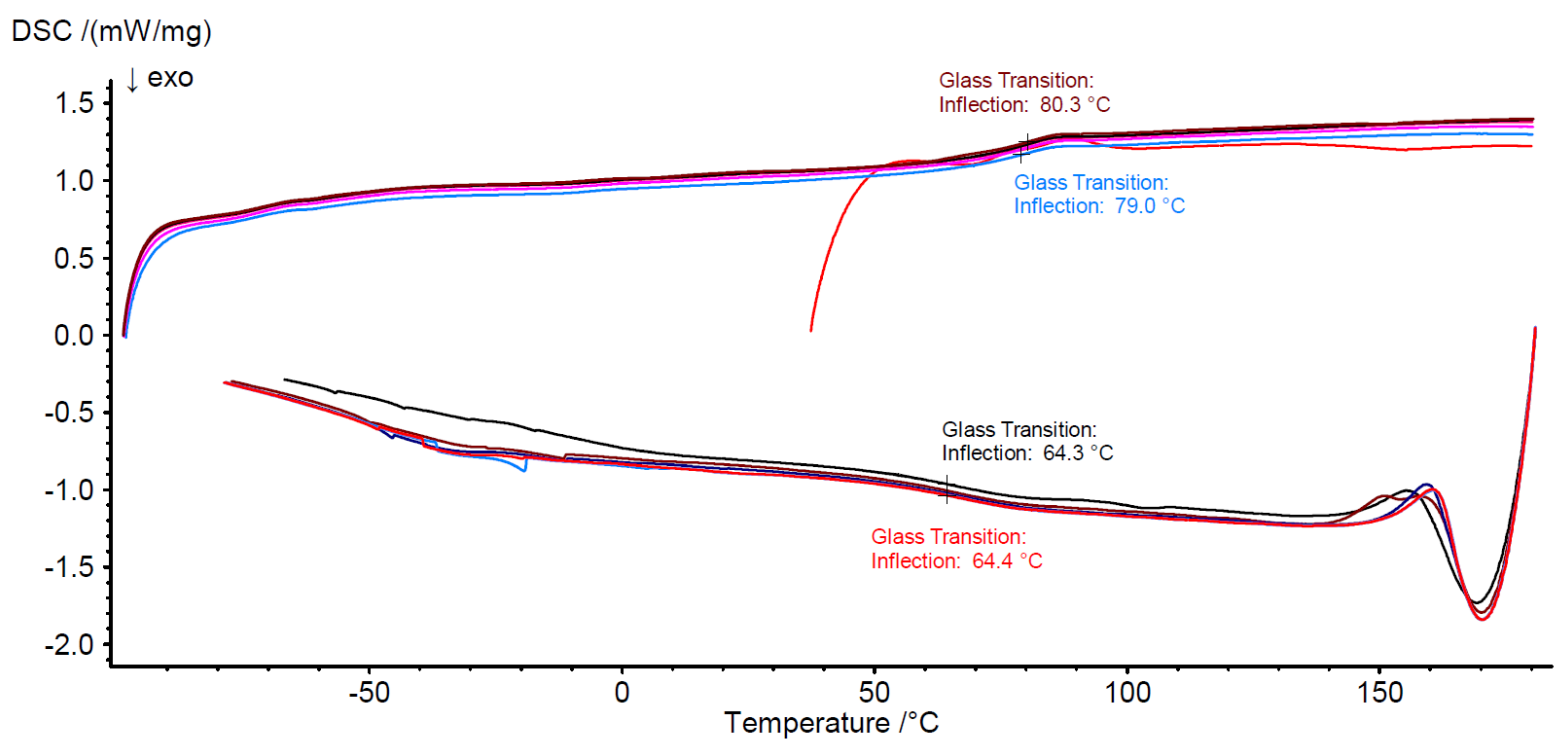

Figure S70: DSC traces detected for first heating and subsequent 5 cooling and heating cycles (heating/cooling rate $30 \mathrm{~K} \mathrm{~min}^{-1}$ ) of the polymer obtained in NMP of styrene initiated by PE-1 (cf. Table 2, entry 1). No melting or crystallization events can be observed. A glass transition at approximately $80{ }^{\circ} \mathrm{C}$ corresponding to the polystyrene block is observed. Repetition of the heating and cooling does not show any additional thermal events. 
For comparison (no copolymer, PE and PS homopolymers):

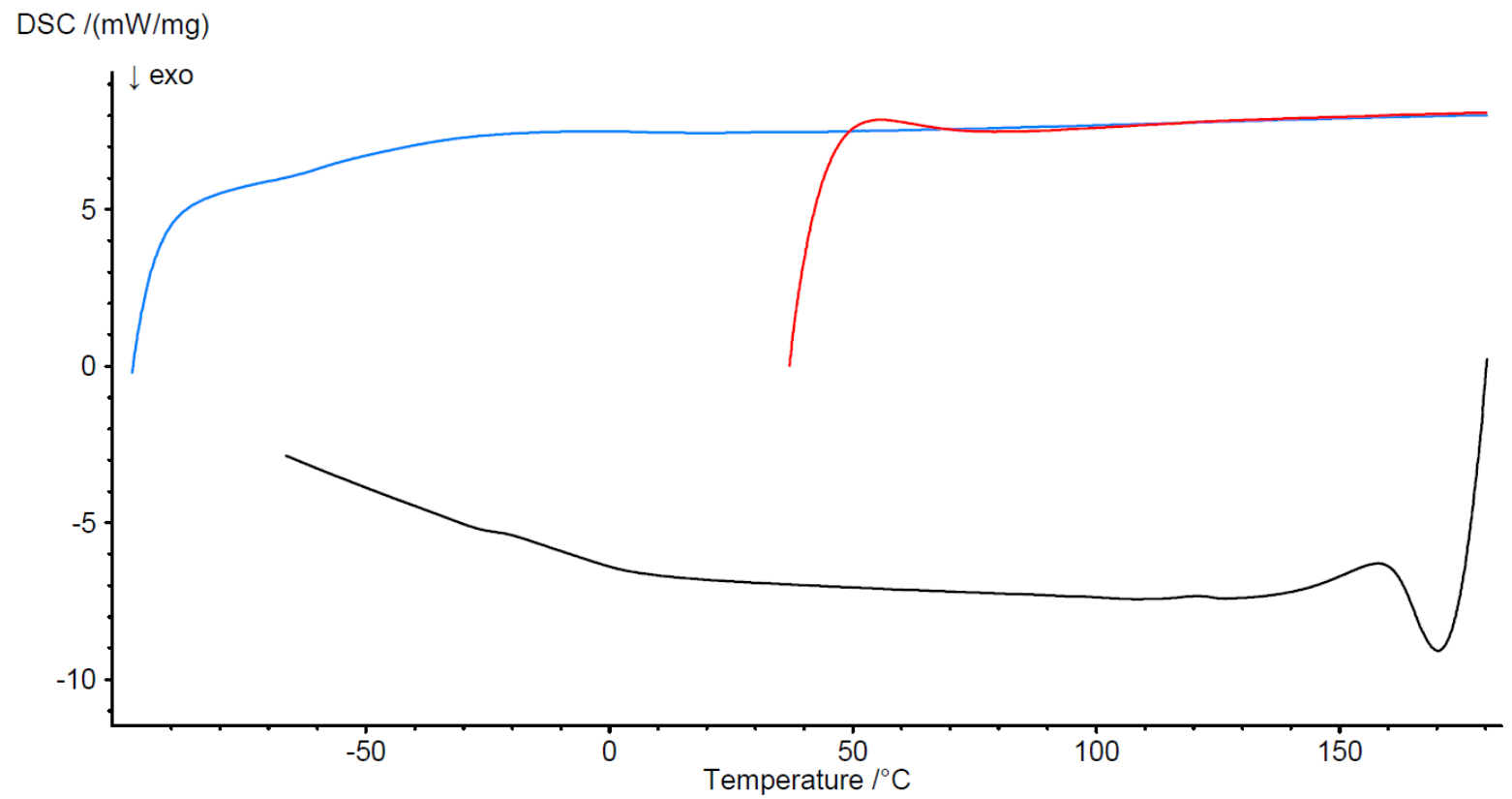

Figure S71: DSC traces detected for first heating and subsequent cooling and heating cycle (heating/cooling rate $30 \mathrm{~K} \mathrm{~min}^{-1}$ ) of triethylsilyl terminated hyperbranched polyethylene (cf. Table S2, entry 4).

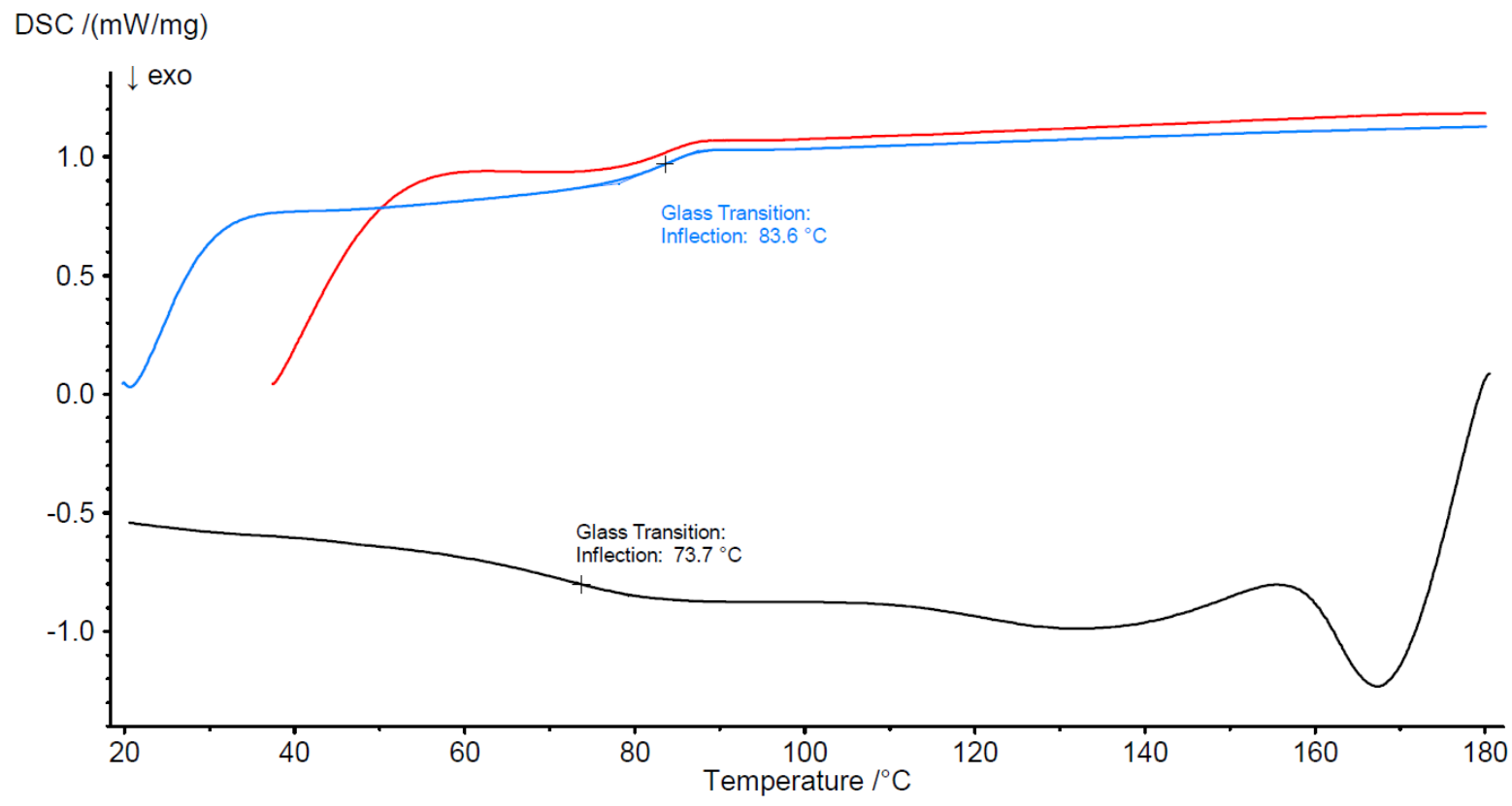

Figure S72: DSC traces detected for first heating and subsequent cooling and heating cycle (heating/cooling rate $30 \mathrm{~K} \mathrm{~min}^{-1}$ ) of atactic polystyrene (cf. Table S3, entry 2). 


\section{Microstructure Analysis (from NMR Spectra)}

\subsection{Calculation of Number Average Molecular Weight $\mathrm{M}_{\mathrm{n}}$ of the Polyethylene Obtained in CTPs}

In order to determine the molecular weight $\mathrm{M}_{\mathrm{n}}$ of polymers, obtained by $\mathrm{CTP}$ in the presence of triethylsilane, by NMR the integral of the Si-CH${ }_{2}$-region $\left(\mathbf{I}_{\text {silyl }}\right)$, overlay of ...-CH $\mathrm{CH}_{2-\mathrm{Si}}-\left(\mathrm{CH}_{2}-\right.$ $\left.\mathrm{CH}_{3}\right)_{3}$ signals, was set to 8 .

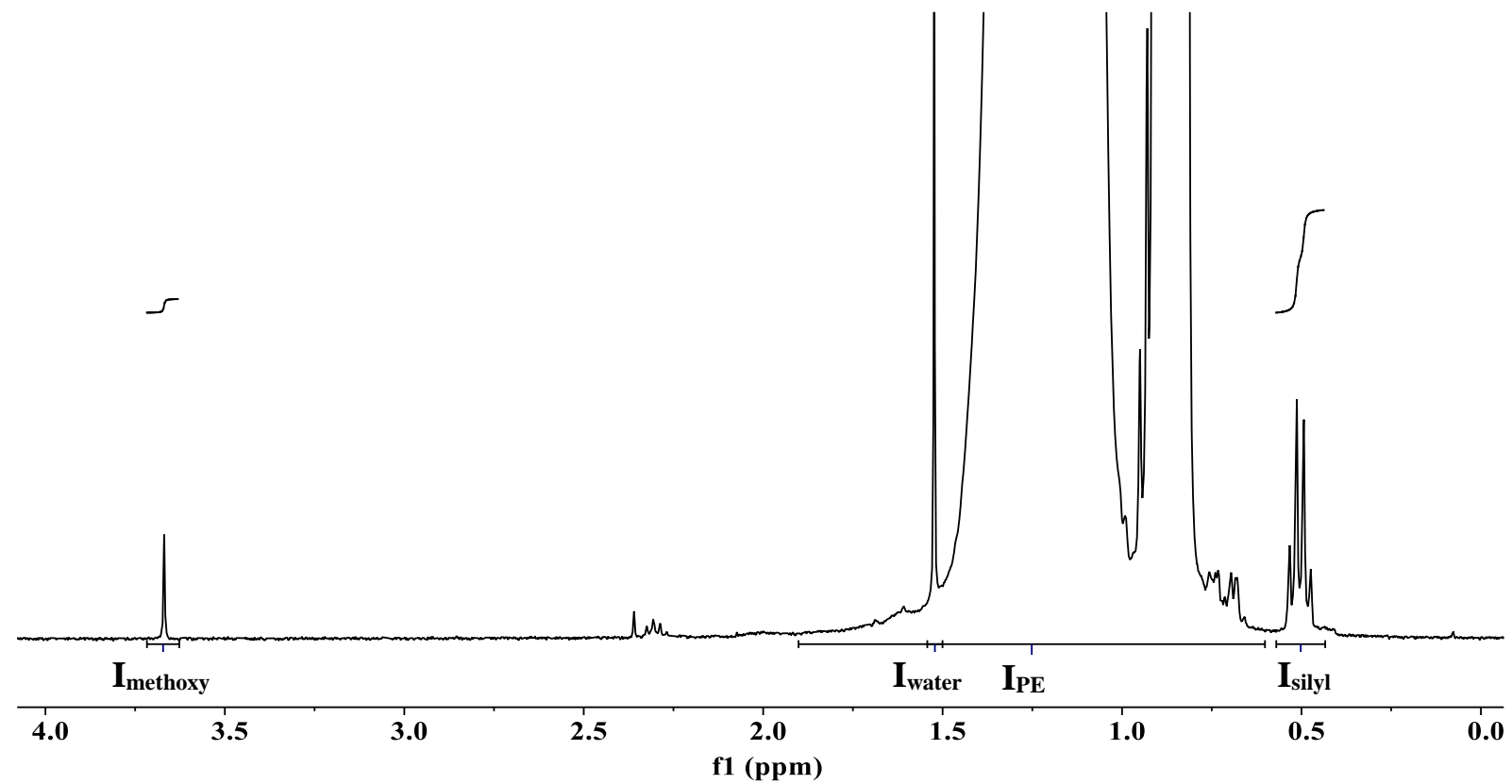

Figure S73: ${ }^{1} \mathrm{H}$ NMR spectrum $\left(400 \mathrm{MHz}, \mathrm{CDCl}_{3}, 300 \mathrm{~K}\right)$ of polymer obtained with precursor complex 2 and 100 equivalents of triethylsilane including integration for determination of number average molecular weight $\mathrm{M}_{\mathrm{n}}$.

Assuming chain transfer consistently yielded chains bearing a silane end group the $\mathrm{M}_{\mathrm{n}}$ can be determined as:

$$
\mathrm{M}_{\mathrm{n}, \mathrm{NMR}}\left(\mathrm{PE}_{\mathrm{SiEt}_{3}}\right)=\frac{\mathrm{I}_{\mathrm{PE}}-\mathrm{I}_{\mathrm{water}}}{4} \times 28,05 \frac{\mathrm{g}}{\mathrm{mol}}
$$

In polymerizations with complex $\mathbf{2}$, the molecular weight can be calculated more exact, by factoring in the polymer chains end-capped with a methoxy group, i.e. the first chain formed per catalyst molecule, which has no silane end group:

$$
M_{n, N M R}\left(P_{\mathrm{SiEt}_{3}}\right)=\frac{\mathrm{I}_{\mathrm{PE}}-\mathrm{I}_{\text {water }}}{4} \times \frac{1}{\frac{\mathrm{I}_{\text {methoxy }}}{3}+\frac{\mathrm{I}_{\text {silyl }}}{8}} \times 28,05 \frac{\mathrm{g}}{\mathrm{mol}}
$$

In order to determine the molecular weight $\mathrm{M}_{\mathrm{n}}$ of polymers, obtained by CTP in the presence of the alkoxyamine modified CTA (1), by NMR the integral of the methine group (11/11') was set to 1 and $\mathrm{M}_{\mathrm{n}}$ was determined as follows: 

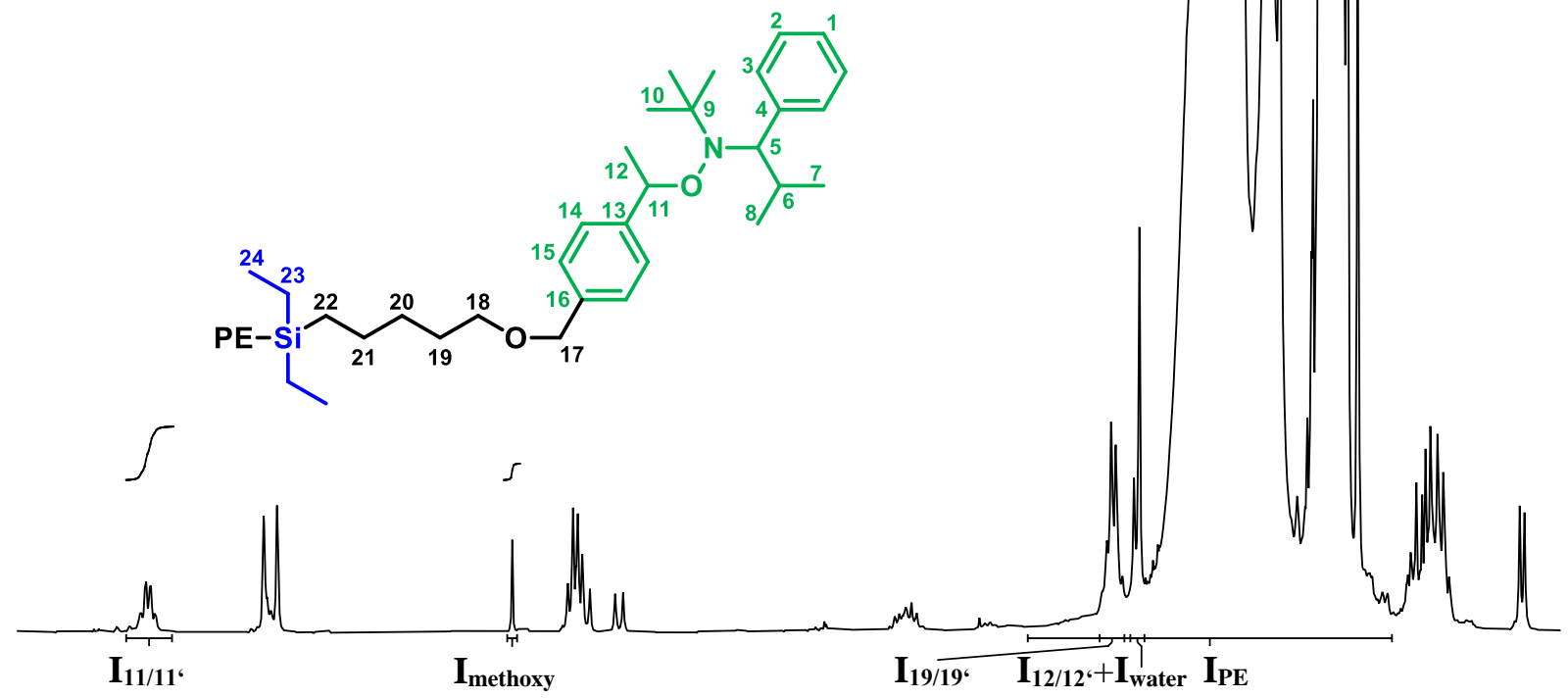

$\begin{array}{llllllllllllllllllllllllllllllllllllllllll}5.2 & 5.0 & 4.8 & 4.6 & 4.4 & 4.2 & 4.0 & 3.8 & 3.6 & 3.4 & 3.2 & 3.0 & 2.8 & 2.6 & 2.4 & 2.2 & 2.0 & 1.8 & 1.6 & 1.4 & 1.2 & 1.0 & 0.8 & 0.6 & 0.4 & 0.2\end{array}$ f1 (ppm)

$$
M_{n, N M R}\left(P_{S_{i E t} R}\right)=\frac{I_{P E}-I_{w_{\text {water }}}-I_{19 / 19^{\prime}}-I_{12 / 12^{\prime}}}{4} \times 28,05 \frac{\mathrm{g}}{\mathrm{mol}}
$$

In polymerizations with complex $\mathbf{2}$, the molecular weight can be calculated more exact, by factoring in the polymer chains end-capped with a methoxy group, i.e. the first chain formed per catalyst molecule, which has no silane end-group:

$$
M_{n, N M R}\left(P E_{S_{E i t} R}\right)=\frac{I_{P E}-I_{\text {water }}-I_{19 / 19^{\prime}}-I_{12 / 12^{\prime}}}{4} \times \frac{1}{\frac{I_{\text {methoxy }}}{3}+\frac{I_{11 / 11^{\prime}}}{1}} \times 28,05 \frac{\mathrm{g}}{\text { mol }}
$$

In order to determine the $\mathrm{M}_{\mathrm{n}}$ of the PE synthesized without the addition of silanes the integral of the methoxy group $I_{\text {methoxy }}$ was set to 3 . Then $M_{n, N M R}$ was calculated as follows:

$$
M_{n, N M R}(P E)=\frac{I_{P E}-I_{w a t e r}}{4} \times 28,05 \frac{g}{\mathrm{~mol}}
$$

\subsection{Calculation of the Amount of Chains Formed per Pd Center}

$$
\text { chains per } \mathrm{Pd}=\frac{\text { yield }}{\mathrm{M}_{\mathrm{n}} \times \mathrm{n}(\mathrm{Pd})}
$$

with $\mathrm{n}(\mathrm{Pd})=10 \times 10^{-6} \mathrm{~mol}, \mathrm{M}_{\mathrm{n}}$ determined by NMR

\subsection{Calculation of the Conversion of Monomer in NMPs}

$$
\%_{\text {conversion of monomer }}=\frac{\text { yield }-\mathrm{m}((\text { macro }) \text { initiator })}{\mathrm{m}(\text { monomer })} \times 100
$$




\section{References}

(1) Stoe; Cie X-Area, Single Crystal Diffraction Software; Darmstadt, Germany, 2005.

(2) Sheldrick, G. M. SHELXL-2016, Program for Crystal Structure Refinement; University of Göttingen, Göttingen, 2016.

(3) Spek, A. L., Single-Crystal Structure Validation with the Program PLATON. J. Appl. Cryst. 2003, 36, 7-13.

(4) Reger, D. L.; Little, C. A.; Lamba, J. J. S.; Brwon, K. J., Sodium Tetrakis(3,5bis(trifluoromethyl)phenyl)borate, $\mathrm{Na}\left[\mathrm{B}\left(3,5-\left(\mathrm{CF}_{3}\right)_{2} \mathrm{C}_{6} \mathrm{H}_{3}\right)_{4}\right]$. Inorg. Synth. 2004, 5-8.

(5) tom Dieck, H.; Svoboda, M.; Greiser, T., Bis(diazadiene)metal(0) Complexes. IV. Nickel(0) Bis(chelates) with Aromatic N-Substituents. Z. Naturforsch., B: Anorg. Chem., Org. Chem. 1981, 36B, 823-832.

(6) Martins, R.; Quinello, L.; Souza, G.; Marques, M., Polymerization of Ethylene with Catalyst Mixture in the Presence of Chain Shuttling Agent. Chem. Chem. Technol. 2012, 6, 153-162.

(7) Clavier, H.; Correa, A.; Cavallo, L.; Escudero-Adán, E. C.; Benet-Buchholz, J.; Slawin, A. M. Z.; Nolan, S. P., [Pd(NHC)(allyl)Cl] Complexes: Synthesis and Determination of the NHC Percent Buried Volume (\% $\left.\mathrm{V}_{\text {bur }}\right)$ Steric Parameter. Eur. J. Inorg. Chem. 2009, 2009, 1767-1773.

(8) Johnson, L. K.; Killian, C. M.; Brookhart, M., New Pd(II)- and Ni(II)-Based Catalysts for Polymerization of Ethylene and Alpha-Olefins. J. Am. Chem. Soc. 1995, 117, 64146415.

(9) Mecking, S.; Johnson, L. K.; Wang, L.; Brookhart, M., Mechanistic Studies of the Palladium-Catalyzed Copolymerization of Ethylene and $\alpha$-Olefins with Methyl Acrylate. J. Am. Chem. Soc. 1998, 120, 888-899.

(10) Dolomanov, O. V.; Bourhis, L. J.; Gildea, R. J.; Howard, J. A. K.; Puschmann, H., OLEX2: A Complete Structure Solution, Refinement and Analysis Program. J. Appl. Cryst. 2009, 42, 339-341.

(11) Sheldrick, G., SHELXT - Integrated Space-Group and Crystal-Structure Determination. Acta. Cryst. 2015, A71, 3-8.

(12) Sheldrick, G., Crystal Structure Refinement with SHELXL. Acta. Cryst. 2015, C71, 38.

(13) Benoit, D.; Chaplinski, V.; Braslau, R.; Hawker, C. J., Development of a Universal Alkoxyamine for "Living" Free Radical Polymerizations. J. Am. Chem. Soc. 1999, 121, 3904-3920.

(14) Mansfeld, U.; Hager, M. D.; Hoogenboom, R.; Ott, C.; Winter, A.; Schubert, U. S., Advanced Supramolecular Initiator for Nitroxide-Mediated Polymerizations Containing Both Metal-ion Coordination and Hydrogen-Bonding Sites. Chem. Commun. 2009, 3386-3388.

(15) Smith, C. D.; Bartley, J. P.; Bottle, S. E.; Micallef, A. S.; Reid, D. A., Electrospray Ionization Mass Spectrometry of Stable Nitroxide Free Radicals and Two Isoindoline Nitroxide Dimers. J. Mass Spectrom. 2000, 35, 607-611.

(16) Lagrille, O.; Cameron, N. R.; Lovell, P. A.; Blanchard, R.; Goeta, A. E.; Koch, R., Novel Acyclic Nitroxides for Nitroxide-Mediated Polymerization: Kinetic, Electron Paramagnetic Resonance Spectroscopic, X-ray Diffraction, and Molecular Modeling Investigations. J. Polym. Sci. Pol. Chem. A: Polym. Chem. 2006, 44, 1926-1940.

(17) Blomberg, S.; Ostberg, S.; Harth, E.; Bosman, A. W.; Van Horn, B.; Hawker, C. J., Production of Crosslinked, Hollow Nanoparticles by Surface-Initiated Living FreeRadical Polymerization. J. Polym. Sci. Pol. Chem. A: Polym. Chem. 2002, 40, 13091320. 
(18) Husseman, M.; Malmström, E. E.; McNamara, M.; Mate, M.; Mecerreyes, D.; Benoit, D. G.; Hedrick, J. L.; Mansky, P.; Huang, E.; Russell, T. P.; Hawker, C. J., Controlled Synthesis of Polymer Brushes by "Living" Free Radical Polymerization Techniques. Macromolecules 1999, 32, 1424-1431.

(19) Bothe, M.; Schmidt-Naake, G., An Improved Catalytic Method for Alkoxyamine Synthesis - Functionalized and Biradical Initiators for Nitroxide-Mediated Radical Polymerization. Macromol. Rapid Commun. 2003, 24, 609-613.

(20) Krause, T.; Habicher, W. D.; Messerschmidt, M.; Voit, B. I., A Novel Method for the Synthesis of Alkoxyamine Initiators for Nitroxide-Mediated Radical Polymerization Using $\mathrm{Mn}(\mathrm{OAc})_{3}$ as Electron-transfer Reagent. Des. Monomers Polym. 2004, 7, 391397.

(21) Rosenberg, L.; Davis, C. W.; Yao, J., Catalytic Dehydrogenative Coupling of Secondary Silanes Using Wilkinson's Catalyst. J. Am. Chem. Soc. 2001, 123, 5120-5121.

(22) Gottfried, A. C.; Brookhart, M., Living and Block Copolymerization of Ethylene and Alpha-Olefins using Palladium(II)-Alpha-Diimine Catalysts. Macromolecules 2003, 36, 3085-3100.

(23) Hyatt, M. G.; Guironnet, D., Silane as Chain Transfer Agent for the Polymerization of Ethylene Catalyzed by a Palladium(II) Diimine Catalyst. ACS Catal. 2017, 7, 57175720 .

(24) Gottfried, A. C.; Brookhart, M., Living Polymerization of Ethylene Using Pd(II) $\alpha$ Diimine Catalysts. Macromolecules 2001, 34, 1140-1142.

(25) Mayo, F. R., Chain Transfer in the Polymerization of Styrene: The Reaction of Solvents with Free Radicals. J. Am. Chem. Soc. 1943, 65, 2324-2329.

(26) Rodlert, M.; Harth, E.; Rees, I.; Hawker, C. J., End-Group Fidelity in NitroxideMediated Living Free-Radical Polymerizations. J. Polym. Sci., Part A: Polym. Chem. 2000, 38, 4749-4763.

(27) Cameron, N. R.; Lagrille, O.; Lovell, P. A.; Thongnuanchan, B., A Nitroxide for Effecting Controlled Nitroxide-Mediated Radical Polymerization at Temperatures $\leq 90{ }^{\circ} \mathrm{C}$. ACS Macro Lett. 2012, 1, 1262-1265.

(28) Marque, S.; Le Mercier, C.; Tordo, P.; Fischer, H., Factors Influencing the $\mathrm{C}-\mathrm{O}-$ Bond Homolysis of Trialkylhydroxylamines. Macromolecules 2000, 33, 4403-4410.

(29) Hawker, C. J.; Bosman, A. W.; Harth, E., New Polymer Synthesis by Nitroxide Mediated Living Radical Polymerizations. Chem. Rev. 2001, 101, 3661-3688. 